\title{
Development of a Performance Index for Stormwater Pipeline Infrastructure
}

\author{
Sowmya Bhimanadhuni
}

Thesis submitted to the faculty of the Virginia Polytechnic Institute and State University in partial fulfillment of the requirements for the degree of

\author{
Master of Science \\ In \\ Civil Engineering
}

\author{
Sunil K. Sinha, Chair \\ Annie Pearce \\ Matt Stolte
}

June 03, 2015

Blacksburg, Virginia

Keywords: Performance Parameters, Weighted Factor Method, Stormwater, Pipeline 


\title{
Development of a Performance Index for Stormwater Pipeline Infrastructure
}

\author{
Sowmya Bhimanadhuni
}

\begin{abstract}
With new government regulations and emerging knowledge of the risk to the environment posed by the failure of stormwater pipelines, stormwater infrastructure asset management is becoming increasingly important in the U.S. An essential aspect of asset management practice is the accurate performance assessment of one's assets. This paper presents a weighted factor framework to determine the performance of stormwater pipes. This paper prepares a list of 50 parameters affecting the performance of stormwater pipelines; the list is based on a review of the literature, existing asset management plans, and feedback from utilities. This list is broken down into essential and preferential parameters. Indeed, not all utilities necessarily possess sufficient resources to collect such a large set of parameters. This study also develops a three-level hierarchical structure of the degradation of stormwater pipeline infrastructure. The structure consists of five failure modules and the essential parameters only. On the basis of the survey results gathered from 10 utilities across the EPA regions, the study combines the essential parameters into a performance index. The index is a scale of 1 to 5, similar to the National Association of Sewer Service Companies' Pipeline Assessment and Certification Program grading system. Grade 1 implies excellent condition and Grade 5 implies collapse is imminent.
\end{abstract}


I dedicate this thesis to my sister Bhimanadhuni Ramya who is a gift to my heart and a friend to my spirit 


\section{Acknowledgements}

I would like to thank my advisor Dr. Sunil Sinha for providing me with this challenging and interesting research project.

I am grateful to my committee members Dr. Annie Pearce and Matt Stotle for providing me with valuable feedback and guiding me throughout the research.

I also appreciate the continual feedback and support provided by utilities across the United States for this research. For their valuable time and support throughout this research, I would like to thank Andy Richter and his team from City of Colorado Springs, Jorge Morales from City of Austin, and Valerie Tucker from Fairfax County.

I would like to acknowledge the National Association of Sewer Service Companies (NASSCO) who awarded me a fellowship for this research.

I am deeply grateful to my parents B. Raghava Reddy and N. Ramanamma who always believed in me and encouraged me throughout this process.

Thank you to all my colleagues at Virginia Tech and in particular Shaoqing Ge, Berk Uslu, and Jose Guevara Maldonado who provided insightful comments. Also, a special thanks to Dr. Christine Fiori for encouraging me through the rough patches. 


\section{Table of Contents}

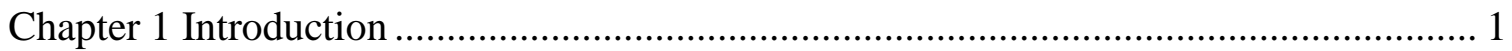

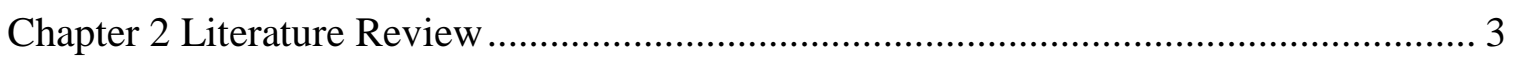

2.1. Overview of Stormwater Infrastructure System................................................. 3

2.2. Stormwater Pipeline Asset Management ………............................................. 4

2.2.1. National Association of Sewer Service Companies' (NASSCO) Pipeline Assessment Certification Program (PACP) .............................................................. 7

2.3. Research Gaps ........................................................................................ 9

Chapter 3 Research Goal and Objectives................................................................ 10

Chapter 4 Research Methodology............................................................................. 11

Chapter 5 Development of Stormwater Pipeline Performance Data ................................. 14

5.1. Stormwater Pipeline Design and Installation .................................................. 15

5.2. Stormwater Pipeline Materials ...................................................................... 18

5.3. Stormwater Failure Modes ...................................................................... 20

5.4. Stormwater Pipe Performance Data Structure ……………………………....... 21

Chapter 6 Development of Stormwater Pipeline Performance Index ............................... 35

6.1. Weighted Factor Method................................................................................ 35

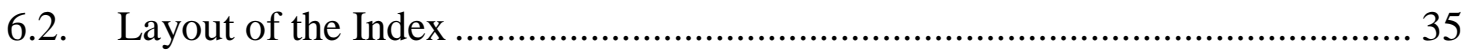

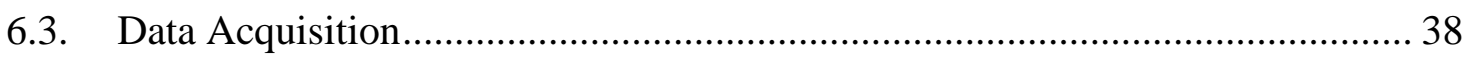

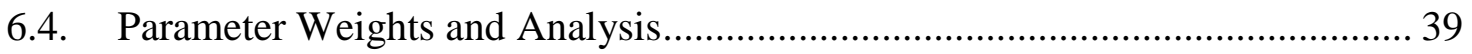

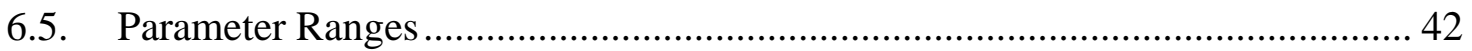

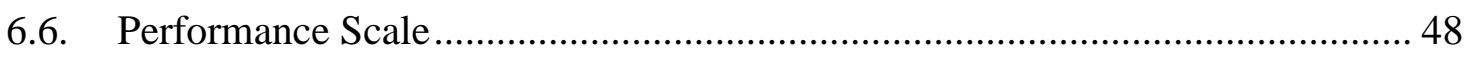

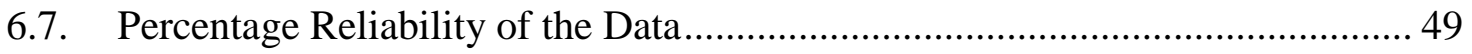

Chapter 7 Partial Validation of the Performance Index................................................. 50

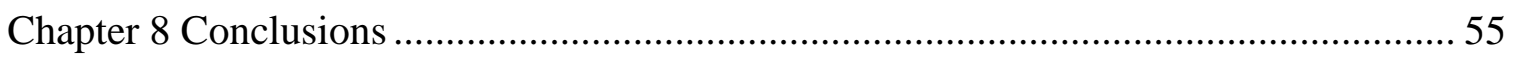

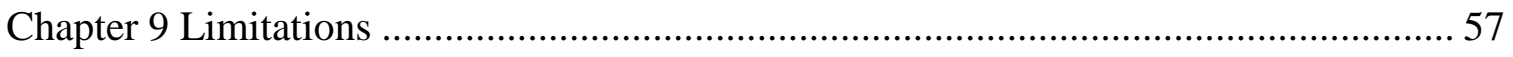

Chapter 10 Future Research................................................................................... 59

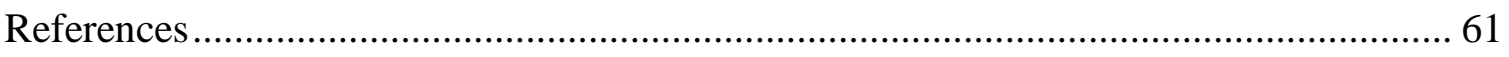

Appendix A. Utility Survey Form and Response Received .......................................... 65

Appendix B. Calculation of the Parameter Weights........................................................ 99

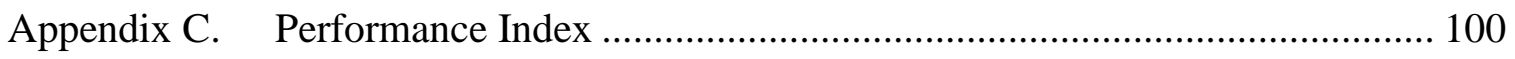


Appendix D. ArcMap representation of Performance Indices.................................... 101

Appendix E. Partial Validation of the Prototype Performance Index ......................... 103 


\section{List of Figures}

Figure 1: A combined sewer system collects wastewater and stormwater runoff in a single pipe system whereas a separate stormwater pipeline system conveys only stormwater. (USEPA. "National Pollution Discharge Elimination System (NPDES)". Healthy Waters in the Mid-Atlantic, < http://www.epa.gov/reg3wapd/images/images_npdes/cso_diagram.gif > (May. 25, 2015). Public domain.). 3 Figure 2: Framework for sustainable municipal asset management program (Gay, L. F. and Sinha, S. K. (2014). Water Infrastructure Asset Management Primer, Report No. INFR9SG09b, Water Environment Research Foundation, Alexandria, VA, 2-14. Used with permission of Carrie W. Capuco, JD, Water Environment Research Foundation.) ........... 5

Figure 3: Relevant stormwater research as per the asset management framework ........... 6

Figure 4: NASSCO's PACP process of determining the pipe condition score ................. 8 Figure 5: Method used to arrive at the performance parameters for stormwater pipelines

Figure 6: Factors affecting the performance of a buried pipe (Sinha, S., Angkasuwansiri, T., and Thomasson, R. (2008). "Phase 1: Development of standard data structure to support wastewater pipe condition and performance prediction." Development of protocols and methods for predicting the remaining economic life of wastewater pipe infrastructure assets. Report No. 06-SAM-1 CO, Water Environment Research Foundation, Alexandria, VA. Used with permission of Carrie W. Capuco, JD, Water Environment Research Foundation.)

Figure 7: The hydrologic cycle. Precipitation and runoff need to be estimated to design stormwater pipe. (Adapted from National Corrugated Steel Pipe Association. (2008). Corrugated Steel Pipe Design Manual. Dallas, TX.).

Figure 8: The sequence of construction of an underground pipe includes foundation preparation, bedding preparation, pipe erection, and backfilling in layers (Adapted from National Corrugated Steel Pipe Association. (2008). Corrugated Steel Pipe Design Manual. Dallas, TX.)

Figure 9: List of stormwater pipeline performance parameters. The parameters highlighted in grey are the essential parameters and the others are preferable parameters. 
Figure 10: Performance deterioration of stormwater pipeline in two level hierarchy structure. The first level indicates the five failure modules. The second level indicates the essential performance parameters affecting each module.

Figure 11: Performance deterioration of Utility A's stormwater pipeline in two level hierarchy structure. The highlighted nine parameters indicate the available and derived parameters to develop the Index. Since only nine of the 32 parameters are available to determine the performance, the reliability of the data will be less. 


\section{List of Tables}

Table 1: Factors affecting performance of stormwater pipe discussed in each published literature.

Table 2: NASSCO's PACP Grades (Sinha, S., and Angkasuwansiri, T. (2010). "Phase 2: Development of a robust wastewater pipe performance index." Development of protocols and methods for predicting the remaining economic life of wastewater pipe infrastructure assets. Report No. 06-SAM-1 CO, Water Environment Research Foundation, Alexandria, VA. Used with permission of Carrie W. Capuco, JD, Water Environment Research Foundation.)

Table 3: Sewer and combined sewer condition/performance assessment models. 12

Table 4: Reasons for failure of stormwater pipes 20

Table 5: List of failure modes encountered in stormwater pipe 21

Table 6: Details of stormwater performance parameters. For each parameter, the unit, the explanation for including the parameter and the source from which the idea to include the parameter was obtained are presented. 24

Table 7: The list of utilities that contributed to the research 39

Table 8: Significance of each failure module in determining the performance of a stormwater pipe

Table 9: Significance of each parameter in determining the performance of a stormwater pipe 40

Table 10: Rating scheme for stormwater performance parameters 42

Table 11: Stormwater performance scale corresponding to pipe score generated from Equation 2 48

Table 12: Parameter Confidence Scale (Sinha, S., and Angkasuwansiri, T. (2010). "Phase

2: Development of a robust wastewater pipe performance index." Development of protocols and methods for predicting the remaining economic life of wastewater pipe infrastructure assets. Report No. 06-SAM-1 CO, Water Environment Research Foundation, Alexandria, VA. Used with permission of Carrie W. Capuco, JD, Water Environment Research Foundation.)

Table 13: Essential stormwater pipeline data parameters available in Utility A's ArcGIS files. 
Table 14: Edited Parameter Ranges to better represent the Utility A's conditions .......... 52

Table 15: Utility A's Stormwater Pipe Performance Distribution.................................. 54

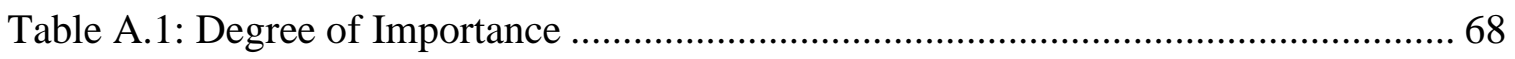

Table A.2: Fill the pair-wise comparison matrix on stormwater pipeline failure modes . 68 


\section{List of Equations}

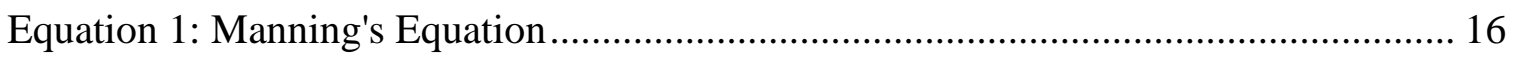

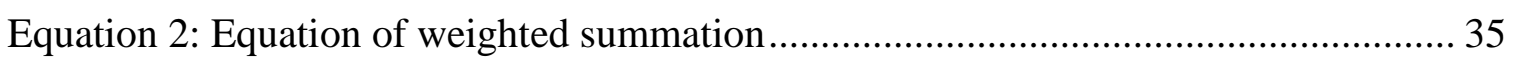

Equation 3: Percentage Reliability is dependent on the confidence of the input data ...... 49

Equation 4: Utility A's Stormwater Pipe Performance Index .......................................... 54 


\section{Chapter 1 Introduction}

Vital to the fabric of a society are its water, wastewater, and stormwater infrastructure systems. While a few of them are over 100 years old, the United States' extensive network of water, wastewater, and stormwater systems were mainly built after World War II. As per the 2013 Infrastructure Report Card, the nation's water, wastewater, and stormwater infrastructure systems are failing and an estimated investment of about 650 billion will be required in the next 20 years to upgrade them (ASCE 2013). The utilities and municipalities entrusted with the responsibility of maintaining and expanding these assets have realized that the problem will not be solved through monetary investments alone. These entities have begun to change the way they operate by adopting a holistic management approach called asset management. Asset management has been defined as "a structure program to minimize the life cycle costs of asset ownership while maintaining required levels of service and sustaining the infrastructure" (Harlow 2001).

Stormwater infrastructure asset management is a relatively new concept (Betz 2013; Grigg 2012). It has been attracting attention due to an increasing number of regulations and an increasing knowledge on the consequence of stormwater infrastructure failure to the society. The United States Environmental Protection Agency (USEPA) and Army Corps of Engineers' finalized a new rule in 2015 under the Clean Water Act (CWA) to protect the nation's streams and wetlands (USEPA 2015). This rule, known as the "Clean Water Rule," extends the jurisdiction of the CWA to non-point sources and clearly defines the waters protected by the CWA. This rule also regulates ditches if they meet the conditions of tributaries. At the beginning of 2014, EPA announced an updated memorandum entitled "Establishing Total Maximum Daily Load (TMDL) Wasteload Allocations (WLAs) for Storm Water Sources and NPDES Permit Requirements Based on those WLAs." It includes "clear, specific, and measurable permit requirements," and, where feasible, numeric effluent limits to National Pollutant Discharge Elimination System permits for stormwater discharges (WEF 2015). The EPA also committed to propose a new national stormwater rule as part of litigation by the Chesapeake Bay Foundation in 2009. The rule, if processed, will focus on integrating urbanizing areas located beyond the limits of currently regulated areas into existing Municipal Separate Storm Sewer System (MS4) programs (WEF 2015). 
Stormwater infrastructure is generally considered a subsidiary of wastewater infrastructure. The American Society of Civil Engineers categorized stormwater infrastructure under wastewater infrastructure in the 2013 Infrastructure Report Card (ASCE 2013). The decision tools developed for wastewater pipelines are generally adopted directly for stormwater pipeline maintenance (Betz 2013). However, this is neither adequate nor appropriate, for the major cause of sewer pipe deterioration is the continuous internal attack by acids associated with sewage. Stormwater pipelines, in contrast, are relatively clean and are predominantly damaged by external factors (Micevski et al. 2002). This research endeavors to develop a tool specific to stormwater infrastructure that evaluates the existing performance of the pipeline and hence contributes towards the development of stormwater asset management programs. 


\section{Chapter 2 Literature Review}

\subsection{Overview of Stormwater Infrastructure System}

Stormwater infrastructure collects the water that flows over land or impervious surfaces as a result of rainfall or snowmelt and diverts it into nearby streams. These systems are managed by local governments. A stormwater system consists of an open and a closed system (Grigg 2012).

An open system consists of stormwater facilities open to the environment. These include structures such as detention ponds, swales, drainage ditches, catch basins, and other water quantity and quality control systems. A closed system consists of enclosed or covered stormwater facilities. These include culverts, stormwater pipes, junction chambers, manholes, and connecting inlets.

Stormwater networks can be either "combined" or "separate" systems. A combined system conveys both sanitary sewage and storm water in one piping system. A separate system conveys only stormwater runoff. Both systems can be seen in Figure 1 below.

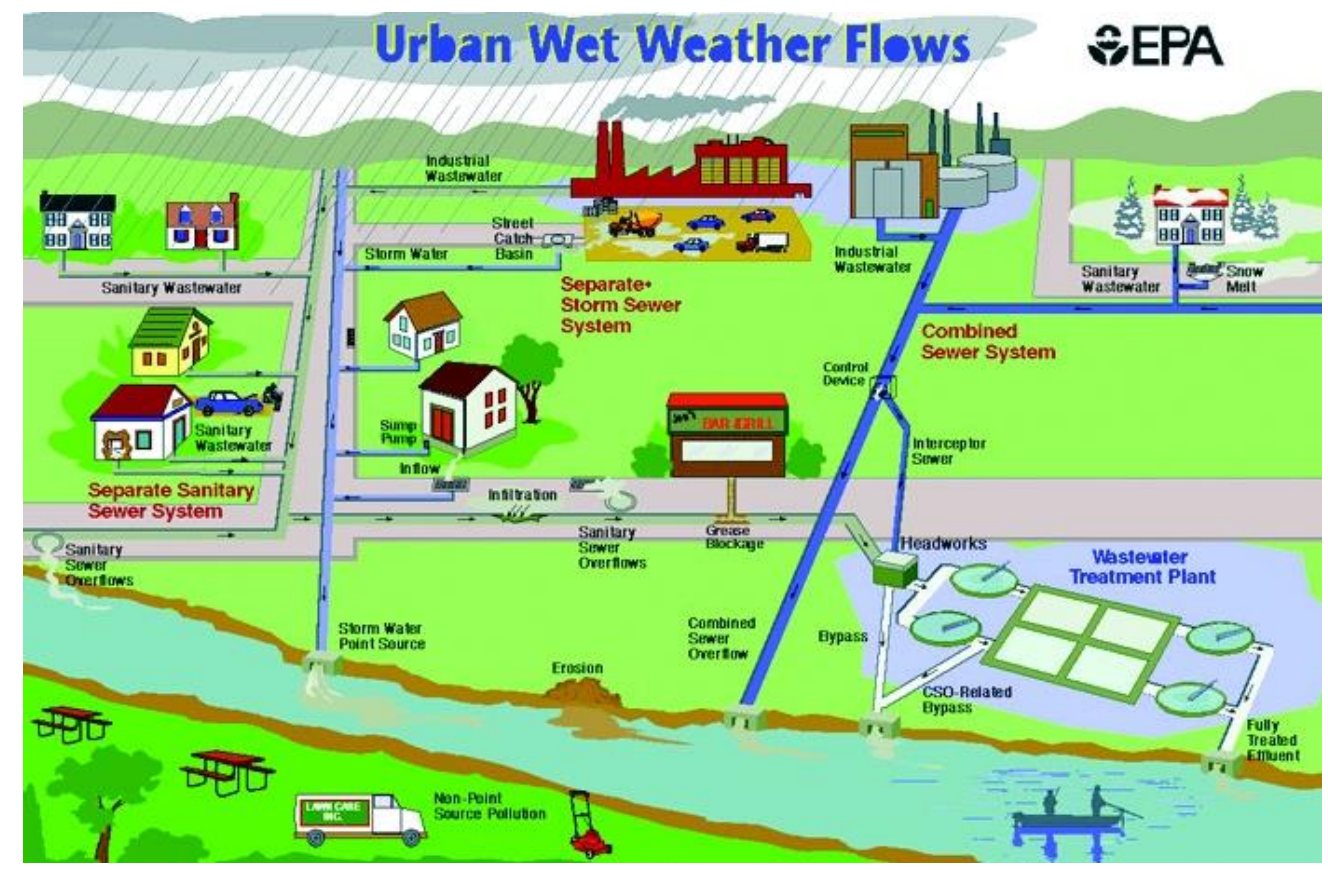

Figure 1: A combined sewer system collects wastewater and stormwater runoff in a single pipe system whereas a separate stormwater pipeline system conveys only stormwater. (USEPA. "National Pollution Discharge Elimination System (NPDES)". Healthy Waters in the MidAtlantic, < http://www.epa.gov/reg3wapd/images/images_npdes/cso_diagram.gif > (May. 25, 2015). Public domain.) 
The scope of this research is restricted to the separate stormwater pipeline system. Hereafter, such system is referred to as a stormwater pipeline system. The length of pipe between manholes or nodes is referred to as a stormwater pipeline. A node can be a junction, a stormwater inlet, or its outlet.

Stormwater pipelines vary greatly in size, age, and material. Materials may include concrete, polyvinyl chloride (PVC), clay, metal, high density polyethylene (HDPE), and in some cases even brick (Betz 2013). A poorly maintained stormwater pipeline system, or one that is inadequately designed to reliably pass increased flows arising from new developments, can result in neighborhood flooding (Jacobs et al. 1993). Besides the loss of human life, flooding can damage property, roadways, bridges, and other public works (Jacobs et al. 1993). It can also cause indirect damage such as loss of productivity due to damaged commercial property, higher insurance rates, cost of temporary housing, and lost wages (Jacobs et al. 1993). A poorly maintained stormwater pipeline system can also lead to contamination of the environment. All these effects highlight how crucial it is to maintain stormwater pipeline infrastructure.

\subsection{Stormwater Pipeline Asset Management}

The basic elements that form the foundation of a sustainable municipal infrastructure asset management program can be seen in the holistic asset management framework shown in Figure 2. As per this asset management framework, this research has collected and studied the available stormwater literature (Figure 3). Outside of the environmental effects, a minimal amount of research was found on stormwater pipelines or even stormwater management (Betz 2013). 


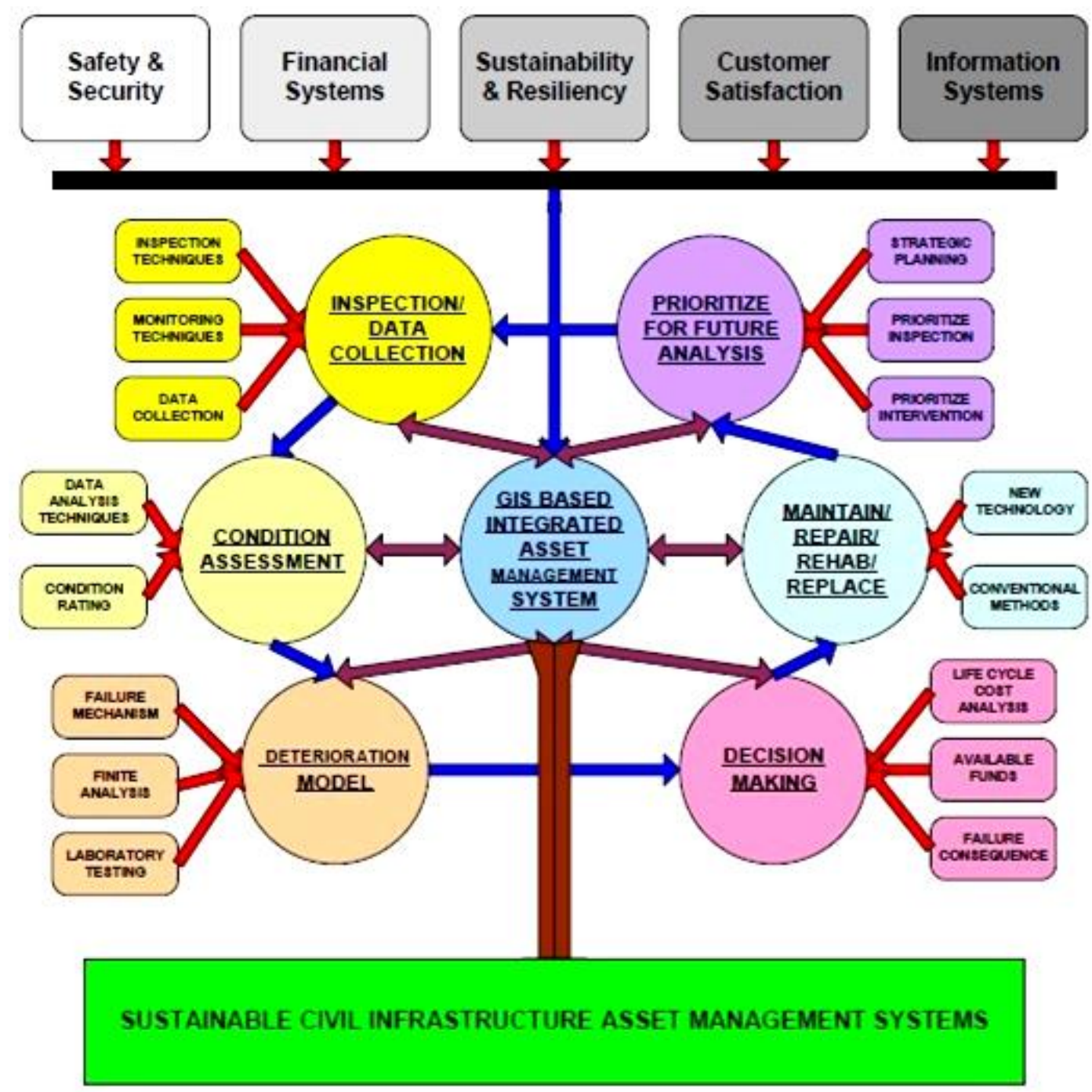

Figure 2: Framework for sustainable municipal asset management program (Gay, L. F. and Sinha, S. K. (2014). Water Infrastructure Asset Management Primer, Report No. INFR9SG09b, Water Environment Research Foundation, Alexandria, VA, 2-14. Used with permission of Carrie W. Capuco, JD, Water Environment Research Foundation.) 
- (Kannapiran et al. 2007)

- (Kannapiran et al. 2008)

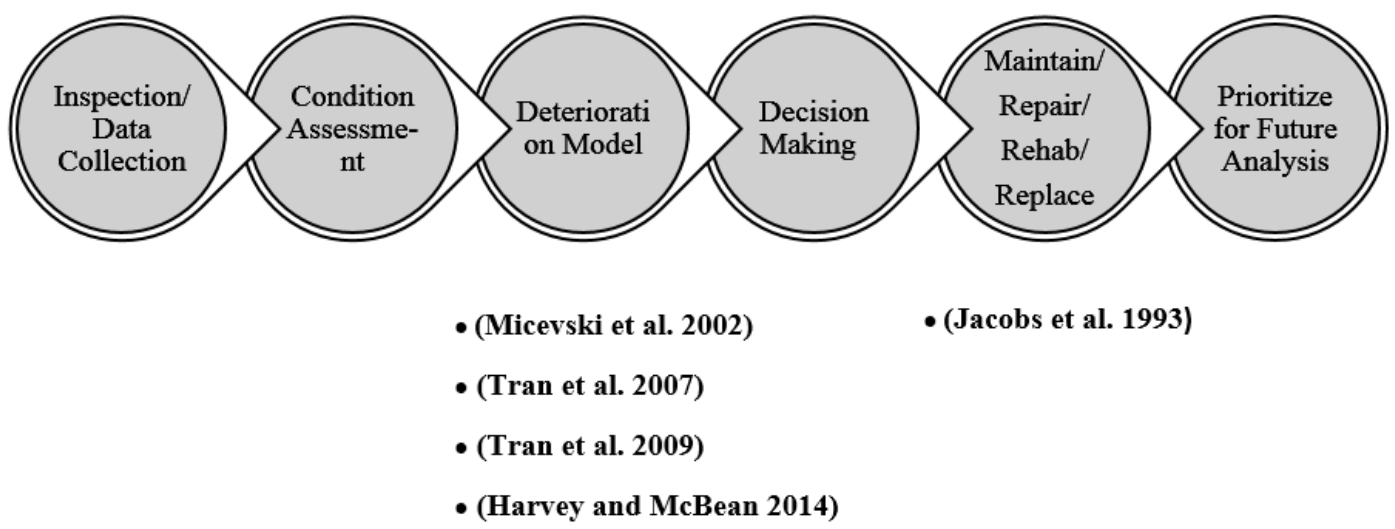

Figure 3: Relevant stormwater research as per the asset management framework

Researchers define the performance of a stormwater pipeline system as its ability to convey stormwater discharges in accordance with hydraulic design requirements, in such a manner that causes minimum damage to the environment; the system is also defined in terms of how well its structural integrity is maintained (Mitchell Shire Council 2012). The performance of a stormwater pipe network is directly and indirectly affected by many factors, including operational conditions, design parameters, external traffic loads, internal loads from operating and surge pressures, temperature changes, loss of bedding support, pipe properties and pipe condition (Kannapiran et al. 2007). Table 1 below summarizes the list of factors discussed in published literature cited in Figure 3 that affect the performance of stormwater pipeline infrastructure. 
Table 1: Factors affecting performance of stormwater pipe discussed in each published literature

\begin{tabular}{|c|c|}
\hline Reference & Factors \\
\hline (Micevski et al. 2002) & $\begin{array}{c}\text { Diameter, Material, Length, Soil type, } \\
\text { Exposure classification }\end{array}$ \\
\hline (Kannapiran et al. 2007) & $\begin{array}{c}\text { Age, Diameter, Material, Length, Traffic } \\
\text { load, Land use, Maintenance frequency }\end{array}$ \\
\hline \multirow{2}{*}{ (Tran et al. 2007); (Tran et al. 2009) } & $\begin{array}{c}\text { Age, Size, Soil type, Location, Pipe depth, } \\
\text { Pipe slope, Tree count around the pipe, } \\
\text { TMI (Tormwaite Moisture Index), } \\
\text { Structural condition, Hydraulic condition }\end{array}$ \\
\hline Age, Diameter, Material, Length, Soil \\
type, Pipe Depth, Pipe slope, Pipe \\
thickness
\end{tabular}

To gauge the performance of their stormwater pipelines, stormwater utilities have developed or adopted different rating systems that meet their program objectives, details, and needs. Most stormwater utilities in the U.S. use a 1-5 based scale and many have adopted the National Association of Sewer Service Companies' Pipeline Assessment Certification Program (Betz 2013). A few other rating systems identified are based on a "Good-Poor-Failed" rating, a 0-5 scale, and a 1-10 scale. A few utilities developed blended rating systems to gauge the condition of their individual asset types like pipes, inlets, and manholes based on their common method of inspection like visual inspection or stick cameras etc. (Betz 2013).

\subsubsection{National Association of Sewer Service Companies' (NASSCO) Pipeline Assessment Certification Program (PACP)}

PACP is a standard developed by NASSCO to conduct CCTV investigations on sanitary sewer, storm sewer, processed sewer, combined sewer, force main and any other wastewater pipe systems in the U.S. This standardization of condition prediction helps detect changes in pipe deterioration over time and also helps in comparing the conditions of two pipes within the same utility as well as between utilities. Shown in Figure 4 below is the process of using NASSCO's PACP to determine the condition index of a pipeline. The defects observed in the pipeline during CCTV 
inspection are recorded using defect codes by experienced personnel. These defect codes are assigned a defect score using the grades given in Table 2. These scores for all the defects in a pipe segment are aggregated, using basic mathematics manipulation, into a "Pipe Score." This "Pipe Score," divided by the total number of defects in the pipe segment, generates the pipe rating index, which is used to prioritize pipes for rehabilitation.

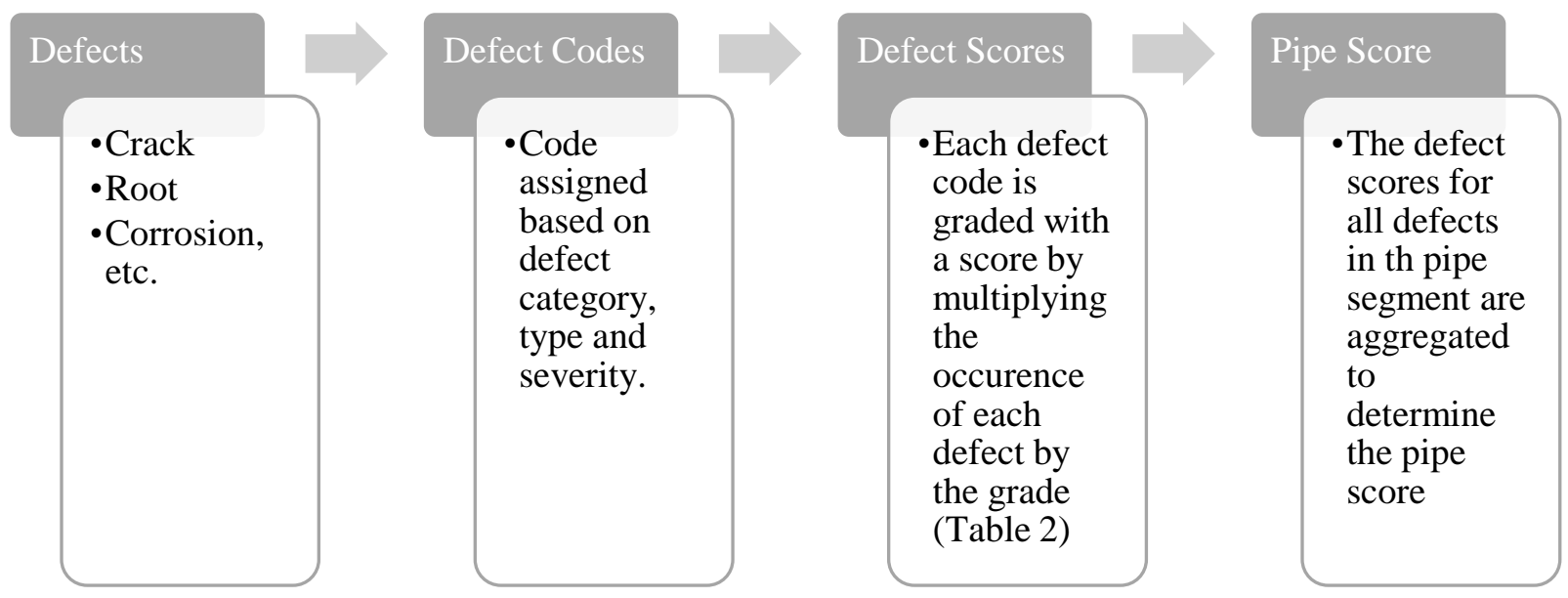

Figure 4: NASSCO's PACP process of determining the pipe condition score

Table 2: NASSCO's PACP Grades (Sinha, S., and Angkasuwansiri, T. (2010). "Phase 2: Development of a robust wastewater pipe performance index." Development of protocols and methods for predicting the remaining economic life of wastewater pipe infrastructure assets. Report No. 06-SAM-1 CO, Water Environment Research Foundation, Alexandria, VA. Used with permission of Carrie W. Capuco, JD, Water Environment Research Foundation.)

\begin{tabular}{|c|c|c|}
\hline Grade & Grade Description & Grade Definition \\
\hline 5 & Immediate Attention & Defects requiring immediate attention \\
\hline 4 & Poor & $\begin{array}{r}\text { Severe defects that will become Grade 5 in the } \\
\text { foreseeable future }\end{array}$ \\
\hline 3 & Fair & Moderate defects that will continue to deteriorate \\
\hline 2 & Good & Defects that have not begun to deteriorate \\
\hline 1 & Excellent & Minor defects \\
\hline
\end{tabular}




\subsection{Research Gaps}

A review of the literature reveals that, overall, there is lack of comprehensive research specific to stormwater pipeline asset management (Betz 2013). No study exists that gives a comprehensive list of factors that affect the performance of stormwater pipeline infrastructure. In addition, an analysis of the data in Table 1, makes it clear that

- performance parameters used across multiple studies do not match,

- different names are being used to indicated the same parameter, for example, pipe diameter and pipe size, and

- common units are not being followed for parameters; for example, diameter is measured, across studies, in different units.

Moreover, no standardized system exists to combine these parameters into a condition or performance index for stormwater pipelines within the U.S. (Betz 2013). The condition index currently being used by stormwater utilities are varied. A significant number of utilities use NASSCO's PACP which is an established standard. This standard is popularly used to measure the condition of wastewater pipelines in practice. With the growing demand for maintenance of stormwater pipelines, the industry needs to acknowledge the difference between wastewater and stormwater systems. Wastewater pipe systems are of higher quality, have longer pipe sections, and are installed at lower depths. Wastewater is chemical intensive, leading to corrosion in pipes. There are firm restrictions on the leakage of wastewater due to its high potential to cause damage. Wastewater pipes have a constant flow pattern and flow both under pressure and by gravity. The quality of stormwater pipe construction depends on the contractor since the pressure testing of the asset is not a mandate after construction (ASCE Standard 2006). Stormwater pipes, installed at relatively shallow depths, are generally made up of short sections and thus include many joints. Stormwater is relatively clean but contains different types of debris than can lead to surface wear of the pipes. The flow pattern in the pipe is not constant; it is linked directly to the precipitation in the area. Also, stormwater pipes generally remain empty for a portion of the year. Given these differences, there is a need to develop a performance index tailored specifically for stormwater pipelines. This index, based on standard parameters, would create a common platform for the utilities to interact and learn from each other's experience. 


\section{Chapter 3 Research Goal and Objectives}

The goal of this research is to work towards the development of a performance index designed specifically for stormwater pipelines. A stormwater pipeline is a single length of pipe between manholes or a node. A node can be a junction, a stormwater inlet, or outlet. The objectives undertaken in this research are as follows:

I. develop a well-defined list of parameters affecting stormwater pipeline performance,

II. find a suitable mathematical technique to combine the parameters into a performance index,

III. develop the performance index, and

IV. develop a prototype of the performance index using real time data from one stormwater utility and validate the results. 


\section{Chapter 4 Research Methodology}

The objective of developing a list of parameters affecting stormwater pipelines was accomplished through a review of the literature and by gathering the heuristic knowledge of industry experts. This research has studied the literature on stormwater pipeline design and listed the factors considered during design. The stormwater pipe material characteristics and failure modes were collected through the study of published stormwater utility asset management plans and other literature. Such efforts shed light on the differences between stormwater and wastewater pipelines. Angkasuwansiri and Sinha (2013) identified a list of approximately 100 parameters that affect performance of wastewater pipelines and divided them into five classes namely Physical/Structural, Environmental, Operational/Functional, Financial and Other. As storm sewers share unique differences and similarities to gravity sanitary sewers, this list of wastewater performance parameters was taken as a basis and tailored to stormwater pipelines. The deletion of non-significant parameters and the addition of new parameters was done at the author's discretion, as indicated in Figure 5.

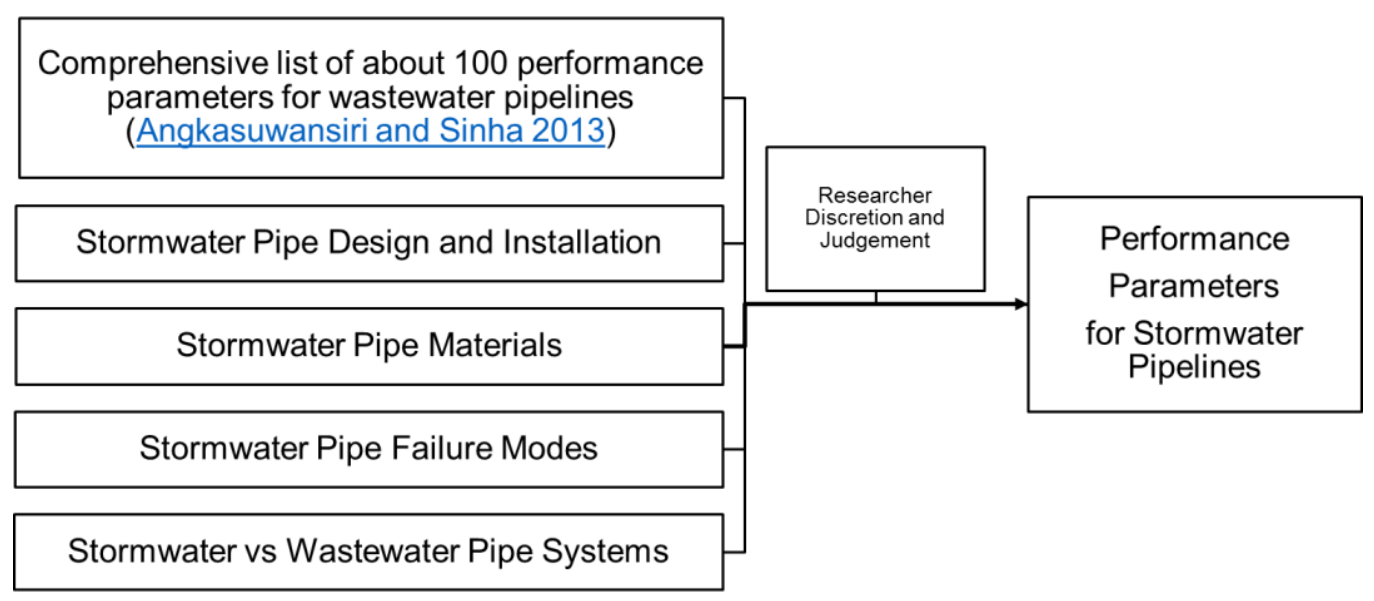

Figure 5: Method used to arrive at the performance parameters for stormwater pipelines

This list of parameters was sent out to 50 utilities across the U.S. for their feedback on the comprehensiveness of the list. The 50 utilities were selected based on available contacts from a previous research project (Betz 2013) and the list of stormwater utilities published in (Campbell 2013). To gather the feedback, the study contacted a minimum of three utilities from each of the EPA regions. One of the utilities replied that the list was quite "thorough." (Appendix A). Three parameters were added to the list based on the feedback from utilities during the course of the 
research. Overall, a list was composed of 50 parameters, with units that affect the performance of stormwater pipelines along with explanations.

The objective of finding a suitable mathematical technique was accomplished by studying the models available in the literature to assess the condition or performance of sewer and combined sewers (Table 3).

Table 3: Sewer and combined sewer condition/performance assessment models

\begin{tabular}{|c|c|}
\hline Reference & Mathematical Method \\
\hline (WRc 2001) & Peak score (Rahman and Vanier 2004) \\
\hline (NASSCO 2003) & $\begin{array}{c}\text { Intermediate aggregation approach } \\
\text { (Kathula et al. 2011) }\end{array}$ \\
\hline (NRC 2004) & $\begin{array}{c}\text { Mean score, Total score, Peak score } \\
\text { (Rahman and Vanier 2004) }\end{array}$ \\
\hline (Najafi and Kulandaivel 2005) & Neural networks \\
\hline (Koo and Ariaratnam 2006) & Multiple regression \\
\hline (Chughtai and Zayed 2007) & Hierarchical evidential reasoning model \\
\hline (Bai et al. 2008) & Fuzzy inference method \\
\hline (Tagherouit et al. 2011) & Analytic Hierarchy Process (AHP), \\
\hline (Fuamba and Ennaouri 2013) & Weighted summation \\
\hline (Angkasuwansiri and Sinha 2014) & Weighted summation, Fuzzy logic \\
\hline
\end{tabular}

Due to field data being limited and this being an introductory study, the study focused on developing a framework to determine the index rather than using a high-end mathematical technique to do so. Hence, a weighted factor method was chosen to determine the performance of a stormwater pipeline.

To develop the index, the study came up with a two-level hierarchal structure representing the performance deterioration of stormwater pipelines. The first level of the structure constituted the five modules in which a stormwater pipeline could fail-blockage, capacity, load, surface wear, and structural. These modules can co-exist in a pipe and are dependent on each other. To simplify the research problem, however, this study considers them to be independent. The module list was 
derived from research on wastewater pipes, evaluating their performance under eight failure modes-load, external corrosion, internal corrosion, surface wear, blockage, infiltration/exfiltration, root intrusion, and capacity (Sinha and Angkasuwansiri 2010). Corrosion is not as complex a problem in stormwater pipes and hence was included under the surface wear module. The utilities feedback on the problem of root intrusion was inconsistent (Appendix A). One utility explained that the lack of water in stormwater pipes throughout the year negates the problem of root intrusion. Another mentioned that it faces the problem of root intrusion. Hence, root intrusion was dropped from the list of modules and is included in the structural module. The infiltration/exfiltration has a direct effect on the stormwater pipe capacity and is therefore included in the capacity module. The second level of the structure constituted the parameters that affect each module. The explanation provided for the inclusion of the parameter in the data structure, also explains its inclusion in a module. A survey document was prepared based on the hierarchal structure and sent out to the same 50 utilities, to determine the relative weights of the five modules and the parameters affecting each module. Also, each of the parameters was rated on a scale of one to five, where one implies "excellent performance" and five implies "very poor performance," based on the literature and inputs from the industry.

The performance index was verified internally by using values of one for each parameter and cross checking to see that the output was one. The process was repeated for values from zero to five. Also, the performance index was run using the data obtained from one of the utilities. The output of the index was presented in the form of percentage of the pipes in the utility that belonged to each of the performance index categories. The utility personnel replied that the results were "Excellent" and that they would fill in the missing parameters to improve the reliability of the index (Appendix E). 


\section{Chapter 5 Development of Stormwater Pipeline Performance Data}

The performance of a stormwater pipeline can be defined as its ability to meet the required levels of service in a manner that it causes minimal damage to the environment while maintaining sound structural and hydraulic integrity. Stormwater pipelines are built of varied materials and are majorly installed using open trench construction. Many factors directly and indirectly affect the short term and long term performance of a stormwater pipe including design parameters, external traffic loads, internal loads from operating and surge pressure, and pipe condition (Kannapiran et al. 2007). These performance factors vary for each pipe material and can result in different failure modes and mechanisms. Figure 6 below shows the examples of factors affecting the performance of a buried pipe.

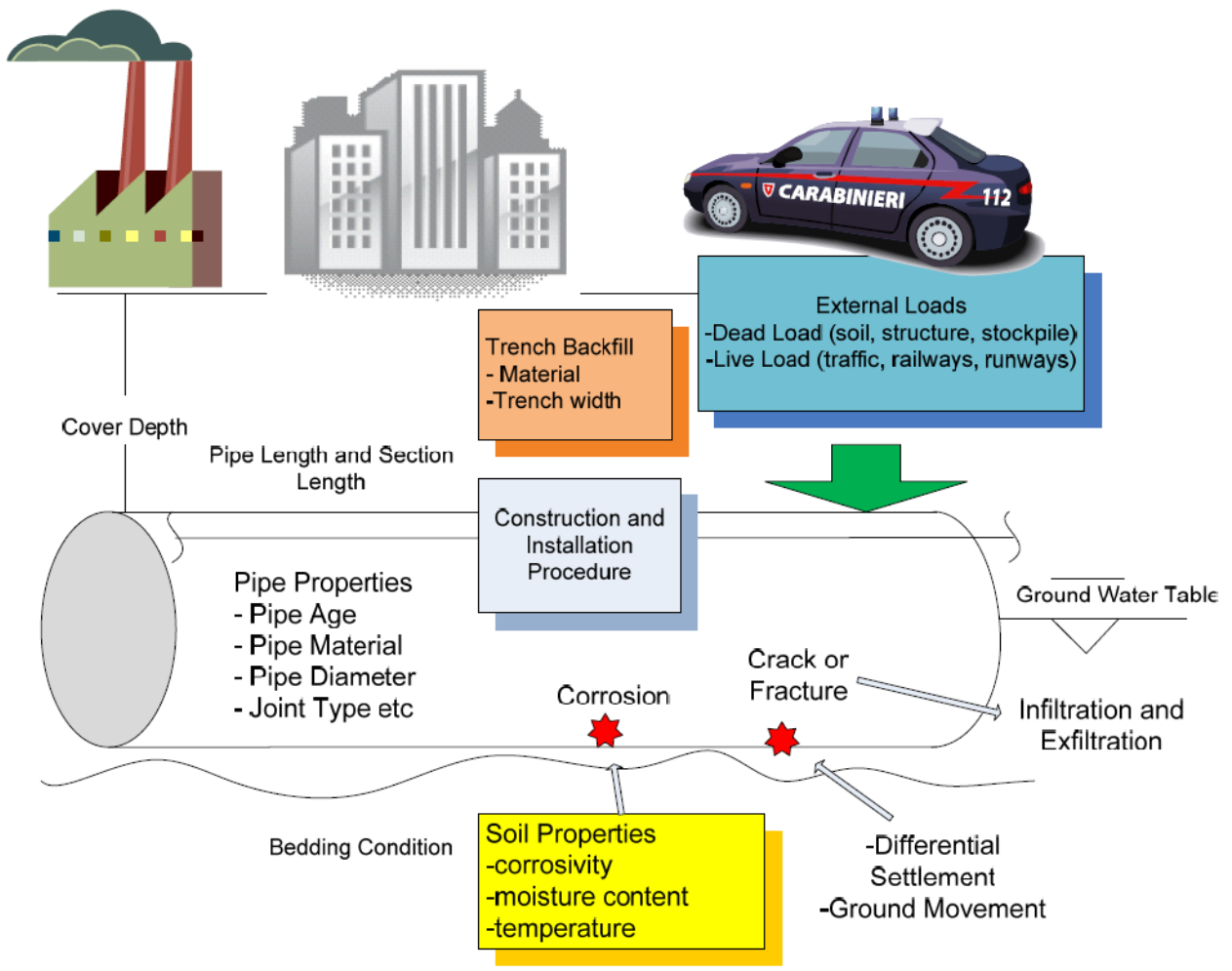

Figure 6: Factors affecting the performance of a buried pipe (Sinha, S., Angkasuwansiri, T., and Thomasson, R. (2008). "Phase 1: Development of standard data structure to support wastewater

pipe condition and performance prediction." Development of protocols and methods for predicting the remaining economic life of wastewater pipe infrastructure assets. Report No. 06SAM-1 CO, Water Environment Research Foundation, Alexandria, VA. Used with permission of Carrie W. Capuco, JD, Water Environment Research Foundation.) 
Stormwater pipes are largely designed to flow under gravity, sharing similarities with the wellresearched gravity sewer systems. A comprehensive list of about 100 parameters that affect the performance of wastewater pipelines was prepared by Sinha et al. (2008). They prepared this list, based on a review of the literature, so as to pertain to all phases of the life cycle of a wastewater pipe. These phases include design, manufacture, construction, operation and maintenance, and repair/rehabilitation/replacement, review of utility databases and interviews with utilities. As there is minimal research on stormwater pipes, this list was taken as merely a basis and then tailored, based on a study of stormwater pipe design, pipe materials, failure modes and feedback from utilities, to stormwater pipelines (Figure 5).

\subsection{Stormwater Pipeline Design and Installation}

The life cycle of a pipeline infrastructure system consists of the design, manufacturing, transportation, construction, operation, and maintenance phases (St Clair 2013). Stormwater pipe design is linked with the land use of an area. Due to the current rate of development, land use and therefore stormwater pipe design factors might change considerably in less time, subjecting the pipe to fatigue. The post-construction inspection of a stormwater pipe is based on the quality of materials, general standard of construction, and does not mandate pressure testing (ASCE Standard 2006). This increases the possibility of cracks or imperfect structural conditions of the pipe going unnoticed. It is crucial to therefore understand the design factors and the process of installation of a stormwater pipe, as they represent the benchmark against which the current performance of the asset can be measured.

The design and installation details that the author believes are crucial for the performance of stormwater pipes are briefly discussed below and were obtained from (ASCE Standard 2006) and (National Corrugated Steel Pipe Association 2008) manuals.

Stormwater pipe details, such as its shape and diameter, are designed based on hydrology, hydraulics, soil condition, and service requirements. Hydrology is the process of the continuous movement of water with respect to land (Figure 7). Precipitation and runoff are components of the hydrologic cycle that need to be estimated in order to design a storm sewer system. The precipitation of an area is represented using a design storm. A design storm is defined in terms of intensity, duration, and frequency of occurrence of the storm. The runoff rate for an area is 
estimated using the design storm, the percentage of impervious cover, and/or the soil characteristics of the area using methods like the rationale method, the Soil Conservation Service (SCS) method, and the Horton method. The runoff entering a pipe is calculated by multiplying the runoff rate with the time taken for overland flow to reach a channel.

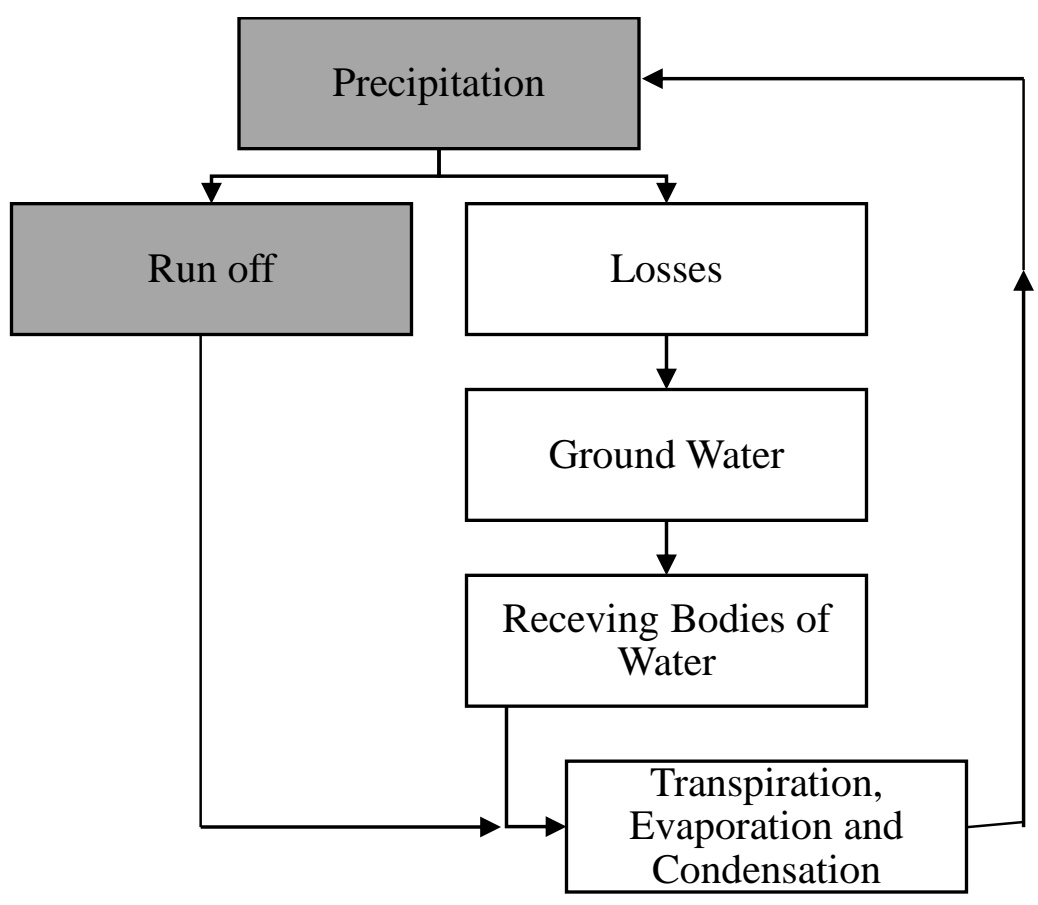

Figure 7: The hydrologic cycle. Precipitation and runoff need to be estimated to design stormwater pipe. (Adapted from National Corrugated Steel Pipe Association. (2008). Corrugated Steel Pipe Design Manual. Dallas, TX.)

The storm sewers are generally hydraulically designed using Manning's Equation, expressed below. The design velocity of a storm sewer is kept at a minimum of $3 \mathrm{ft} / \mathrm{s}$ to prevent deposition and a maximum of $12-15 \mathrm{ft} / \mathrm{s}$ to avoid erosive damage to pipe.

$$
\begin{gathered}
Q=A V \\
Q=\frac{1.486}{n} S_{f}^{1 / 2} A R^{2 / 3}
\end{gathered}
$$

Where:

\section{Equation 1: Manning's Equation}

$\mathrm{Q}=$ flow (cubic ft. /s)

$A=$ cross sectional area (square ft.) 
$\mathrm{V}=$ velocity of flow in the conduit (ft. /s)

$\mathrm{n}=$ roughness coefficient of the conduit

$\mathrm{R}=$ hydraulic radius which is the area of flow divided by the wetted perimeter (ft.)

$\mathrm{S}_{\mathrm{f}}=$ channel slope of the conduit in (ft. /ft.)

$\mathrm{P}=$ wetted perimeter (ft.)

The structural design of the stormwater pipe is made to withstand the dead loads (embankment trench fill materials plus stationary superimposed surface loads), live loads (moving loads including impact), construction forces and hydraulic forces. The structural strength of a stormwater pipe is dependent on the pipe wall strength, bedding and backfill conditions. The wall strength of the pipe is designed to be adequate to transfer the loads into the surrounding soil. The back fill provides lateral support to the pipe and controls deflection under load. Quality of backfill is characterized by soil stiffness, a property that results from nature of soil and level of compaction. The supporting soil beneath the pipe is called the bedding which maintains the pipe shape and uniformly distributes the pipe load, avoiding stress accumulation in pipe wall.

Most storm sewers in the past were constructed using open trench construction methods which typically include preparation of the foundation, bedding material, placing the pipe on the bedding material and then backfilling in layers. Figure 8 below indicates the sequence of construction of stormwater pipes.

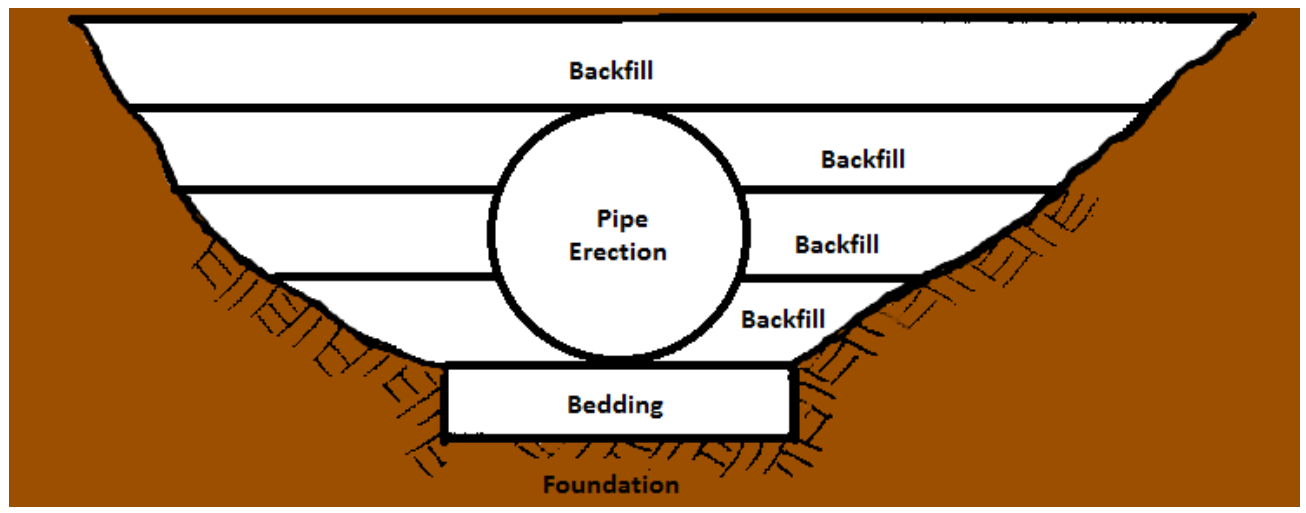

Figure 8: The sequence of construction of an underground pipe includes foundation preparation, bedding preparation, pipe erection, and backfilling in layers (Adapted from National Corrugated Steel Pipe Association. (2008). Corrugated Steel Pipe Design Manual. Dallas, TX.) 


\subsection{Stormwater Pipeline Materials}

Material type influences the structural strength of a pipe and the mode of deterioration of a pipe (Makar and Kleiner 2000). Each pipe material has its advantages and disadvantages. A stormwater network comprises of numerous connected pipes made of different materials installed at different time periods and joined together. The material type, the type of the join, the conditions of the surroundings and the loadings determine the failure path of a stormwater pipe.

Based on material type, stormwater pipes can be classified as rigid (concrete, vitrified clay), semirigid (corrugated metal, brick), and flexible (high-density polyethylene (HDPE), polyvinyl chloride (PVC)) as per the ASCE Standard (2006). Betz (2013) reported that, though clay and brick pipes are part of many current stormwater pipe network in the U.S., utilities are discouraging their use in new installations. They are thus dropped from the discussion below. The stormwater pipe materials are discussed below within the metal pipe, plastic pipe, and concrete pipe categories. The reasons for and modes of deterioration of each material type are assembled from the literature (Bishop and Sertich 2013; ASCE Standard 2006; Sinha et al. 2008; National Corrugated Steel Pipe Association 2008) and interaction with the utilities.

\section{- Corrugated Metal pipe}

Corrugated metal stormwater pipes are made of steel or aluminum. For over 100 years, utilities have used corrugated steel pipe to build stormwater systems. Corrugated steel can be subject to corrosion and surface wear on the soil side of the pipes, and corrosion, abrasion, and surface wear on the water side of the pipe. The rate of these deteriorations are based on the soil $\mathrm{pH}$ and resistivity, stormwater $\mathrm{pH}$ and resistivity, velocity of flow of stormwater, and the floating particles in stormwater. A common failure observed in corrugated metal pipes with age is the rotting of the invert.

Improper placement and compaction of the back fill and bedding can result in invert lifting, pipe end lifting, and distortion. Pipe end defects and differential settlements along the length of stormwater pipe lead to separated joints. Joint separation can further compromise the condition of the backfill due to exfiltration of stormwater. Joint separation also affects the condition of pipe due to infiltration of water and backfill from the surroundings into pipe. In fact, a major cause of sink holes, which lead to catastrophic failures, are separated joints. A lack of a minimum cover 
over the top of the metal pipes, especially with high external loading, can result in excessive deformation of metal pipes. Repair of interior coating and clearing out clogs are common maintenance measures for metal pipes.

- Plastic pipe

Both HDPE and PVC are made of viscous-elastic material and are flexible, their long term performance depends on proper fill and compaction of backfill. A common failure type in plastic pipes is deflection, leading to changes in pipe diameter, which can lead to cracking, crushing and gaps at joints. Inadequate depth of cover from the surface also results in holes and broken pipes at joints. It is also easy for another utility like electricity or phone departments to drill, without even realizing it, through a plastic pipe during their construction. Open joints and holes can result in settling or washouts. Thermal expansion and debris build up are other reasons for failure of plastic stormwater pipes.

- Concrete pipe

The poor structural condition of concrete pipes may be a result of improper designs of concrete mix and reinforcement, designs that do not consider site-specific conditions or adverse weather conditions. External loads, improper construction and handling can lead to minor cracks and opened joints. An opened joint leads to entry of surrounding soil into pipe, this load and improper bedding can lead to differential settlements in the pipe, followed by cracking and resulting in deformation. Table 4 below provides a broad overview of the reasons for failure of stormwater pipe materials. 
Table 4: Reasons for failure of stormwater pipes

\begin{tabular}{|c|c|c|}
\hline Concrete Pipe & Corrugated Metal Pipe & $\begin{array}{c}\text { Plastic Pipe } \\
\text { (HDPE and PVC) }\end{array}$ \\
\hline $\begin{array}{l}\text { Improper design of concrete } \\
\text { mix and reinforcement for the } \\
\text { specific site and external } \\
\text { loading }\end{array}$ & Inadequate depth of cover & $\begin{array}{l}\text { Deflection during installation, } \\
\text { inadequate depth of cover }\end{array}$ \\
\hline Infiltration of soil particles & Corrosive soil and water & Thermal expansion and holes \\
\hline \multicolumn{3}{|c|}{ Poor joints } \\
\hline \multicolumn{3}{|c|}{ Clogging and debris } \\
\hline \multicolumn{3}{|c|}{ Inaccurate placement and improper compaction of backfill } \\
\hline \multicolumn{3}{|c|}{ Inadequate design storage volume } \\
\hline & $\mathrm{d}$ walls or $\mathrm{o}$ & \\
\hline
\end{tabular}

\subsection{Stormwater Failure Modes}

Failure modes are defined as the type of failures that occur within a pipe (Sinha and St Clair 2014). In determining the failure modes of a stormwater pipe, inspectors generally use CCTV investigations, stick cameras, or visual inspections. Knowing the failure modes in a pipe, utilities are better able to plan for its rehabilitation and understand the factors that contributed to the defect formation. Based on a review of the documents, Integrated Science and Engineering Inc. (2013), MnDoT Bridge Hydraulics (2013), and Burns and McDonnell Engineering Company Inc. (2010), and through interaction with utility personnel, this study compiled a list of the defects found in stormwater pipelines, which are listed below in Table 5. This list is an assemblage of failure modes of stormwater pipes, which can be personalized to each pipe material in future research with further inputs from the industry. 
Table 5: List of failure modes encountered in stormwater pipe

\begin{tabular}{|c|c|}
\hline Failure Mode & Details \\
\hline Cracks and Fractures & $\begin{array}{l}\text { Longitudinal, circumferential, multiple, } \\
\text { helical/Spiral }\end{array}$ \\
\hline $\begin{array}{l}\text { Deformed, collapsed and } \\
\text { broken pipes }\end{array}$ & Punctures, breaks, deflection/compression, dent, collapse \\
\hline Displaced and open joints & $\begin{array}{c}\text { Gaps in joint, horizontal and vertical joint offset, dropped } \\
\text { invert/misalignment }\end{array}$ \\
\hline Surface damage & Exposed reinforcement and aggregate \\
\hline Defective connections & Mid line or break in type connections without manholes \\
\hline $\begin{array}{l}\text { Debris, silt and } \\
\text { obstructions }\end{array}$ & $\begin{array}{l}\text { Foreign obstructions that reduce the hydraulic capacity of } \\
\text { the pipe including roots }\end{array}$ \\
\hline Infiltration & Water infiltration within pipe structure \\
\hline Exfiltration & Water exfiltration to surroundings \\
\hline Settlement & Scouring/erosion of bedding material \\
\hline $\begin{array}{l}\text { Encrustation, scale and } \\
\text { physical damage }\end{array}$ & $\begin{array}{l}\text { Erosion of pipe lining, chipping, puncturing, scaling, } \\
\text { spalling, rusting, collapse, corrosion }\end{array}$ \\
\hline Water Level & Level of water in the pipe above design level \\
\hline
\end{tabular}

From the above list, it can be seen that most of the stormwater failure categories are addressed in NASSCO's PACP. However, there is scope to alter the detailed defect codes. For example, holes are a major defect for stormwater pipes. Codes that cover holes can be expanded to include intrusions from other utilities, sink holes, and so forth. Also, there is scope to revise the scores of the existing defect codes. Indeed, between stormwater pipes and wastewater pipes, the severity of the defects varies. For example, the visible reinforcement in a concrete pipe needs to be downgraded as stormwater is not as corrosive as wastewater.

\subsection{Stormwater Pipe Performance Data Structure}

A data structure is an organized form of collecting and storing data. Time-dependent and organized performance data will aid stormwater utilities in understanding their assets and developing performance indices and deterioration models. A data structure of about 100 parameters that affect 
the performance of wastewater pipelines was developed by Angkasuwansiri and Sinha (2013) based on a review of the literature. The parameters pertain to all phases of the life cycle of a wastewater pipe including design, manufacture, construction, operation and maintenance, and repair/rehabilitation/replacement, review of utility databases and interviews with utilities (Sinha et al. 2008). This data structure was broken into the following four modes: Wood (11 parameters), for very small utilities; Bronze (23 parameters), for small utilities; Silver (51 parameters), for utilities larger than bronze utilities but that have no special team devoted to updating the wastewater database, and Gold (98 parameters), for the largest cities that have a special team devoted to keeping data records up to date (Sinha et al. 2008). Primarily because of funding and workforce constraints, the U.S. stormwater utilities perform limited inspections of their systems, mainly just trouble spots (Betz 2013). The Gold data structure mode would be an overwhelming data collection standard for stormwater utilities that are bound by workforce constraints. Hence, the Silver data structure was taken as a basis and modified to suit stormwater pipelines. Of the Silver data structure's 51 parameters, 18 that were not crucial to determining the performance of a stormwater pipe were deleted at the author's discretion and judgment. The units of the remaining 33 parameters were altered; their inclusion in the list of stormwater data structure is explained by the author. Also, four parameters from the Gold data structure which affect the performance of stormwater pipelines were added to the data structure. Based on the study of stormwater pipe design, stormwater utility asset management plans, and the failure modes, the author added to the data structure 10 new critical parameters for stormwater performance. Based on the feedback received from utilities, three more parameters were added to the list.

The final list contains 50 stormwater performance parameters. Based on their characteristics, they were divided into the following four classes: Physical/Structural, Environmental, Operational/Functional, and Other. Considering that all the utilities might not have sufficient resources to collect all 50 parameters, the list was further broken down into essential and preferential data (Angkasuwansiri and Sinha 2013). Figure 10 below lists the performance parameters for stormwater pipelines. 


\begin{tabular}{|c|c|c|c|}
\hline Physical/Structural & Environmental & Functional/Operational & Other \\
\hline Age & Soil Type & Average Flow Velocity & Post Installation Condition \\
\hline Diameter & Ground Water Table & Minimum Flow Velocity & Maintenance Method \\
\hline Shape & Location & Overflow Frequency & Inspection/CCTVRecord \\
\hline Length & Loading Condition (Dead Load) & Surcharging & Renewal Record \\
\hline Material & Loading Condition (Live Load) & Inflow and Infiltration & Failure Record \\
\hline Depth of Cover & Average Precipitation Intensity & Exfiltration & Complaint Record \\
\hline Slope & Average Precipitation Duration & Debris Level & Capital Cost \\
\hline Joint Type & Frost Penetration & Sedimentation Level & Annual operation and maintenance cost \\
\hline Associated Structures & Soil Corrosivity & Smell of Vermin Level & \\
\hline Lateral Connections & Proximity to Trees & Maximum Allowable Velocity & \\
\hline Bedding Condition & Proximity to Utilities & Presence of stagnant water in pipe & \\
\hline Trench Backfill & Extreme Temperature & & \\
\hline Design Life & Record of Extreme Event & & \\
\hline \multicolumn{4}{|l|}{ Design Storm } \\
\hline \multicolumn{4}{|l|}{ Function } \\
\hline \multicolumn{4}{|l|}{ Thickness } \\
\hline \multicolumn{4}{|l|}{ Coating } \\
\hline Lining & & & \\
\hline
\end{tabular}

Figure 9: List of stormwater pipeline performance parameters. The parameters highlighted in grey are the essential parameters and the others are preferable parameters. 
Table 6: Details of stormwater performance parameters. For each parameter, the unit, the explanation for including the parameter and the source from which the idea to include the parameter was obtained are presented.

\begin{tabular}{|c|c|c|c|}
\hline Parameter & Unit & Explanation & Source \\
\hline \multicolumn{4}{|c|}{ Physical/Structural } \\
\hline $\begin{array}{c}\text { Age } \\
\text { (Essential) }\end{array}$ & Year & $\begin{array}{l}\text { Age is the length of time since pipe was installed. It } \\
\text { may or may not be a strong indicator of pipe } \\
\text { deterioration. Typically, it is assumed that effects of } \\
\text { pipe deterioration become more apparent with time. }\end{array}$ & $\begin{array}{l}\text { (Harvey and McBean 2014; } \\
\text { Kannapiran et al. 2007; Tran } \\
\text { et al. 2007) }\end{array}$ \\
\hline $\begin{array}{l}\text { Diameter } \\
\text { (Essential) }\end{array}$ & Inch & $\begin{array}{l}\text { Diameter is typically classified by nominal or outside } \\
\text { diameter rather than inside diameter. The failure } \\
\text { pattern and rate of failure vary with a pipe diameter. } \\
\text { Smaller diameter pipes are more susceptible to failure } \\
\text { than larger diameter pipes as they can be easily } \\
\text { blocked and their depth of cover requirements are } \\
\text { underestimated by designers. }\end{array}$ & $\begin{array}{l}\text { (Harvey and McBean 2014; } \\
\text { Micevski et al. 2002; } \\
\text { Kannapiran et al. 2007; Tran } \\
\quad \text { et al. 2007) }\end{array}$ \\
\hline $\begin{array}{c}\text { Shape } \\
\text { (Essential) }\end{array}$ & Type & $\begin{array}{l}\text { The pressure on a pipe due to similar load varies with } \\
\text { the shape of the pipe. Moreover, the cross section area } \\
\text { in contact with water differs with pipe shape, for the } \\
\text { same volume of water. }\end{array}$ & $\begin{array}{c}\text { (Angkasuwansiri and Sinha } \\
\text { 2013) }\end{array}$ \\
\hline $\begin{array}{c}\text { Length } \\
\text { (Essential) }\end{array}$ & Feet & $\begin{array}{l}\text { Length of pipe refers to the distance between manholes } \\
\text { or nodes. Short length pipes have an increased number } \\
\text { of joints leading to more possible point of failure. }\end{array}$ & (Harvey and McBean 2014) \\
\hline
\end{tabular}




\begin{tabular}{|c|c|c|c|}
\hline Parameter & Unit & Explanation & Source \\
\hline Thickness & Inch & $\begin{array}{l}\text { Thickness can dictate the time corrosion takes to result } \\
\text { in pipe failure. The loading stress on a pipe is a } \\
\text { function of depth of cover and thickness of pipe. }\end{array}$ & $\begin{array}{l}\text { (Angkasuwansiri and Sinha } \\
\text { 2013; Harvey and McBean } \\
\text { 2014) }\end{array}$ \\
\hline $\begin{array}{c}\text { Material } \\
\text { (Essential) }\end{array}$ & Type & $\begin{array}{l}\text { Different material type are designed for different } \\
\text { service needs and dictate the resistance to corrosion } \\
\text { and resilience to strength. }\end{array}$ & $\begin{array}{l}\text { (Angkasuwansiri and Sinha } \\
\text { 2013; Micevski et al. 2002) }\end{array}$ \\
\hline $\begin{array}{l}\text { Depth of Cover } \\
\text { (Essential) }\end{array}$ & Feet & $\begin{array}{l}\text { The depth of pipe has a role in the stress being } \\
\text { transferred from the live and dead load on surface and } \\
\text { protection from frost. Shallow pipes fail faster than } \\
\text { deeper pipes. Stormwater pipes typically are said to be } \\
\text { at shallower depths in comparison to wastewater } \\
\text { pipelines. }\end{array}$ & $\begin{array}{c}\text { (Harvey and McBean 2014 } \\
\text { Tran et al. 2007) }\end{array}$ \\
\hline $\begin{array}{c}\text { Slope } \\
\text { (Essential) }\end{array}$ & Gradient & $\begin{array}{l}\text { Slope effects the rate of gravity flow. Steep slopes lead } \\
\text { to faster flow rates, thereby having a higher } \\
\text { deterioration rates when compared to flatter slopes. If } \\
\text { the slope of the stormwater pipe is not adequate it may } \\
\text { result in blockage or sedimentation. }\end{array}$ & $\begin{array}{c}\text { (Harvey and McBean 2014 } \\
\text { Tran et al. 2007) }\end{array}$ \\
\hline $\begin{array}{l}\text { Joint Type } \\
\text { (Essential) }\end{array}$ & Type & $\begin{array}{l}\text { Different choice of joint types are available for each } \\
\text { pipe material. It is crucial to understand the features of } \\
\text { the pipe material and required performance of the joint }\end{array}$ & $\begin{array}{l}\text { (Angkasuwansiri and Sinha } \\
\text { 2013; Sanders 2009) }\end{array}$ \\
\hline
\end{tabular}




\begin{tabular}{|c|c|c|c|}
\hline Parameter & Unit & Explanation & Source \\
\hline & & $\begin{array}{l}\text { (leak resistant, soil tight, withstand bending, pull-apart } \\
\text { scenarios etc.) to design the joining system. A wrong } \\
\text { choice or deteriorated joint affects the performance of } \\
\text { the storm sewer by aggravating infiltration and } \\
\text { exfiltration or creating stress. }\end{array}$ & \\
\hline Coating & $\begin{array}{l}\text { Yes/No } \\
\text { Type }\end{array}$ & $\begin{array}{c}\text { External coating increases the service life of } \\
\text { stormwater pipes by preventing against corrosion and } \\
\text { abrasion. It is important for metal pipes. . }\end{array}$ & $\begin{array}{c}\text { (Angkasuwansiri and Sinha } \\
\text { 2013) }\end{array}$ \\
\hline Lining & $\begin{array}{l}\text { Yes/No } \\
\text { Type }\end{array}$ & $\begin{array}{l}\text { Internal surface of a pipe can be coated to halt material } \\
\text { deterioration, provide structural strength, and prevent } \\
\text { infiltration and exfiltration. The lining materials can } \\
\text { alter the water quality. Popular materials include } \\
\text { cement mortar, epoxy, polyurethane and polyurea. }\end{array}$ & $\begin{array}{l}\text { (Angkasuwansiri and Sinha } \\
\text { 2013; Tabor et al. 2013) }\end{array}$ \\
\hline $\begin{array}{l}\text { Associated } \\
\text { Structures } \\
\text { (Essential) }\end{array}$ & $\begin{array}{c}\text { Type } \\
\text { Condition }\end{array}$ & $\begin{array}{l}\text { Different types of drainage structures are associated } \\
\text { with a stormwater pipe. Stormwater is typically } \\
\text { collected by catch basins, grated inlets, hooded grate } \\
\text { inlets, etc. Headwalls, flared end sections and end of } \\
\text { pipe structures can either collect or discharge } \\
\text { stormwater runoff. Junction boxes and manholes are } \\
\text { used to accommodate change in pipe direction, } \\
\text { diameter or depth. The structure condition and }\end{array}$ & $\begin{array}{l}\text { (Integrated Science and } \\
\text { Engineering Inc 2013); } \\
\quad \text { Survey Input }\end{array}$ \\
\hline
\end{tabular}




\begin{tabular}{|c|c|c|c|}
\hline Parameter & Unit & Explanation & Source \\
\hline & & $\begin{array}{l}\text { sediment, debris or water levels in the structure are } \\
\text { crucial to the performance (esp. blockage levels) of the } \\
\text { attached stormwater pipes. }\end{array}$ & \\
\hline $\begin{array}{c}\text { Lateral } \\
\text { connections } \\
\text { (Essential) }\end{array}$ & $\begin{array}{l}\text { No./ } \\
\text { length }\end{array}$ & $\begin{array}{l}\text { The required capacity of the stormwater pipe is } \\
\text { depended on the service connections. If the size of the } \\
\text { pipe is inadequate it leads to frequent overflows. }\end{array}$ & $\begin{array}{l}\text { (Angkasuwansiri and Sinha } \\
\text { 2013) }\end{array}$ \\
\hline $\begin{array}{l}\text { Bedding } \\
\text { Condition } \\
\text { (Essential) }\end{array}$ & $\begin{array}{c}\text { Yes/No } \\
\text { Condition }\end{array}$ & $\begin{array}{l}\text { A pipe must be supported through even bedding that is } \\
\text { properly tamped. Loss of bedding can lead to beam } \\
\text { stress on pipe. }\end{array}$ & $\begin{array}{c}\text { (Angkasuwansiri and Sinha } \\
\text { 2013; Kannapiran et al. 2007) }\end{array}$ \\
\hline $\begin{array}{c}\text { Trench Backfill } \\
\text { (Essential) }\end{array}$ & $\begin{array}{c}\text { Type } \\
\text { Condition }\end{array}$ & $\begin{array}{l}\text { Trench backfill provides surrounding support for pipe } \\
\text { stability and reduces displacements. Poor backfill can } \\
\text { create shearing or friction forces on the side of the } \\
\text { pipe. }\end{array}$ & $\begin{array}{l}\text { (Angkasuwansiri and Sinha } \\
\text { 2013; Bishop and Sertich } \\
\text { 2013) }\end{array}$ \\
\hline $\begin{array}{l}\text { Design Life } \\
\text { (Essential) }\end{array}$ & Year & $\begin{array}{l}\text { The period of time the pipe was expected to function } \\
\text { operationally when installed. }\end{array}$ & $\begin{array}{c}\text { (Angkasuwansiri and Sinha } \\
\text { 2013) }\end{array}$ \\
\hline $\begin{array}{l}\text { Design Storm } \\
\text { (Essential) }\end{array}$ & $\begin{array}{l}\text { Intensity- } \\
\text { Inch/hour, } \\
\text { Duration-Hour, } \\
\text { Frequency-Years }\end{array}$ & $\begin{array}{l}\text { Design storm is a mathematical representation of } \\
\text { precipitation in a given area for design of } \\
\text { infrastructure. It is classified by intensity (how much } \\
\text { inches of precipitation occurred in a given time), } \\
\text { duration (how long the storm lasted) and recurrence } \\
\text { interval ( } 2 \text { year or } 5 \text { year or } 10 \text { year). A storm of given }\end{array}$ & $\begin{array}{l}\text { (Division of Sewerage and } \\
\text { Drainage 2006; Rudick and } \\
\quad \text { Lincoln 2014) }\end{array}$ \\
\hline
\end{tabular}




\begin{tabular}{|c|c|c|c|}
\hline Parameter & Unit & Explanation & Source \\
\hline & & $\begin{array}{l}\text { intensity and duration and can occur only one time } \\
\text { every ' } x \text { ' years. A } 2 \text { year storm is less severe than } 5 \\
\text { year storm and so on. }\end{array}$ & \\
\hline $\begin{array}{l}\text { Function } \\
\text { (Essential) }\end{array}$ & Type & $\begin{array}{l}\text { Different uses of the pipe (gravity main, lateral, } \\
\text { pressurized main) affect the deterioration rate of the } \\
\text { pipe. The unit is type. }\end{array}$ & $\begin{array}{c}\text { (Angkasuwansiri and Sinha } \\
\text { 2013; Environmental } \\
\text { Protection Services } \\
\text { Department 2013) }\end{array}$ \\
\hline \multicolumn{4}{|c|}{ Environmental } \\
\hline $\begin{array}{l}\text { Soil Type } \\
\text { (Essential) }\end{array}$ & Type & $\begin{array}{l}\text { The pipe trench (with or without bedding and backfill) } \\
\text { is sitting in a soil type. Certain soil types have high } \\
\text { corrosion potential, are more prone to expansion and } \\
\text { contraction when wet and have varying unit weights } \\
\text { that determine the dead load from the soil. }\end{array}$ & $\begin{array}{l}\text { (Harvey and McBean 2014; } \\
\text { Micevski et al. 2002; Tran et } \\
\text { al. 2007) }\end{array}$ \\
\hline Soil Corrosivity & Level & $\begin{array}{l}\text { Soil corrosivity cannot be directly measure and hence } \\
\text { needs to be documented. It is function of several soil } \\
\text { properties like soil redox potential, soil pH, soil } \\
\text { resistivity, soil sulfides, moisture content etc. }\end{array}$ & $\begin{array}{c}\text { (Angkasuwansiri and Sinha } \\
\text { 2013) }\end{array}$ \\
\hline $\begin{array}{l}\text { Groundwater } \\
\text { Table } \\
\text { (Essential) }\end{array}$ & Feet or Level & $\begin{array}{l}\text { The proximal location of groundwater table may lead } \\
\text { to ground loss and subsequent flotation of pipes. Also, } \\
\text { the exfiltrated stormwater, if any, would enter the } \\
\text { groundwater without proper filtration resulting in }\end{array}$ & $\begin{array}{c}\text { (Angkasuwansiri and Sinha } \\
\text { 2013; Tran et al. 2007) }\end{array}$ \\
\hline
\end{tabular}




\begin{tabular}{|c|c|c|c|}
\hline Parameter & Unit & Explanation & Source \\
\hline & & $\begin{array}{l}\text { groundwater contamination. If groundwater level is } \\
\text { above the pipe crown it can lead to infiltration. }\end{array}$ & \\
\hline $\begin{array}{l}\text { Location } \\
\text { (Essential) }\end{array}$ & Type & $\begin{array}{l}\text { Location of the pipe determines the usage of the land } \\
\text { which create different conditions and loads on the pipe. } \\
\text { It also determines the quantity and quality of } \\
\text { stormwater runoff (runoff coefficient for design) } \\
\text { generated. It is a measure of consequence of failure. }\end{array}$ & $\begin{array}{l}\text { (Micevski et al. 2002; } \\
\text { Kannapiran et al. 2007; Tran } \\
\text { et al. 2007) }\end{array}$ \\
\hline $\begin{array}{c}\text { Loading } \\
\text { Condition (Dead } \\
\text { Load) } \\
\text { (Essential) }\end{array}$ & Level & $\begin{array}{l}\text { The magnitude of increase in the load on the pipe due } \\
\text { to modernization or development leads to compressive } \\
\text { forces on the pipe wall. If the pipe material and } \\
\text { thickness do not match the load upon the pipe, it might } \\
\text { lead to deformation in pipes. }\end{array}$ & $\begin{array}{l}\text { (Angkasuwansiri and Sinha } \\
\text { 2013) }\end{array}$ \\
\hline $\begin{array}{c}\text { Loading } \\
\text { Condition (Live } \\
\text { Load) } \\
\text { (Essential) }\end{array}$ & Level & $\begin{array}{l}\text { Live loading from traffic can also lead to compressive } \\
\text { forces on the pipe wall. Excessive bending and } \\
\text { excessive crushing forces can lead to longitudinal and } \\
\text { circumferential cracking online. It is also a measure } \\
\text { for consequence of failure. }\end{array}$ & $\begin{array}{l}\text { (Angkasuwansiri and Sinha } \\
\text { 2013) }\end{array}$ \\
\hline $\begin{array}{l}\text { Proximity to } \\
\text { Trees }\end{array}$ & Feet & $\begin{array}{l}\text { A pipe that is in close proximity to trees has a higher } \\
\text { probability of being subject to root intrusion. }\end{array}$ & $\begin{array}{c}\text { (Angkasuwansiri and Sinha } \\
\text { 2013; Tran et al. 2007) }\end{array}$ \\
\hline
\end{tabular}




\begin{tabular}{|c|c|c|c|}
\hline Parameter & Unit & Explanation & Source \\
\hline $\begin{array}{l}\text { Proximity to } \\
\text { Utilities }\end{array}$ & $\begin{array}{l}\text { Type } \\
\text { Feet }\end{array}$ & $\begin{array}{l}\text { One of the major reasons for damage of stormwater } \\
\text { pipes is when the existing utilities damage them during } \\
\text { their respective installation or repair activities. }\end{array}$ & Survey feedback \\
\hline $\begin{array}{c}\text { Average } \\
\text { Precipitation } \\
\text { Intensity } \\
\text { (Essential) }\end{array}$ & Inch/hour & $\begin{array}{c}\text { This factor enables to gauge if the stormwater pipe } \\
\text { capacity is adequate. }\end{array}$ & Author Discretion \\
\hline $\begin{array}{c}\text { Average } \\
\text { Precipitation } \\
\text { Duration } \\
\text { (Essential) }\end{array}$ & Hour & $\begin{array}{l}\text { This factor enables to gauge if the stormwater pipe } \\
\text { capacity is adequate. }\end{array}$ & Author Discretion \\
\hline Frost Penetration & Feet & $\begin{array}{l}\text { It is an important design parameter for stormwater } \\
\text { pipes. Installing stormwater pipes below the frost line } \\
\text { protects them from excessive frost loading and } \\
\text { prevents water from freezing in pipes. }\end{array}$ & $\begin{array}{l}\text { (Angkasuwansiri and Sinha } \\
\text { 2013; CWP 1997) }\end{array}$ \\
\hline $\begin{array}{c}\text { Extreme } \\
\text { Temperature }\end{array}$ & $\mathrm{F}$ & $\begin{array}{l}\text { An obvious measure of climate is temperature. } \\
\text { Extreme cold can cause rapid freezing which can cause } \\
\text { pipes to burst. Extreme cold can reduce the infiltration } \\
\text { capacity of the soil resulting in larger runoff volumes. }\end{array}$ & $\begin{array}{c}\text { (Angkasuwansiri and Sinha } \\
\text { 2013; CWP 1997) }\end{array}$ \\
\hline $\begin{array}{c}\text { Record of } \\
\text { Extreme Event }\end{array}$ & Text & $\begin{array}{l}\text { Any extreme event like third party disturbance or } \\
\text { natural calamity that affected the stormwater pipe shall }\end{array}$ & $\begin{array}{c}\text { (Angkasuwansiri and Sinha } \\
\text { 2013) }\end{array}$ \\
\hline
\end{tabular}




\begin{tabular}{|c|c|c|c|}
\hline Parameter & Unit & Explanation & Source \\
\hline & & $\begin{array}{l}\text { be documented here. This will help in improving the } \\
\text { knowledge of the utilities about their assets. }\end{array}$ & \\
\hline \multicolumn{4}{|c|}{ Functional/Operational } \\
\hline $\begin{array}{l}\text { Average Flow } \\
\text { Velocity } \\
\text { (Essential) }\end{array}$ & Fps & $\begin{array}{l}\text { The flow velocity in a stormwater pipe should be a } \\
\text { minimum of } 2 \mathrm{fps}-3 \mathrm{fps} \text { (as per the utility standard) to } \\
\text { ensure self-cleaning. Also, velocities above the } \\
\text { maximum allowable limit lead to surface wear. }\end{array}$ & $\begin{array}{l}\text { (City of Cincinnati 2012; } \\
\text { United States Environmental } \\
\text { Protection Agency 2002); } \\
\quad \text { Survey Feedback }\end{array}$ \\
\hline $\begin{array}{l}\text { Minimum Flow } \\
\text { Velocity } \\
\text { (Essential) }\end{array}$ & Fps & $\begin{array}{l}\text { The minimum flow velocity should be above the } \\
\text { standard to ensure self-cleaning of pipe. }\end{array}$ & (USEPA 2002) \\
\hline $\begin{array}{l}\text { Maximum } \\
\text { Allowable } \\
\text { Velocity }\end{array}$ & Fps & $\begin{array}{c}\text { The maximum allowable flow velocity for a pipe } \\
\text { material to avoid mechanical surface wear. }\end{array}$ & (USEPA 2002) \\
\hline $\begin{array}{l}\text { Overflow } \\
\text { Frequency } \\
\text { (Essential) }\end{array}$ & Level & $\begin{array}{l}\text { Hydraulic deterioration is a process that reduces the } \\
\text { discharge capacity of the pipe. The frequency and } \\
\text { volume of overflows are an indication of hydraulic } \\
\text { failure of the stormwater pipe. }\end{array}$ & (Tran et al. 2007) \\
\hline $\begin{array}{l}\text { Surcharging } \\
\text { (Essential) }\end{array}$ & Level & $\begin{array}{l}\text { Surcharging is the condition where pipe flows full and } \\
\text { under pressure. It is a consequence of hydraulic } \\
\text { deterioration of the pipe or high groundwater tables. }\end{array}$ & $\begin{array}{l}\text { (Angkasuwansiri and Sinha } \\
\text { 2013) }\end{array}$ \\
\hline
\end{tabular}




\begin{tabular}{|c|c|c|c|}
\hline Parameter & Unit & Explanation & Source \\
\hline $\begin{array}{l}\text { Inflow and } \\
\text { Infiltration } \\
\text { (Essential) }\end{array}$ & Level & $\begin{array}{l}\text { Inflow and Infiltration is the outside water getting into } \\
\text { the system through cracks, holes or defects in joints. It } \\
\text { increases the inflow volume and leads to entry of } \\
\text { surrounding soil into pipe. }\end{array}$ & $\begin{array}{c}\text { (Angkasuwansiri and Sinha } \\
\text { 2013; MnDoT Bridge } \\
\text { Hydraulics 2013) }\end{array}$ \\
\hline $\begin{array}{l}\text { Exfiltration } \\
\text { (Essential) }\end{array}$ & Level & $\begin{array}{l}\text { Exfiltration refers to water getting out of the system } \\
\text { through cracks, holes or defects in joints. It can give a } \\
\text { false impression about the capacity of the storm sewer. } \\
\text { It can contaminate the surrounding environment and } \\
\text { groundwater. }\end{array}$ & $\begin{array}{l}\text { (Angkasuwansiri and Sinha } \\
\text { 2013) }\end{array}$ \\
\hline $\begin{array}{c}\text { Presence of } \\
\text { stagnant water in } \\
\text { pipe }\end{array}$ & Yes/No & $\begin{array}{l}\text { Presence of stagnant water can lead to increased rate of } \\
\text { corrosion in metal pipes. It is also an indication of a } \\
\text { poor gravity flow design. The unit is yes/no. }\end{array}$ & $\begin{array}{l}\text { (Integrated Science and } \\
\text { Engineering Inc 2013) }\end{array}$ \\
\hline $\begin{array}{l}\text { Debris Level } \\
\text { (Essential) }\end{array}$ & Level & $\begin{array}{l}\text { It is the amount of leaf matter, wooden matter, trash or } \\
\text { other material observed in the pipe that affect its ability } \\
\text { function to full capacity. }\end{array}$ & $\begin{array}{l}\text { (Integrated Science and } \\
\text { Engineering Inc 2013) }\end{array}$ \\
\hline $\begin{array}{l}\text { Sedimentation } \\
\text { Level } \\
\text { (Essential) }\end{array}$ & Level & $\begin{array}{l}\text { It is the amount of sediment observed in the pipe. It } \\
\text { affects the hydraulic capacity of the pipe. }\end{array}$ & $\begin{array}{l}\text { (Integrated Science and } \\
\text { Engineering Inc 2013) }\end{array}$ \\
\hline $\begin{array}{c}\text { Smell or } \\
\text { Vermin Level } \\
\text { (Essential) }\end{array}$ & Level & $\begin{array}{l}\text { Smell is an indication of maintenance requirement of } \\
\text { the pipe. }\end{array}$ & (Mitchell Shire Council 2012) \\
\hline
\end{tabular}




\begin{tabular}{|c|c|c|c|}
\hline Parameter & Unit & Explanation & Source \\
\hline \multicolumn{4}{|c|}{ Other } \\
\hline $\begin{array}{l}\text { Post Installation } \\
\text { Condition } \\
\text { (Essential) }\end{array}$ & Text & $\begin{array}{l}\text { This parameter indicates the condition of the pipe post } \\
\text { construction. It is typically assumed that all storm } \\
\text { sewers have been laid as per the construction } \\
\text { specifications. However it is well acknowledged that } \\
\text { poor installations can cause damage to pipe or poor } \\
\text { bedding support. }\end{array}$ & Survey Feedback \\
\hline $\begin{array}{l}\text { Maintenance } \\
\text { Method } \\
\text { (Essential) }\end{array}$ & $\begin{array}{c}\text { Type } \\
\text { Frequency }\end{array}$ & $\begin{array}{c}\text { Inappropriate maintenance methods used to clean } \\
\text { stormwater pipe can lead to accelerated deterioration } \\
\text { for example jetting involves high water pressure } \\
\text { resulting in surface wear. }\end{array}$ & (Davies et al. 2001) \\
\hline $\begin{array}{c}\text { Inspection/ } \\
\text { CCTV Record }\end{array}$ & Text & $\begin{array}{l}\text { Records help in understanding the stormwater pipe } \\
\text { deterioration process. They provide an idea of the } \\
\text { frequent problems associated with a pipe. }\end{array}$ & $\begin{array}{c}\text { (Angkasuwansiri and Sinha } \\
\text { 2013) }\end{array}$ \\
\hline Renewal Record & Text & $\begin{array}{l}\text { Records help in understanding the stormwater pipe } \\
\text { deterioration process. They provide an idea of the } \\
\text { frequent problems associated with a pipe. }\end{array}$ & $\begin{array}{c}\text { (Angkasuwansiri and Sinha } \\
\text { 2013) }\end{array}$ \\
\hline Failure Record & Text & $\begin{array}{l}\text { Records help in understanding the stormwater pipe } \\
\text { deterioration process. They provide an idea of the } \\
\text { frequent problems associated with a pipe. }\end{array}$ & $\begin{array}{c}\text { (Angkasuwansiri and Sinha } \\
\text { 2013) }\end{array}$ \\
\hline
\end{tabular}




\begin{tabular}{|c|c|c|c|}
\hline Parameter & Unit & Explanation & Source \\
\hline $\begin{array}{c}\text { Complaint } \\
\text { Record }\end{array}$ & Text & $\begin{array}{r}\text { Records help in understanding the stormwater pipe } \\
\text { deterioration process. They provide an idea of the } \\
\text { frequent problems associated with a pipe. }\end{array}$ & $\begin{array}{c}\text { (Angkasuwansiri and Sinha } \\
\text { 2013) }\end{array}$ \\
\hline $\begin{array}{c}\text { Capital Cost } \\
\text { Annual } \\
\text { Maintenance } \\
\text { Cost }\end{array}$ & Dollar & $\begin{array}{r}\text { Records help in understanding the cost of replacing a } \\
\text { stormwater pipe. }\end{array}$ & (Angkasuwansiri and Sinha \\
& Dollar & $\begin{array}{c}\text { Records help in understanding the annual amount spent } \\
\text { on the maintenance and functioning of the pipe. If this } \\
\text { amount is higher than the capital cost then the utility } \\
\text { can consider the replacement of the pipe in the next } \\
\text { (Angkasuwansiri and Sinha }\end{array}$ & 2013) \\
\hline
\end{tabular}




\section{Chapter 6 Development of Stormwater Pipeline Performance Index}

In the U.S., there presently exists no standard condition assessment system specific for stormwater pipelines (Betz 2013). Many utilities have adopted NASSCO's PACP or use an in-house system developed for broader infrastructure to gauge the condition of their stormwater pipelines (Betz 2013). After studying the mathematical models developed in the literature to assess the condition or performance of sewer and combined sewers, a weighted factor method was chosen to determine the performance of stormwater pipe.

\subsection{Weighted Factor Method}

The Weighted Factor method is a form of multi-attribute or multi-criteria analysis. It involves evaluation of all attributes that are relevant to the problem, allocation of a score to each attribute based on a rating scheme and allocation of weight to each attribute based on its relative importance. The model can be represented using Equation 2 below:

$$
Y=\sum_{i=1}^{n} w_{i} \times p_{i}
$$

\section{Equation 2: Equation of weighted summation}

Where,

$\mathrm{Y}$ is the performance index

$w_{\mathrm{i}}$ refers to weights

$p_{\mathrm{i}}$ refers to attributes

\subsection{Layout of the Index}

A simplified hierarchal structure was developed to represent the problem of performance evaluation of stormwater pipeline. The first level represents the major deterioration paths of a stormwater pipe; the five are Capacity, Blockage, Load, Surface wear, and Structural. The capacity module indicates that the design capacity of a stormwater pipe is not sufficient to hold the current stormwater runoff in a location, resulting in overflows and surcharging. The blockage module indicates that the pipe has sufficient capacity but the extraneous material entering the stormwater 
pipe is leading to flow disruption. The surface wear module indicates the failure in the surface of the pipe, failures that include spalling, wear, mineral deposits, corrosion, and so forth. The Load Module indicates the change in pipe structure or shape. The Structural Module includes all structural defects not defined by the surface wear and load modules, such defects as cracks, fractures, breaks, holes, joints, lining, and so on. The second level indicates all the essential performance parameters affecting each module. By analyzing the problem in separate modules, the utilities will be able to identify the cause behind the low performance of their pipe and thereby plan their remediation activities.

In the Surface Wear, Load, and Structural Modules, a parameter not discussed in Table 6 was added-“condition as per NASSCO's PACP.” As explained in previous sections, NASSCO's PACP, an established condition assessment system in the wastewater industry, is known for its comprehensive structural defect coding. It is outside the scope of this study to tailor the defect codes and defect grades of NASSCO's PACP to stormwater pipelines. Hence, the current NASSCO's PACP condition rating specific to each module was used and augmented by stormwater pipe performance parameters.

The essential performance parameters - design life and design storm - have been dropped from the hierarchal structure. These will be used, later in the research, in the rating of their counterpart parameters - age and actual precipitation. The post-installation condition has been dropped from the hierarchal structure, as it is assumed to be in the form of text. This textual parameter, however, will be provided along with the index. Figure 10 below shows the hierarchal structure of stormwater pipe performance deterioration. 


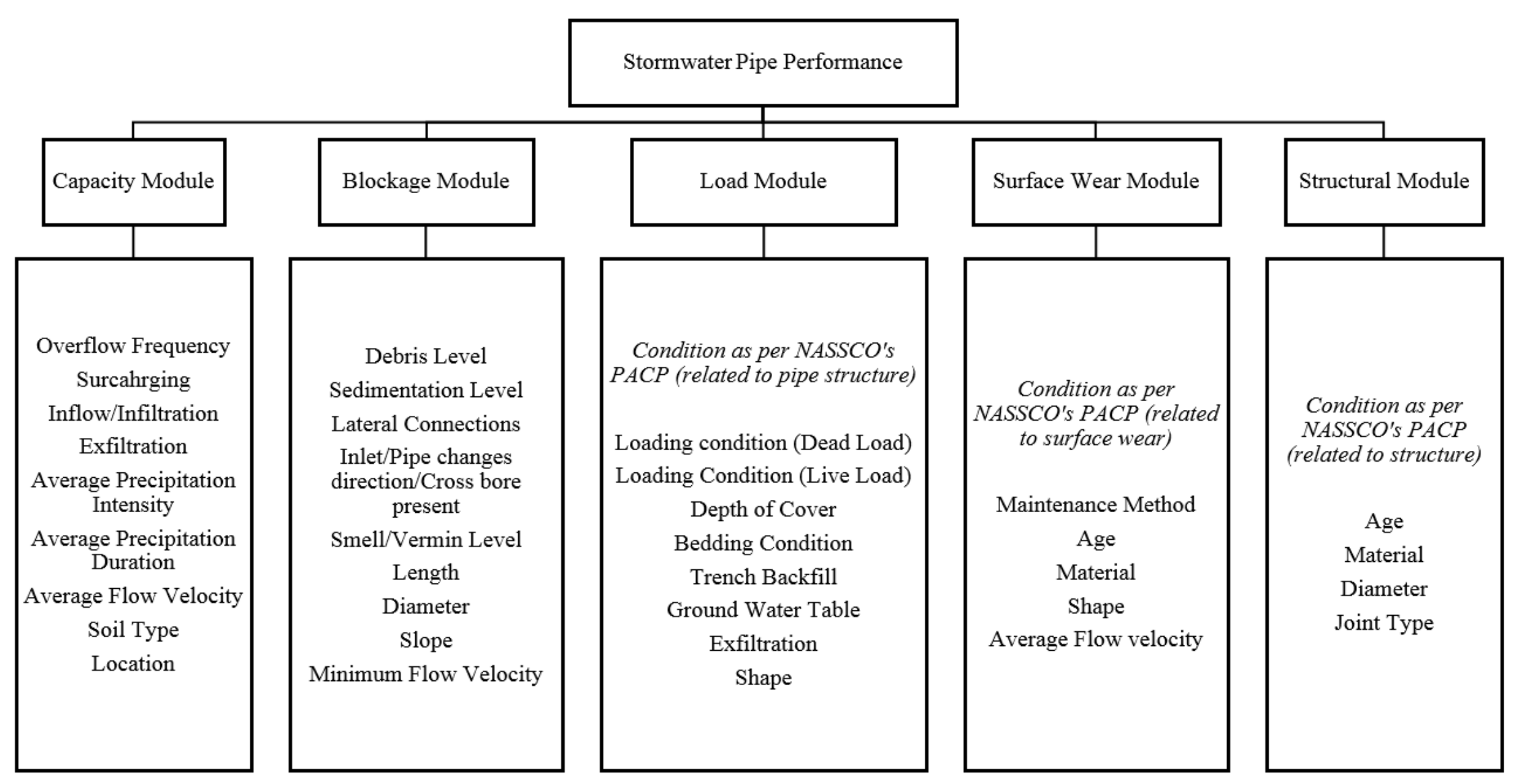

Figure 10: Performance deterioration of stormwater pipeline in two level hierarchy structure. The first level indicates the five failure modules. The second level indicates the essential performance parameters affecting each module. 


\subsection{Data Acquisition}

A survey document was prepared and sent to stormwater utilities across all the Environmental Protection Agency (EPA) regions in the U.S. to determine the relative weights of the five modules and the parameters affecting each module. The survey document was prepared based on the templates used by students in the past to collect similar data from the water and wastewater industry (Sekhar 2011; St Clair 2013). The survey included a pairwise comparison matrix for the failure modules to determine the relative weights. The pairwise matrix was preferred as it helps in improving the understanding of the five modules and their effects on stormwater pipe performance. In the second half of the survey, the utilities were asked to provide the significance value (Very High, High, Medium, Low, Very Low) for each of the performance parameters affecting a particular module. The survey document is attached in Appendix A.

Out of the 1417 stormwater utilities in U.S, 50 utilities were contacted to fill out the survey (Campbell 2013). The aim was to target a set of utilities and motivate the asset managers to fill the survey out by dedicating voluntary time. The list of 50 utilities was prepared based on available contacts from a previous research project (Betz 2013) and from a list of stormwater utilities published by Campbell (2013). A minimum of three utilities were contacted from each of the EPA regions. 10 replies were obtained for the survey, 8 of which provided the survey inputs and two other provided insights that helped the project. The list of utilities which provided replies can be seen in Table 7 below. No replies were received from either EPA Regions 1 or 2. However, there are no stormwater utilities in EPA Region 2 and minimal utilities in EPA Region 1 (Campbell 2013). 
Table 7: The list of utilities that contributed to the research

\begin{tabular}{|c|c|c|c|}
\hline EPA Region & State & Utility & Provided Survey \\
\hline 3 & VA & Fairfax & $\mathrm{Y}$ \\
\hline 3 & VA & Charlottesville & $\mathrm{Y}$ \\
\hline 4 & GA & Griffin & $\mathrm{Y}$ \\
\hline 5 & $\mathrm{OH}$ & Cincinnati & $\mathrm{Y}$ \\
\hline 6 & $\mathrm{TX}$ & Austin & $\mathrm{Y}$ \\
\hline 7 & MO & Kansas city & $\mathrm{N}$, Got an email reply with good insights \\
\hline 8 & $\mathrm{CO}$ & Aurora & $\mathrm{Y}$ \\
\hline 8 & $\mathrm{CO}$ & Colorado Springs & $\mathrm{Y}$ \\
\hline 9 & CA & Frensco & $\mathrm{N}$, Got an email reply with good insights \\
\hline 10 & CA & Tacoma & $\mathrm{Y}$ \\
\hline
\end{tabular}

\subsection{Parameter Weights and Analysis}

The survey results were used to determine the weights of the performance parameters. The pairwise comparison matrix from each utility was normalized to determine the weights of the five failure modules. The survey input from one utility indicated inconsistency and hence was dropped from the calculations. The weights obtained from the remaining seven utilities were averaged to determine the weight of the modules, indicated in Table 8 below.

Table 8: Significance of each failure module in determining the performance of a stormwater pipe

\begin{tabular}{|c|c|}
\hline Module & Weight (\%) \\
\hline Capacity & 18 \\
\hline Blockage & 22 \\
\hline Surface Wear & 8 \\
\hline Load/Deformation & 10 \\
\hline Structural & 42 \\
\hline
\end{tabular}

The weights indicate that the performance of a stormwater pipeline is highly affected by its structural condition, followed by blockage and capacity. The weights for surface wear, 
load/deformation and structural modules add up to 60 percent and the weights of capacity and blockage module add up to 40 percent. This supports the idea that the hydraulic condition of stormwater pipeline is crucial for its performance. An expert from a utility indicated that the capacity module dictates approximately 53 percent of the performance calculation of their storm sewers; i.e., the current runoff of the area is higher than the design capacity of the pipes. The experts from another utility indicated that the blockage module dictates about 50 percent of their storm sewers' performance. An interesting fact about both these utilities is that they were established in the same year 1984 (Campbell 2013). This reflects the complexity in determining the performance of a stormwater pipe, as its hydraulic performance is tied to the geographic location and development of the area.

The weights of the performance parameters were obtained by averaging the values provided from the seven utilities and multiplying it with the corresponding weight of the module from Table 8 above. The performance parameter weights are provided in Table 9 below. The calculations were performed in an Excel spreadsheet, which is attached in Appendix B.

Table 9: Significance of each parameter in determining the performance of a stormwater pipe

\begin{tabular}{|l|c|c|}
\hline \multirow{4}{*}{ Module } & Parameter & Weight (\%) \\
\hline \multirow{5}{*}{ Capacity } & Average Precipitation Intensity & 2.5 \\
\cline { 2 - 3 } & Surcharging & 2.4 \\
\cline { 2 - 3 } & Location & 2.4 \\
\cline { 2 - 3 } & Overflow Frequency & 2.1 \\
\cline { 2 - 3 } & Average Precipitation Duration & 2.2 \\
\cline { 2 - 3 } & Average Flow Velocity & 1.8 \\
\cline { 2 - 3 } & Soil Type & 1.9 \\
\cline { 2 - 3 } & Inflow and Infiltration & 1.5 \\
\cline { 2 - 3 } & Exfiltration & 1.5 \\
\hline \multirow{5}{*}{ Blockage } & Debris Level & 3.5 \\
\cline { 2 - 3 } & Sedimentation Level & 3.1 \\
\cline { 2 - 3 } & Diameter & 2.8 \\
\cline { 2 - 3 } & Slope & 2.5 \\
\hline
\end{tabular}




\begin{tabular}{|c|c|c|}
\hline Module & Parameter & Weight $(\%)$ \\
\hline & $\begin{array}{l}\text { If Inlet/Outlet is attached or if pipe changes } \\
\text { direction or if cross bore is present }\end{array}$ & 2.4 \\
\hline & Minimum Flow Velocity & 2.2 \\
\hline & Length & 2.3 \\
\hline & Lateral Connections & 2.3 \\
\hline & Smell or Vermin Level & 1.2 \\
\hline \multirow{6}{*}{ Surface Wear } & $\begin{array}{c}\text { Surface Wear Condition Rating as per Visual, } \\
\text { CCTV or other Inspections }\end{array}$ & 1.6 \\
\hline & Material & 1.7 \\
\hline & Age & 1.3 \\
\hline & Average Flow Velocity & 1.1 \\
\hline & Shape & 1.1 \\
\hline & Maintenance Method & 0.8 \\
\hline \multirow{9}{*}{ Load/Deformation } & $\begin{array}{c}\text { Rating of Pipe Structure per Visual, CCTV or } \\
\text { other Inspections }\end{array}$ & 1.4 \\
\hline & Depth of Cover & 1.3 \\
\hline & Bedding Condition & 1.3 \\
\hline & Trench Backfill & 1.3 \\
\hline & Loading Condition (Live Load) & 1.1 \\
\hline & Ground Water Table & 1.0 \\
\hline & Loading Condition (Dead Load) & 0.9 \\
\hline & Shape & 0.8 \\
\hline & Exfiltration & 0.8 \\
\hline \multirow{5}{*}{ Structural } & $\begin{array}{c}\text { Condition Rating as per Visual, CCTV or other } \\
\text { Inspections }\end{array}$ & 10.6 \\
\hline & Material & 9.1 \\
\hline & Age & 7.7 \\
\hline & Joint Type & 8.2 \\
\hline & Diameter & 6.1 \\
\hline
\end{tabular}




\subsection{Parameter Ranges}

Each of the parameters are rated on a scale of 1 to 5, where 1 implies "Excellent" and 5 implies "Very Poor," as indicated in Table 10 below. The rating scheme was developed on the basis of the literature (NASSCO 2003; Sinha and Angkasuwansiri 2010) and inputs from utility experts. Few of the parameter ranges were established. Nevertheless, their corresponding scores were left blank, to be awarded by the respective utility experts before the use of the index.

Table 10: Rating scheme for stormwater performance parameters

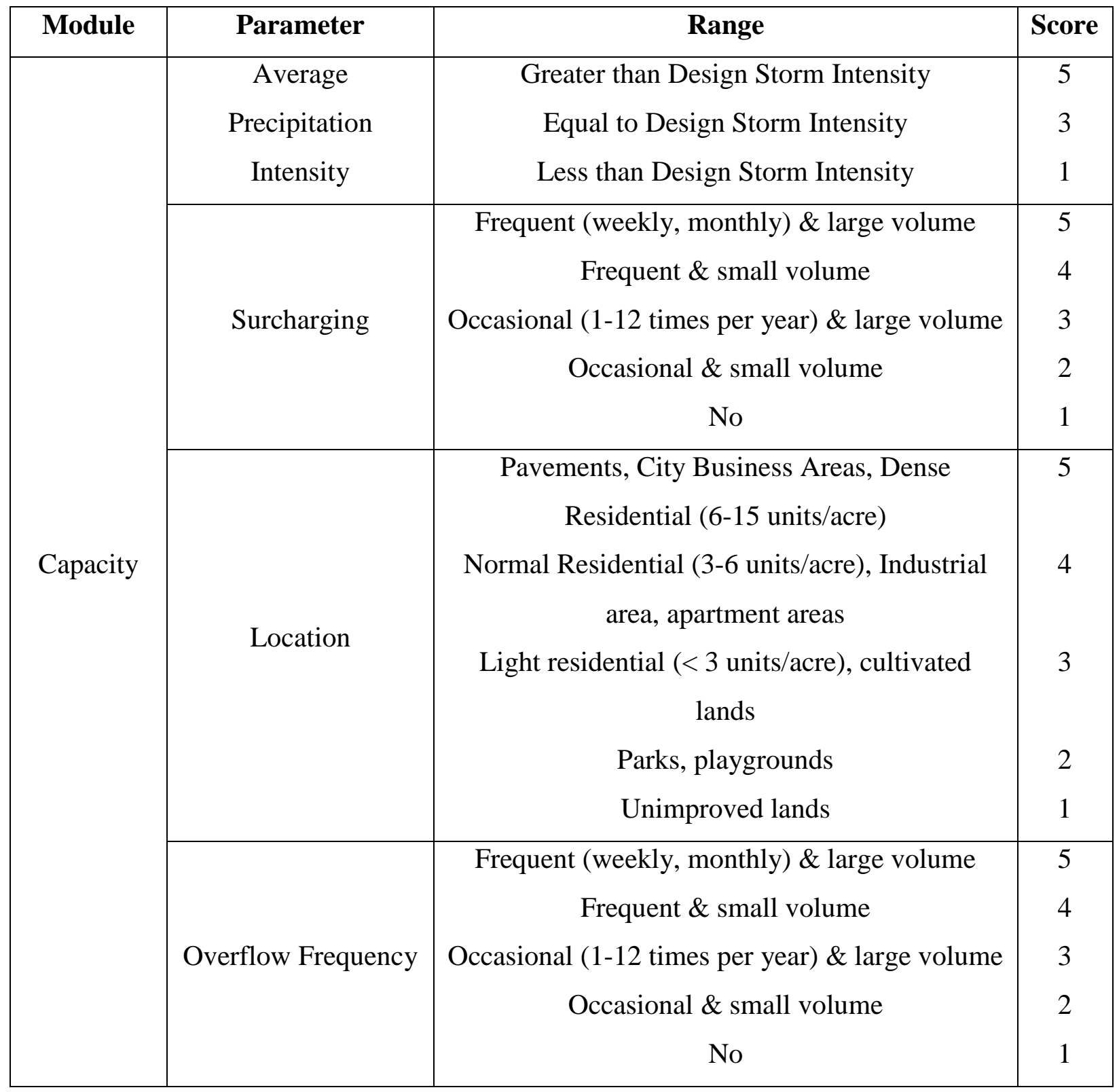




\begin{tabular}{|c|c|c|c|}
\hline Module & Parameter & Range & Score \\
\hline & $\begin{array}{c}\text { Average } \\
\text { Precipitation } \\
\text { Duration }\end{array}$ & $\begin{array}{l}\text { Greater than Design Storm Duration } \\
\text { Equal to Design Storm Duration } \\
\text { Less than Design Storm Duration }\end{array}$ & $\begin{array}{l}5 \\
3 \\
1\end{array}$ \\
\hline & $\begin{array}{c}\text { Average Flow } \\
\text { Velocity }\end{array}$ & $\begin{array}{l}\text { Less than minimum design flow velocity (2 fps - } \\
\qquad 3 \mathrm{fps} \text { ) } \\
\text { Greater than maximum design flow velocity } \\
\text { Between minimum and maximum design flow } \\
\text { velocity }\end{array}$ & $\begin{array}{l}5 \\
3 \\
1\end{array}$ \\
\hline & Soil Type & $\begin{array}{c}\text { high plasticity clay (Group D) } \\
\text { low plasticity clay (Group C) } \\
\text { fine sand and silt (Group B) } \\
\text { Coarse sand (Group A) } \\
\text { Gravel (Group A) }\end{array}$ & $\begin{array}{l}5 \\
4 \\
3 \\
1 \\
1\end{array}$ \\
\hline & $\begin{array}{l}\text { Inflow and } \\
\text { Infiltration }\end{array}$ & $\begin{array}{c}\text { Gusher } \\
\text { Runner (continuous flow of water) } \\
\text { Dripper (water dripping) } \\
\text { Weeper (slow ingress of water) } \\
\text { No }\end{array}$ & $\begin{array}{l}5 \\
4 \\
3 \\
2 \\
1\end{array}$ \\
\hline & Exfiltration & $\begin{array}{c}\text { Significant erosion of soil around pipe } \\
\text { Very High erosion of soil } \\
\text { Moderate erosion of soil } \\
\text { Minimal erosion of soil } \\
\text { No erosion of soil }\end{array}$ & $\begin{array}{l}5 \\
4 \\
3 \\
2 \\
1\end{array}$ \\
\hline \multirow[t]{2}{*}{ Blockage } & Debris Level & $\begin{array}{l}\text { Occupy more than } 75 \% \text { of pipe } \\
\text { Occupy } 50 \%-75 \% \text { of the pipe } \\
\text { Occupy } 25 \%-50 \% \text { of the pipe } \\
\text { Occupy } 1 \%-25 \% \text { of the pipe } \\
\text { No }\end{array}$ & $\begin{array}{l}5 \\
4 \\
3 \\
2 \\
1\end{array}$ \\
\hline & Sedimentation Level & $\begin{array}{l}\text { Occupy more than } 75 \% \text { of pipe } \\
\text { Occupy } 50 \%-75 \% \text { of the pipe }\end{array}$ & $\begin{array}{l}5 \\
4\end{array}$ \\
\hline
\end{tabular}




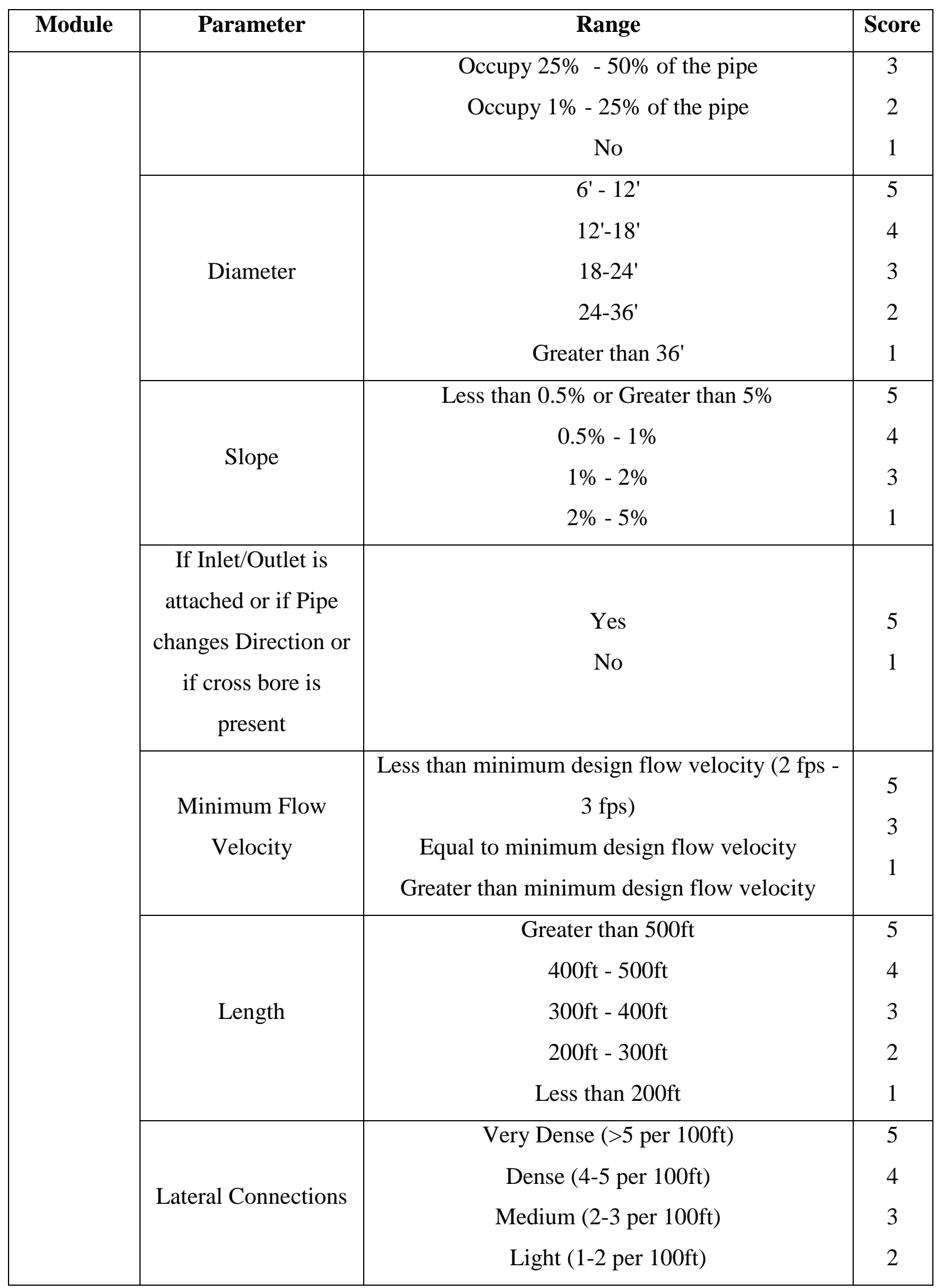




\begin{tabular}{|c|c|c|c|}
\hline Module & Parameter & Range & Score \\
\hline & & Very Light $(<1$ per $100 \mathrm{ft})$ & 1 \\
\hline & & Significant & 5 \\
\hline & & Very High & 4 \\
\hline & smeil or vermin & Moderate & 3 \\
\hline & & Minimal & 2 \\
\hline & & No & 1 \\
\hline \multirow{22}{*}{$\begin{array}{l}\text { Surface } \\
\text { Wear }\end{array}$} & \multirow{5}{*}{$\begin{array}{c}\text { Surface Wear } \\
\text { Condition Rating as } \\
\text { per Visual, CCTV or } \\
\text { other Inspections }\end{array}$} & Emergency repairs/replacement required & 5 \\
\hline & & Poor Condition & 4 \\
\hline & & Fair Condition & 3 \\
\hline & & Good Condition & 2 \\
\hline & & No deficiencies & 1 \\
\hline & \multirow{5}{*}{ Material } & Reinforced Concrete & \\
\hline & & HDPE & \\
\hline & & Polymeric Coated Corrugated Metal & \\
\hline & & Aluminized Corrugated Metal & \\
\hline & & Galvanized Corrugated Metal & \\
\hline & \multirow{5}{*}{ Age } & Significantly greater than design life & 5 \\
\hline & & Very Highly greater than design life & 4 \\
\hline & & Moderately greater than design life & 3 \\
\hline & & Equal to design life & 2 \\
\hline & & Less than design life & 1 \\
\hline & \multirow{3}{*}{$\begin{array}{l}\text { Average Flow } \\
\text { Velocity }\end{array}$} & $\begin{array}{l}\text { Less than minimum design flow velocity (2 fps - } \\
\qquad 3 \mathrm{fps})\end{array}$ & 5 \\
\hline & & Greater than maximum design flow velocity & 3 \\
\hline & & $\begin{array}{l}\text { Between minimum and maximum design flow } \\
\text { velocity }\end{array}$ & 1 \\
\hline & \multirow{4}{*}{ Shape } & Round & \\
\hline & & Elliptical & \\
\hline & & Arch & \\
\hline & & Rectangular & \\
\hline
\end{tabular}




\begin{tabular}{|c|c|c|c|}
\hline \multirow[t]{3}{*}{ Module } & Parameter & Range & Score \\
\hline & & $\begin{array}{l}\text { Trapezoidal } \\
\text { V shaped }\end{array}$ & \\
\hline & Maintenance Method & $\begin{array}{l}\text { Annual Maintenance } \\
5 \text { Year Maintenance } \\
\text { Upon Failure }\end{array}$ & $\begin{array}{l}5 \\
3 \\
1\end{array}$ \\
\hline \multirow{6}{*}{$\begin{array}{l}\text { Load/ } \\
\text { Deformatio } \\
\mathrm{n}\end{array}$} & $\begin{array}{c}\text { Rating of Pipe } \\
\text { Structure per Visual, } \\
\text { CCTV or other } \\
\text { Inspections }\end{array}$ & $\begin{array}{c}\text { Emergency repairs/replacement required } \\
\text { Poor Condition } \\
\text { Fair Condition } \\
\text { Good Condition } \\
\text { No deficiencies }\end{array}$ & $\begin{array}{l}5 \\
4 \\
3 \\
2 \\
1\end{array}$ \\
\hline & Depth of Cover & $\begin{array}{c}0 \mathrm{ft}-5 \mathrm{ft} \\
5 \mathrm{ft}-10 \mathrm{ft} \\
10 \mathrm{ft}-20 \mathrm{ft} \\
20 \mathrm{ft}-30 \mathrm{ft} \\
\text { Greater than } 30 \mathrm{ft}\end{array}$ & $\begin{array}{l}5 \\
4 \\
3 \\
2 \\
1\end{array}$ \\
\hline & Bedding Condition & $\begin{array}{l}\text { Poor } \\
\text { Fair } \\
\text { Good }\end{array}$ & $\begin{array}{l}5 \\
3 \\
1\end{array}$ \\
\hline & Trench Backfill & $\begin{array}{l}\text { Poor } \\
\text { Fair } \\
\text { Good }\end{array}$ & $\begin{array}{l}5 \\
3 \\
1\end{array}$ \\
\hline & $\begin{array}{l}\text { Loading Condition } \\
\text { (Live Load) }\end{array}$ & $\begin{array}{c}\text { Heavy - } 20 \mathrm{ft} \text {. from major road/railway } \\
\text { Medium - } 50 \mathrm{ft} \text { from road/railway } \\
\text { Light - >50 ft. from road/railway }\end{array}$ & $\begin{array}{l}5 \\
3 \\
1\end{array}$ \\
\hline & Ground Water Table & $\begin{array}{l}\text { In the regular backfill } \\
\text { In the trench backfill - above pipe crown } \\
\text { In the trench backfill - close to pipe } \\
\text { In the bedding } \\
\text { Below bedding }\end{array}$ & $\begin{array}{l}5 \\
4 \\
3 \\
2 \\
1\end{array}$ \\
\hline
\end{tabular}




\begin{tabular}{|c|c|c|c|}
\hline Module & Parameter & Range & Score \\
\hline & $\begin{array}{l}\text { Loading Condition } \\
\text { (Dead Load) }\end{array}$ & $\begin{array}{l}\text { High(increased significantly from the day of } \\
\text { installation) } \\
\text { Medium (changed from the day of installation) } \\
\text { Low(did not change from the day of installation) }\end{array}$ & $\begin{array}{l}5 \\
3 \\
1\end{array}$ \\
\hline & Shape & $\begin{array}{c}\text { Round } \\
\text { Elliptical } \\
\text { Arch } \\
\text { Rectangular } \\
\text { Trapezoidal } \\
\text { V shaped }\end{array}$ & \\
\hline & Exfiltration & $\begin{array}{l}\text { Significant erosion of soil around pipe } \\
\text { Very High erosion of soil } \\
\text { Moderate erosion of soil } \\
\text { Minimal erosion of soil } \\
\text { No erosion of soil }\end{array}$ & $\begin{array}{l}5 \\
4 \\
3 \\
2 \\
1\end{array}$ \\
\hline \multirow{3}{*}{ Structural } & $\begin{array}{l}\text { Condition Rating as } \\
\text { per Visual, CCTV or } \\
\text { other Inspections }\end{array}$ & $\begin{array}{c}\text { Emergency repairs/replacement required } \\
\text { Poor Condition } \\
\text { Fair Condition } \\
\text { Good Condition } \\
\text { No deficiencies }\end{array}$ & $\begin{array}{l}5 \\
4 \\
3 \\
2 \\
1\end{array}$ \\
\hline & Material & $\begin{array}{c}\text { Reinforced Concrete } \\
\text { HDPE } \\
\text { Polymeric Coated Corrugated Metal } \\
\text { Aluminized Corrugated Metal } \\
\text { Galvanized Corrugated Metal }\end{array}$ & \\
\hline & Age & $\begin{array}{l}\text { Significantly greater than design life } \\
\text { Very Highly greater than design life } \\
\text { Moderately greater than design life } \\
\text { Equal to design life } \\
\text { Less than design life }\end{array}$ & $\begin{array}{l}5 \\
4 \\
3 \\
2 \\
1\end{array}$ \\
\hline
\end{tabular}




\begin{tabular}{|l|c|c|c|}
\hline Module & Parameter & Range & Score \\
\hline \multirow{3}{*}{ Joint Type } & Concrete Slip with Mastic & \\
& HDPE-Butt Welded & \\
& Diameter & Corrugated Metal Pipe Band & \\
& Corrugated Metal Slip & 5 \\
& PVC Slip & 4 \\
& $6^{\prime}-12^{\prime}$ & 3 \\
& $12^{\prime}-18^{\prime}$ & 2 \\
& $18-24^{\prime}$ & 1 \\
\hline
\end{tabular}

\subsection{Performance Scale}

The performance of a stormwater pipe can be calculated by incorporating the values from Tables 9 and 10 into Equation 2. Presently, many though certainly not all stormwater utilities have adopted NASCCO's PACP 1-5 scale. Others gauge the condition of their assets by using a "Good-PoorFailed" rating, a 0-5 scale, or a 1-10 scale (Betz 2013). The current research's performance scale is similar to NASSCO's PACP scale of 1-5 condition rating where 5 implies immediate attention required and 1 implies minor defects. Table 11 below indicates the calculated pipe score and the corresponding performance.

Table 11: Stormwater performance scale corresponding to pipe score generated from Equation 2

\begin{tabular}{|c|c|c|}
\hline Pipe Score & Performance Scale & Description \\
\hline $1.0-1.5$ & 1 & Excellent \\
\hline $1.5-2.5$ & 2 & Good \\
\hline $2.5-3.5$ & 3 & Fair \\
\hline $3.5-4.5$ & 4 & Poor \\
\hline $4.5-5.0$ & 5 & Immediate Attention Required \\
\hline
\end{tabular}




\subsection{Percentage Reliability of the Data}

From the survey replies, it was observed that the stormwater utilities currently collect minimal information about their assets. It is thus unrealistic to obtain all the parameters required to calculate the performance index. However, a few parameters like soil type can be obtained from other indirect sources like the United States Geological Survey (USGS) website. The utility personnel would also be able to estimate certain parameters based on their experience. The data that is fed into the performance index determines the reliability of the output of the index. The number of parameters that could be obtained versus the number of parameters actually supported by the index reduces the accuracy of the index output. Moreover, the confidence of the input parameters is also a measure of the accuracy of the index output (St Clair 2013). The source from which the parameter was obtained is used to determine the confidence in the data as shown in Table 12 below.

Table 12: Parameter Confidence Scale (Sinha, S., and Angkasuwansiri, T. (2010). "Phase 2: Development of a robust wastewater pipe performance index." Development of protocols and methods for predicting the remaining economic life of wastewater pipe infrastructure assets. Report No. 06-SAM-1 CO, Water Environment Research Foundation, Alexandria, VA. Used with permission of Carrie W. Capuco, JD, Water Environment Research Foundation.)

\begin{tabular}{|c|c|}
\hline Parameter Source & Confidence Scale (CS) \\
\hline Direct Record & 5 \\
\hline Derived Indirectly & 4 \\
\hline Educated Guess (High Confidence) & 3 \\
\hline Educated Guess (Medium Confidence) & 2 \\
\hline Educated Guess (Low Confidence) & 1 \\
\hline
\end{tabular}

The following equation shall be used to determine the reliability of the data.

$$
\begin{gathered}
\text { Reliability Percentage }=\frac{\text { Obtained Parameters }(=n)}{\text { Requested Parameters }(=38)} * \frac{\sum_{i=1}^{n} C S_{i}}{(5 * n)} * 100 \\
\text { Reliability Percentage }=\frac{\sum_{i=1}^{n} C S_{i}}{5 * 38} * 100 \\
\text { Percentage Reliability }=\frac{\sum_{i=1}^{n} C S_{i}}{1.9} \%
\end{gathered}
$$

Equation 3: Percentage Reliability is dependent on the confidence of the input data 


\section{Chapter 7 Partial Validation of the Performance Index}

Utility A is a stormwater utility serving a population of approximately 500,000. It manages approximately 500 miles of pipe; 300 miles of open drainage; 21,000 inlets, outlets, manholes and junction boxes; 550 culverts, and 100 detention ponds. The utility provided, by mail, its geodatabase to the author and research team at Virginia Tech. Altogether there were four layers in the geodatabase. A brief description of these layers is provided below. One unique characteristic of the layers is that there were a few features with no details coded except for a unique id. There was no information on even the type of structure. However, when they are spotted on the Arcmap, their location seemed consistent. That is, they were attached to maintain the flow of the polylines. A brief description of the layers is provided below with the changes made to arrive at the required parameters.

\section{- Stormwater Lines}

The stormwater lines layer consists entirely of linear infrastructure elements such as culverts, pipes, detention ponds, swales ("ditches" that conduct water away from a building) and curb and gutter. The attribute table consists of parameters such as structure type, material, structure shape, size ( $\mathrm{X}$ and $\mathrm{Y}$ inches), slope, year installed, length, basin, owner, and details of the person and date the data was updated. The age of the features was calculated by subtracting the year installed from 2015. Many of the $Y$ inches, slope, and year installed fields were left blank. About 49 pipes had all the details about the pipeline included in the table; however, they were not projected onto the map.

\section{- Open Drainage}

This layer consists of all open drainage features including the open culverts under bridges.

- Stormwater Points

The stormwater point's layer consists of all point features that function as inlets, outlets and junctions. It is interesting to note that the structures such as pipe, curb cut, culvert, and chase have been marked as inlets at a few points and as outlets at others. This layer was spatially joined with the stormwater lines to determine the associated structures with each pipe.

- Discharge Points 
This layer consists of all outfall points to the tributaries, most of them are pipes and channels. This layer was also spatially joined with the stormwater lines to determine the associated structures with each pipe.

Table 13 highlights the essential stormwater pipeline data parameters that were obtained from the utilities' GIS files.

Table 13: Essential stormwater pipeline data parameters available in Utility A's ArcGIS files

\begin{tabular}{|c|}
\hline Physical/Structural \\
\hline Age \\
\hline Diameter \\
\hline Shape \\
\hline Length \\
\hline Material \\
\hline Slope \\
\hline Associated Structures \\
\hline
\end{tabular}

Additionally, the soil data was derived from the United States Department of Agriculture web soil surveys (USDA NRCS 2013). The data about district boundaries and average precipitation was obtained from Colorado's Decision Support Systems website that maintains GIS files. The precipitation was calculated using the isohyetal method. An isohyetal is a line of equal rainfall. The precipitation received by a pipe was approximated as the average of the isohyetals between which it lies (CWCB and DWR 1993). The loading condition (Live Load) was determined by measuring the proximity of the pipe to the major roads and highways. The GIS files of El Paso County's major roads and highways was obtained from the Colorado's Department of Transportation website (Colorado Department of Transportation).

A few of the parameter ranges were edited based on discussions with the utility personnel; these editions are indicated in Table 14. The maintenance method parameter feedback of this utility was quite informative and hence was adopted in the final list of parameter ranges. 
Table 14: Edited Parameter Ranges to better represent the Utility A's conditions

\begin{tabular}{|c|c|c|}
\hline Parameter & Range & Score \\
\hline \multirow{3}{*}{ Material } & Reinforced Concrete & 5 \\
& HDPE & 4 \\
& Polymeric Coated Corrugated Metal & 3 \\
& Aluminized Corrugated Metal & 2 \\
& Galvanized Corrugated Metal & 1 \\
\hline \multirow{2}{*}{ Shape } & Round & 5 \\
& Elliptical & 4 \\
& Arch, Rectangular & 2 \\
Maintenance Method & Trapezoidal, V shaped & 1 \\
\hline \multirow{3}{*}{ Joint Type } & Annual Maintenance & 5 \\
& 5 Year Maintenance & 3 \\
& Upon Failure & 1 \\
\hline & Concrete Slip with Mastic & 5 \\
& HDPE-Butt Welded & 4 \\
& Corrugated Metal Pipe Band & 3 \\
& Corrugated Metal Slip & 2 \\
& PVC Slip & 1 \\
\hline
\end{tabular}

Each pipe section was evaluated using the parameter ranges prepared through discussions with the utility personnel. Parameters left blank or given a value of zero in the geodatabase were awarded a weight of zero. Excluded from the analysis were the 49 pipes included in the meta-table but not appearing on the map. Based on the shape of the pipe, both its width (X variable) and height ( $\mathrm{Y}$ variable) were recorded in the geodatabase. For this study, the widths were considered to be diameters and graded. The height was not graded. The materials like cast iron, ductile iron were present in minimal numbers, and were awarded a value of zero since their weight was not provided by the utility personnel.

Figure 11 highlights the parameters that are available in the database and the derived parameters to calculate the performance index of the 18352 stormwater pipes. Equation 4 indicates the performance index developed using these parameters along with the weights. 


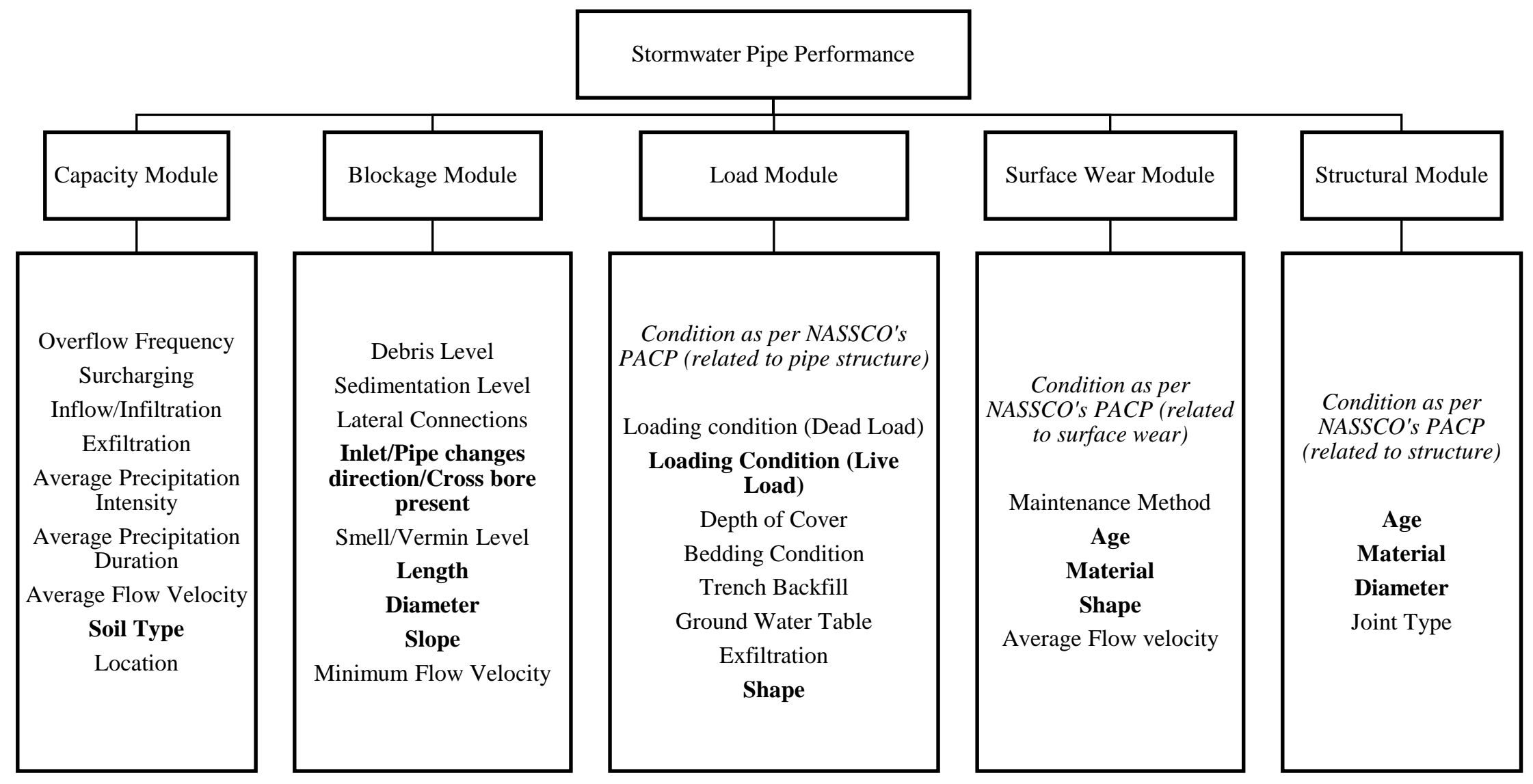

Figure 11: Performance deterioration of Utility A's stormwater pipeline in two level hierarchy structure. The highlighted nine parameters indicate the available and derived parameters to develop the Index. Since only nine of the 32 parameters are available to determine the performance, the reliability of the data will be less. 


$$
\begin{gathered}
\text { Performance Index }=0.019 * \text { Soil Type }+ \\
0.024 *(\text { Inlet/Pipe changes direction/Cross bore present })+ \\
0.023 * \text { Length }+0.09 * \text { Diameter }+0.025 * \text { Slope }+ \\
0.011 * \text { Loading Condition (Live Load) }+0.09 * \text { Age }+0.019 * \text { Shape }+
\end{gathered}
$$

$$
0.108 * \text { Material }
$$

\section{Equation 4: Utility A's Stormwater Pipe Performance Index}

The performance index and percentage reliability of the data, calculations were made in an Excel spreadsheet (Appendix C). Table 15 indicates the performance distribution of the 18,352 pipes. The percentage reliability of the data obtained from Colorado Springs to calculate the performance index varies between 5 and 23 percent. The calculated performance index values were added to the stormwater lines layer in ArcGIS and their distribution across utilities was shown on the ArcMap (Appendix D).

Table 15: Utility A's Stormwater Pipe Performance Distribution

\begin{tabular}{|c|c|c|c|}
\hline $\begin{array}{c}\text { Performance } \\
\text { Scale }\end{array}$ & Description & No. of Pipe & $\begin{array}{c}\text { Percentage of } \\
\text { Utility A's Pipe }\end{array}$ \\
\hline 1 & Excellent & 175 & $1 \%$ \\
\hline 2 & Good & 1630 & $9 \%$ \\
\hline 3 & Fair & 8396 & $46 \%$ \\
\hline 4 & Poor & 7951 & $43 \%$ \\
\hline 5 & Immediate Attention Required & 200 & $1 \%$ \\
\hline
\end{tabular}

To obtain their feedback, the author forwarded to Utility A's Stormwater Asset Management Team the Excel spreadsheet with calculations (Appendix C), the ArcMap with the results (Appendix D), and the explanation provided in this section. The Asset Management Supervisor expressed that the results matched his expectations, which were based on his knowledge of the ground scenario of the utility. The Asset Management Team called this a good start for gauging the condition of their assets and that they would work towards gathering the remaining parameters and conducting more inspections to increase the percentage reliability of the data (Appendix E). 


\section{Chapter 8 Conclusions}

Stormwater pipeline infrastructure asset management is a relatively new concept that offers immense scope for further research. An effort was made in this study to assist stormwater utilities in answering one of the core questions of asset management: "What is the current state of our assets?"

To gauge the performance of stormwater pipelines, this study developed a framework based on a weighted summation method. The significant challenge associated with this research was the dearth of literature pertaining specifically to stormwater pipelines, a challenge met by actively involving utility asset managers. This study has provided a preliminary understanding of the lifecycle of a stormwater pipe and of why they fail. It developed a data structure of over 50 parameters that affect the performance of stormwater pipelines, their internal and external environments. Utilities can adopt this list as a data collection or inspection standard and thereby organize both historic data and the data to be collected during future inspections. Using the essential parameters, this study came up with a hierarchal structure representing the deterioration process of stormwater pipelines. A survey form was prepared and mailed to stormwater utilities across the U.S. to get their feedback on the list of parameters and their weights. The responses received were realistic. Thus, the mean of all responses was used to generate the weights of the performance index. The weights indicate that the performance of a stormwater pipeline is highly affected most by it structural condition, followed by blockage and capacity of the pipe, which leads to the conclusion that what is crucial to the performance of a stormwater pipe is its hydraulic condition.

The study applied the developed performance index framework to one stormwater utility. While not revising the parameters or weights, the study did edit the range of a few parameters and their scales based on the inputs from the utility experts. The index was run on the inspection data available with the utility. The utility experts validated the generated results.

The framework developed should enable stormwater utilities to gauge the performance of their existing pipelines. The performance evaluation will aid the utilities in their repair, rehabilitation, and replacement decisions. The evaluated performance and the accompanying data percentage reliability will encourage the utilities to continually improve their data collection standards. The

performance index will also help in explaining to the authorities and public the funding 
requirements of their stormwater infrastructure. The evaluated performance and the accompanying data percentage reliability will encourage the utilities to continually improve their data collection standards.

This introductory research is a stepping stone towards shifting the stormwater utility maintenance efforts from being reactive to proactive. 


\section{Chapter 9 Limitations}

This introductory research on stormwater pipeline asset management uses both qualitative and quantitative methods to achieve the research goal. As with any study, it has various limitations.

The list of parameters affecting the performance of stormwater pipelines was developed on the basis of wastewater pipe performance parameters and a literature review; it was later reviewed by industry experts. This method might have resulted in minimal parameters acquired from the industry's point of view. Also, the list of parameters and units in this research were developed to suit all utilities across the U.S. A few of the parameters might not apply to certain regions or the units of measurement used by a utility might be different and tedious to alter.

The stormwater pipeline parameter ranges established were inspired by the wastewater pipeline parameter ranges and the NASSCO's PACP standard. They were later reviewed by industry experts. This review of established ranges might have led to a bias in the feedback from the experts.

The generalizability of the performance index is limited, as the weights were developed on the basis of replies from experts based in eight stormwater utilities across the U.S. Moreover, a simple average of all these replies was performed to obtain the weights of the performance index. Though the eight utilities are geographically spread across the country, a larger set of replies will enable the use of improved mathematical techniques to derive the weights and also increase the confidence in the obtained weights.

The simple and convenient weighted summation method was used to establish the performance index. Weighted summation method is applied on the assumption that there is no interaction between the performance parameters, meaning that the performance parameters were independent. However, this is not a realistic assumption, as the five failure modules interact with one another.

The developed performance index was not fully validated. The actual performance index of the stormwater pipelines could not be obtained from the contacted utilities to cross check the calculated performance values.

Before a utility applies the performance index, it may need to be modified. Each objective, starting from the development of the list of parameters to establishing the parameter ranges, may be tailored 
more closely to a stormwater utility. A framework for the development of a stormwater performance index was established in study rather than a stringent equation.

The developed performance index only gauges the performance of closed stormwater pipes. The performance of a stormwater pipe is also affected by the performance of the associated structures like manholes, inlets and outlets. This research uses the "Associated Structures" variable which establishes the number of associated structures with a stormwater pipe but does not incorporate their performance or condition. 


\section{Chapter 10 Future Research}

The comprehensiveness of the list of stormwater performance parameters still needs to be verified. A committee of experienced personnel from across the nation should be established and asked to develop, based on their knowledge, a list of performance parameters. This list can be used to validate and augment the current parameters.

A standard central database should be established to store the stormwater performance parameters of all stormwater utilities in the U.S. This database will help in establishing the range of performance parameters. The committee of experienced personnel could also support the refining of the parameter ranges. The database will help improve the understanding on the performance deterioration of stormwater pipelines and facilitate the development of improved performance and deterioration models.

The study can be repeated with all the nation's stormwater utilities. An improvised survey document that uses the pair wise comparison or other equivalent method to obtain the weights of all the parameters should be used for conducting the nationwide survey.

This foundation study used the weighted factor method to develop the performance index. With better availability of performance data and with the interaction of industry experts, future studies could develop the performance index by using improved techniques as fuzzy logic and neural networks that capture the interdepend ability between the parameters.

The current model was implemented using data from one utility to show its usability and the results were partially validated based on the heuristic knowledge of utility experts. Future research works can incorporate improvised verification and validation techniques, preferably laboratory experiments to establish the accuracy of the results.

It is important to gauge the condition of open conduits and different inlet and outlet structures, which determine the performance of the attached stormwater pipes. Future research can develop separate performance indices for all types of major stormwater infrastructure and incorporate them while determining the performance of the stormwater pipe. The performance index of each stormwater infrastructure could be developed using a framework similar to this research. 
This research developed the performance index with Microsoft Excel using macros. In the future, computer programming languages could be used to create a user-friendly interface for the utilities, and also link it to a geodatabase for data retrieval and ArcMap to automatically generate the pictorial representation of the data.

Presently, there is minimal understanding of the failure mechanisms of different stormwater pipeline materials. Future research could aim to improve this understanding by capturing the knowledge of industry experts. The better the understanding of the failure path of a stormwater pipe, the better maintenance and rehabilitation decisions can be made.

NASSCO's PACP is a comprehensive and well-established standard in the industry. There is scope for research to revise the detailed defect codes and defect scores to better suit stormwater pipelines. Future research in this area will be of great value for the stormwater utilities. The utilities will be able to better manage their assets at minimum or no additional cost, since they have personnel already trained on using NASSCO's PACP.

The initial steps to developing a strategic asset management program are data collection and performance evaluation. Future work should concentrate on developing performance prediction models to predict the remaining service life of the pipelines. This would aid the stormwater utilities in making effective financial decisions.

In conclusion, future work should address the following core research objectives to develop a robust performance index and deterioration curve for stormwater pipeline asset management:

- quantify the parameter ranges considered in this research. Quantifying the parameter ranges based on fundamental research will help improve the variability in the model output.

- improve the stormwater performance index from a 1-5 scale to 1-7 scale or higher for better representation. A rating scale with higher points helps in making improved observations and conclusions about the performance of the stormwater pipelines.

- develop techniques to predict the remaining economic life of the stormwater pipelines to aid utilities in decision making for prioritizing future inspection and renewal engineering. 


\section{References}

American Society of Civil Engineers (ASCE). (2006). Standard guidelines for the design of urban stormwater systems, Standard guidelines for the installation of urban stormwater systems, and Standard guidelines for the operation and maintenance of urban stormwater systems. ASCE/EWRI 45-05, 46-05 and 47-05, Reston, VA.

Angkasuwansiri, T., and Sinha, S. K. (2013). "Comprehensive List of Parameters Affecting Wastewater Pipe Performance." Technology Interface International Journal, 13(2), 68-79.

Angkasuwansiri, T., and Sinha, S. K. (2014). "Development of a Robust Wastewater Pipe Performance Index." Journal of Performance of Constructed Facilities, 29(1), 4014042.

ASCE. (2013). “2013 Report Card for America's Infrastructure.” <http://www.infrastructurereportcard.org/> (Feb. 23, 2015).

Bai, H., Sadiq, R., Najjaran, H., and Rajani, B. (2008). "Condition Assessment of Buried Pipes Using Hierarchical Evidential Reasoning Model." Journal of Computing in Civil Engineering, 22(2), 114-122.

Betz, J. W. (2013). "Fundamentals of Stormsewer Pipe Asset Management." Project and Report, Masters in Civil Engineering, Virginia Polytechnic Institute and State University.

Bishop, J., and Sertich, S. (2013). "Stormwater Management Options and How They Can Fail." Continuing Education Center, <http://ce.construction.com/article.php?L=227\&C=1097> (May 20, 2013).

Burns \& McDonnell Engineering Company Inc. (2010). Storm Sewer Pipe Material Technical Manual. 3rd Edition, Urban Drainage and Flood Control District, Denver, CO.

Campbell, C. W. (2013). "Western Kentucky University Stormwater Utility Survey 2013." <http://www.wku.edu/engineering/civil/fpm/swusurvey/western_kentucky_university_swu_surv ey_2013.pdf> (Jan. 15, 2014).

Center for Watershed Protection (CWP). (1997). Stormwater BMP Design Supplement for Cold Climates. United States Environmental Protection Agency, Washington, D.C.

Chughtai, F., and Zayed, T. (2007). "Sewer Pipeline Operational Condition Prediction Using Multiple Regression." Pipelines 2007: Advances and Experiences with Trenchless Pipeline Projects, American Society of Civil Engineers, Reston, VA, 1-11.

Colorado Department of Transportation. "El Paso County Geographic Data" Online Transportation Information System, < http://dtdapps.coloradodot.info/Otis/catalog> (Apr. 20, 2015).

Colorado Water Conservation Board (CWCB) and Colorado Division of Water Resources (DWR). (1993). “Average Precipitation (1951-1980)." Colorado's Decision Support Systems < http://cdss.state.co.us/GIS/Pages/AllGISData.aspx> (Apr. 20, 2015). 
Division of Sewerage and Drainage. (2006). Stormwater Drainage Manual. Department of Public Utilities, City of Columbus, $\mathrm{OH}$.

Davies, J., Clarke, B., Whiter, J., and Cunningham, R. (2001). "Factors influencing the structural deterioration and collapse of rigid sewer pipes." Urban Water, 3(1), 73-89.

Environmental Protection Services Department. (2013). Stormwater Asset Management and Capital Improvement Plan. City of Grand Rapids, MI.

Fuamba, M., and Ennaouri, I. (2013). "New Integrated Condition-Assessment Model for Combined Storm-Sewer Systems." Journal of Water Resources Planning and Management, 139(1), 53-64.

Gay, L. F. and Sinha, S. K. (2014). Water Infrastructure Asset Management Primer, Report No. INFR9SG09b, Water Environment Research Foundation, Alexandria, VA, 2-14.

Grigg, N. S. (2012). Water, wastewater, and stormwater infrastructure management, 1st Edition, Lewis Publishers, Boca Raton, FL.

Harlow, V. K. (2001). "Asset Management: The life-cycle approach." Proceedings of the Water Environment Federation, 2001(11), 1-8.

Harvey, R., and McBean, E. (2014). "Understanding Stormwater Pipe Deterioration through Data Mining." Journal of Water Management Modeling, C374.

Integrated Science and Engineering Inc. (2013). Stormwater Infrastructure Assessment. City of Mountain Park, GA.

Jacobs, T. L., Medina, M. A., Kaufman, N., and Wood, D. M. (1993). "Optimal Long-Term Scheduling of Stormwater Drainage Rehabilitation." Journal of the American Water Resources Association, 29(1), 47-54.

Kannapiran, A., Chanan, A., Singh, G., Tambosis, P., Jeyakumaran, J., and Kandasamy, J. (2007). "An innovative model for sustainable cost effective management of stormwater drainage assets." Water Asset Management International, 3, 04-11.

Kannapiran, A., Chanan, A., Singh, G., Tambosis, P., Jeyakumaran, J., and Kandasamy, J. (2008). "Strategic asset management planning of stormwater drainage systems." Water Practice and Technology, 3 (3), 01-08.

Kathula, V., Rowe, R., Bergin, J., and Kennedy, C. C. (2011). "Asset Management Likelihood of Failure Scoring Improved by Condition Assessment Scoring Integration Techniques." Pipelines 2011: A Sound Conduit for Sharing Solutions, American Society of Civil Engineers, Seattle, Washington, 170-181.

Koo, D.H., and Ariaratnam, S. T. (2006). "Innovative method for assessment of underground sewer pipe condition." Automation in Construction, 15(4), 479-488. 
Najafi, M., and Kulandaivel, G.and (2005). "Pipeline Condition Prediction Using Neural Network Models." Pipelines 2005: Optimizing Pipeline Design, Operations and Maintenance, American Society of Civil Engineers, Reston, VA, 767-781.

Makar, J.M., and Kleiner, Y. (2000). "Maintaining water pipeline integrity". Water Infrastructure Conference and Exhibition, American Water Works Association, Baltimore, MD, 1-13.

Micevski, T., Kuczera, G., and Coombes, P. (2002). "Markov Model for Storm Water Pipe Deterioration." Journal of Infrastructure Systems, 8(2), 49-56.

Minnesota Department of Transportation (MnDoT). (2013). HydInfra Inspection Manual: Culvert and Storm Drainage Systems. St. Paul, MN.

Mitchell Shire Council. (2012). "Part F - Urban Stormwater Drainage System." Infrastructure Asset Management Plan. Victoria, Australia.

National Association of Sewer Service Companies (NASSCO). (2003). Pipeline assessment and certification program (PACP) reference manual. Pikeville, MD.

National Corrugated Steel Pipe Association. (2008). Corrugated Steel Pipe Design Manual. Dallas, TX.

National Research Council Canada (NRC). (2004). "Assessment and Evaluation of Storm and Wastewater Collection Systems." National Guide to Sustainable Municipal Infrastructure. Ottawa, Canada.

Rahman, S., and Vanier, D.J. (2004). "An evaluation of condition assessment protocols for sewer management." Municipal Infrastructure Investment Planning (MIPP), National Research Council Canada, Ottawa, Canada.

Rudick, D. A., and Lincoln, J. T. (2014). "Chapter 9 Stormwater Design Requirements" Infrastructure Design Manual. Department of Public Works and Engineering, City of Houston, TX.

Sanders, D. (2009). "Pipe Joints and Critical Performance Requirements by System Application." $C E$ News, <http://www.conteches.com/DesktopModules/Bring2mind/DMX/Download.aspx?Command=Co re_Download\&EntryId=4568\&PortalId=0\&TabId=144> $($ Mar 16, 2015).

Sekhar, V. R. (2011). "Web-Based and Geospatially Enabled Tool for Water and Wastewater Pipeline Infrastructure Risk Management." Thesis, Virginia Polytechnic and State University.

Sinha, S., and Angkasuwansiri, T. (2010). "Phase 2: Development of a robust wastewater pipe performance index." Development of protocols and methods for predicting the remaining economic life of wastewater pipe infrastructure assets. Report No. 06-SAM-1 CO, Water Environment Research Foundation, Alexandria, VA.

Sinha, S., Angkasuwansiri, T., and Thomasson, R. (2008). "Phase 1: Development of standard data structure to support wastewater pipe condition and performance prediction." Development of 
protocols and methods for predicting the remaining economic life of wastewater pipe infrastructure assets. Report No. 06-SAM-1 CO, Water Environment Research Foundation, Alexandria, VA.

Sinha, S. K., and Eslambolchi, S. S. (2006). Bridging the Gap: An Educational Primer on Sustainable Water Infrastructure Asset Management. United States Environmental Protection Agency and Pennsylvania State University, USA.

Sinha, S., and St Clair, A. M. (2014). "Development of a Standard Data Structure for Predicting the Remaining Physical Life and Consequence of Failure of Water Pipes." Journal of Performance of Constructed Facilities, 28(1), 191-203.

St Clair, A. M. (2013). "Development of a Novel Performance Index and a Performance Prediction Model for Metallic Drinking Water Pipelines." Dissertation, Virginia Polytechnic Institute and State University.

Tabor, M., Donaldson, B., Salehi, M., Estaba, J., and Whelton, A. J. (2013). "Impact of Infrastructure Coating Materials on Storm-Water Quality: Review and Experimental Study." Journal of Environmental Engineering, 139(5), 746-756.

Tagherouit, W. B., Bennis, S., and Bengassem, J. (2011). "A Fuzzy Expert System for Prioritizing Rehabilitation of Sewer Networks." Computer-Aided Civil and Infrastructure Engineering, 26(2), 146-152.

Tran, D., Perera, B., and Ng, A. W. M. (2009). "Comparison of structural deterioration models for stormwater drainage pipes." Computer-Aided Civil and Infrastructure Engineering, 24(2), 145156.

Tran, D. H., Ng, A. W. M., and Perera, B. (2007). "Neural networks deterioration models for serviceability condition of buried stormwater pipes." Engineering Applications of Artificial Intelligence, 20(8), 1144-1151.

USEPA. "National Pollution Discharge Elimination System (NPDES)". Healthy Waters in the Mid-Atlantic, < http://www.epa.gov/reg3wapd/images/images_npdes/cso_diagram.gif > (May. 25, 2015).

USEPA. (2002). Collection Systems Technology Fact Sheet: Sewers, Conventional Gravity. Municipal Technology Branch, Washington, D.C.

USEPA. (2015). "Stormwater Homepage." United States Environmental Protection Agency, <http://water.epa.gov/polwaste/npdes/stormwater/> (Feb. 23, 2015).

US Department of Agriculture (USDA) and Natural Resources Conservation Service (NRCS). (2013). "Web Soil Survey." < http://websoilsurvey.sc.egov.usda.gov/App/HomePage.htm > (Apr. 20, 2015).

Water Research Center (WRc). (2001). Sewer Rehabilitation Manual. 4th Edition, Sweden, U.K. 


\section{Appendix A. Utility Survey Form and Response Received}

This appendix contains the Utility Survey Form which was mailed to the asset managers to get

their feedback on the failure module and parameter weights. Also, the responses received from eight utility managers are enclosed in the appendix. 


\section{Performance Index}

For

\section{Stormwater Pipeline Infrastructure}

Sowmya Bhimanadhuni, Dr. Sunil Sinha

\section{( bsowmya@vt.edu ; 540-750-0986 )}

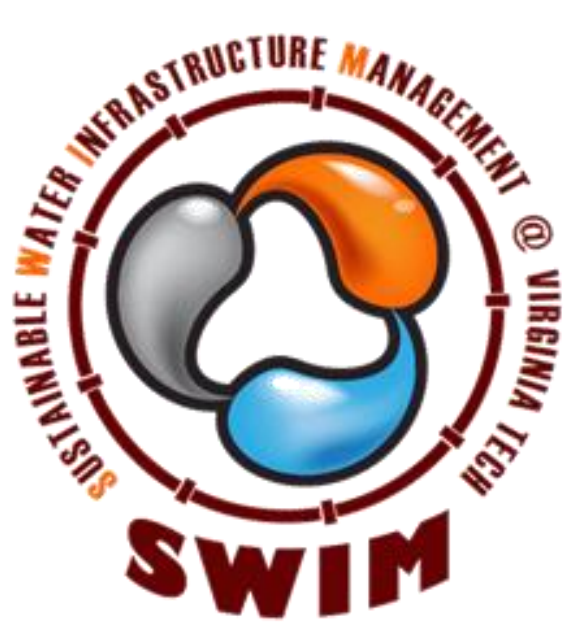

SUSTAINABLE WATER INFRASTRUCTURE MANAGEMENT (SWIM) CENTER 


\section{VIRGINIA TECH}

\section{Project Background}

An infrastructure system, often taken for granted even more so than water distribution or wastewater collection systems, is the stormwater pipeline infrastructure. It is clearly not discussed separately in the ASCE Report card and there is no existing comprehensive national study related to the management of stormwater infrastructure. The majority of the utilities in the U.S, are considering the deterioration of stormwater pipeline infrastructure to be similar to deterioration of sewers that had been studied more frequently. They are adopting the sanitary sewer rating systems, such as NASSCO's Pipeline Assessment and Certification Program (PACP), or using an in-house system developed for a broader infrastructure asset assessment system (such as seen in different state transportation departments) to determine the performance of their stormwater pipelines. However, this is not adequate, as the major cause for deterioration of the sewer pipes is the internal attack by acids associated with sewage; whereas, stormwater pipelines are relatively clean, and are predominantly damaged by external factors. Moreover, it is crucial to have a robust performance rating system tailored specifically for stormwater infrastructure to accurately gauge the condition of the asset and thereby plan and prioritize the maintenance and repair/replacement/rehabilitation activities.

\subsection{Project Objective}

The objective of this project is to develop a performance index for stormwater pipeline infrastructure. The index shall be on a scale of 1 to 5 similar to NASSCO's PACP grading system.

\subsection{Project Scope}

The stormwater infrastructure system is comprised of both conveyance and storage components. However, the scope of this study is primarily limited to the drainage pipes. The effects of the inlet/outlet structures and service lateral connections was incorporated to an extent that is deemed important to determine the condition of the drainage pipes.

\subsection{Project Work Completed till Date}

Due to the fact that minimal literature is available on failure mode of stormwater pipelines, this project relies to a large extent on industry survey.

1. A list of parameters effecting the condition of stormwater pipelines and their unit of measurement was prepared. This list was sent out to utilities across all the EPA regions for review. Based on the received replies, a final list of $\mathbf{5 0}$ parameters that are crucial to determining the condition of stormwater pipelines was prepared.

\section{I would like to express my sincerely thanks to the contributing utilities.}

The significance factors obtained through this questionnaire will be used to determine the factor weights in the stormwater performance index equation. 


\section{Questionnaire for Stormwater Performance Index}

STEP 1: Fill Table A.2 on stormwater pipeline failure modes using the rule given below and Table A.1.

If the Column variable is of higher importance than the Row variable, use the appropriate factor from Table 1 to establish the degree of importance. For example, if Blockage is of "Moderate Importance" than Capacity fill the block highlighted in Table 1 with 3, which is the number corresponding to "Moderate Importance".

Table A.1: Degree of Importance

\begin{tabular}{|c|c|}
\hline Degree of Importance & Definition \\
\hline 0 & Less Importance \\
\hline 1 & Equal Importance \\
\hline 3 & Moderate Importance \\
\hline 5 & Strong Importance \\
\hline 7 & Very Strong Importance \\
\hline 9 & Extreme Importance \\
\hline
\end{tabular}

Table A.2: Fill the pair-wise comparison matrix on stormwater pipeline failure modes Column

$\downarrow \mid$\begin{tabular}{|c|c|c|c|c|c|}
\hline- & Capacity & Blockage & $\begin{array}{c}\text { Surface } \\
\text { Wear }\end{array}$ & Load & $\begin{array}{c}\text { Structural } \\
\text { Defects }\end{array}$ \\
\hline Capacity & - & & & & \\
\hline $\begin{array}{c}\text { Blockage } \\
\text { Surface } \\
\text { Wear }\end{array}$ & & - & & & \\
\hline Load & & & - & & \\
\hline $\begin{array}{c}\text { Structural } \\
\text { Defects }\end{array}$ & & & & - & - \\
\hline
\end{tabular}

Definitions: Capacity failure Mode is when pipe size is not sufficient to hold the stormwater flow resulting in overflows and surcharging. Blockage Failure Mode is when extraneous material entering the stormwater pipe results in flow disruption. Surface Wear Failure Mode refers to spalling, wear, mineral deposits, corrosion etc., which effect the surface of the pipe. Load Failure Mode refers to anything that effects the pipe structure. Structural Defects refer to all other structural defects not defined by surface wear or load failure modes like crack, fracture, broken, hole, leaking joint, lining failure, etc., mentioned in PACP. 
STEP 2: Provide the significance values (Very Low (5), Low (4), Medium (3), High (2), Very High (1)) for each of the attributes affecting a particular stormwater pipeline failure mode.

Please mark " $\mathrm{X}$ " at the significance level next to each attribute below. If you feel an attribute does not affect the corresponding failure mode, please leave it blank. If you feel any other factor should strongly be considered, do provide it in the space provided as "other factors" with an explanation.

\section{A. Capacity}

\begin{tabular}{|c|c|c|c|c|c|c|}
\hline \multirow{2}{*}{ No. } & Factor & \multicolumn{5}{|c|}{ Significance } \\
\cline { 4 - 6 } & & Very Low & Low & Medium & High & Very High \\
\hline 1 & Overflow Frequency & & & & & \\
\hline 2 & Pipe Surcharging & & & & & \\
\hline 3 & Inflow/Infiltration Level & & & & & \\
\hline 4 & Exfiltration Level & & & & & \\
\hline 5 & Average Rainfall Intensity & & & & & \\
\hline 6 & Average Rainfall Duration & & & & & \\
\hline 7 & Average Flow Velocity & & & & & \\
\hline 8 & Soil Type & & & & & \\
\hline 9 & Pipe Location & & & & & \\
\hline
\end{tabular}

\section{B. Blockage}

\begin{tabular}{|c|c|l|l|l|l|l|}
\hline \multirow{2}{*}{ No. } & Factor & \multicolumn{3}{|c|}{ Significance } \\
\cline { 3 - 6 } & Debris Level & Very Low & Low & Medium & High & Very High \\
\hline 1 & Sedimentation Level & & & & & \\
\hline 3 & $\begin{array}{c}\text { Number of Lateral } \\
\text { Connections }\end{array}$ & & & & & \\
\hline 4 & $\begin{array}{c}\text { If Inlet is attached or if Pipe } \\
\text { changes Direction }\end{array}$ & & & & & \\
\hline 5 & Smell or Vermin Level & & & & & \\
\hline 6 & Pipe Length & & & & & \\
\hline 7 & Pipe Diameter & & & & & \\
\hline 8 & Pipe Slope & & & & & \\
\hline 9 & Minimum Flow Velocity & & & & & \\
\hline
\end{tabular}

\section{Surface Wear}

\begin{tabular}{|c|c|l|l|l|l|l|}
\hline No. & Factor & \multicolumn{5}{|c|}{ Significance } \\
\cline { 3 - 6 } & & Very Low & Low & Medium & High & Very High \\
\hline 1 & $\begin{array}{c}\text { Surface Wear Condition } \\
\text { Rating as per Visual, CCTV } \\
\text { or other Inspections }\end{array}$ & & & & & \\
\hline 2 & Maintenance Method Type & & & & & \\
\hline 3 & Pipe Age & & & & & \\
\hline
\end{tabular}




\begin{tabular}{|c|c|c|c|c|c|c|}
\hline \multirow{2}{*}{ No. } & Factor & \multicolumn{5}{|c|}{ Significance } \\
\cline { 4 - 6 } & & Very Low & Low & Medium & High & Very High \\
\hline 4 & Pipe Material & & & & & \\
\hline 5 & Pipe Shape & & & & & \\
\hline 6 & Average Flow Velocity & & & & & \\
\hline
\end{tabular}

\section{Load}

\begin{tabular}{|c|c|c|c|c|c|c|}
\hline \multirow{2}{*}{ No. } & Factor & \multicolumn{3}{|c|}{ Significance } \\
\cline { 3 - 6 } & & Very Low & Low & Medium & High & Very High \\
\hline & $\begin{array}{c}\text { Rating of Pipe Structure per } \\
\text { Visual, CCTV or other } \\
\text { Inspections }\end{array}$ & & & & \\
\hline 2 & $\begin{array}{c}\text { Loading Condition (Dead } \\
\text { Load) }\end{array}$ & & & & & \\
\hline 3 & Loading Condition (Live Load) & & & & & \\
\hline 4 & Depth of Cover & & & & & \\
\hline 5 & Pipe Bedding Type & & & & & \\
\hline 6 & Trench Backfill Type & & & & & \\
\hline 7 & Groundwater Table Level & & & & & \\
\hline 8 & Exfiltration Level & & & & & \\
\hline 9 & Pipe Shape & & & & & \\
\hline
\end{tabular}

E. Structural Defects (crack, fracture, broken, leaking joint, lining failure etc.)

\begin{tabular}{|c|c|l|l|l|l|l|}
\hline \multirow{2}{*}{ No. } & Factor & \multicolumn{5}{|c|}{ Significance } \\
\cline { 3 - 6 } & Very Low & Low & Medium & High & Very High \\
\hline 1 & $\begin{array}{c}\text { Condition Rating as per } \\
\text { Visual, CCTV or other } \\
\text { Inspections }\end{array}$ & & & & & \\
\hline 2 & Pipe Age & & & & & \\
\hline 3 & Pipe Material & & & & & \\
\hline 4 & Pipe Diameter & & & & & \\
\hline 5 & Pipe Joint Type & & & & & \\
\hline
\end{tabular}

\section{F. Other factors}

\begin{tabular}{|l|l|l|l|l|}
\hline No. & Factor & Failure Mode & Explanation & Significance \\
\hline & & & & \\
\hline & & & & \\
\hline & & & & \\
\hline
\end{tabular}




\section{Response 1}

\section{STEP 1:}

\begin{tabular}{|c|c|c|c|c|c|}
\hline- & Capacity & Blockage & $\begin{array}{c}\text { Surface } \\
\text { Wear }\end{array}$ & Load & $\begin{array}{c}\text { Structural } \\
\text { Defects }\end{array}$ \\
\hline Capacity & - & 7 & 3 & 7 & 9 \\
\hline Blockage & & - & & & 9 \\
\hline $\begin{array}{c}\text { Surface } \\
\text { Wear }\end{array}$ & & 9 & - & 7 & 9 \\
\hline Load & & 5 & & - & 7 \\
\hline $\begin{array}{c}\text { Structural } \\
\text { Defects }\end{array}$ & & & & & - \\
\hline
\end{tabular}




\section{STEP 2:}

\section{A. Capacity}

\begin{tabular}{|c|c|c|c|c|c|c|}
\hline \multirow[t]{2}{*}{ No. } & \multirow[t]{2}{*}{ Factor } & \multicolumn{5}{|c|}{ Significance } \\
\hline & & Very Low & Low & Medium & High & Very High \\
\hline 1 & Overflow Frequency & $x$ & & & & \\
\hline 2 & Pipe Surcharging & & & & $X$ & \\
\hline 3 & Inflow/Infiltration Level & & & & & $x+$ \\
\hline 4 & Exfiltration Level & & & & & $x *$ \\
\hline 5 & Average Rainfall Intensity & $x$ & & & & \\
\hline 6 & Average Rainfall Duration & $x$ & & & & \\
\hline 7 & Average Flow Velocity & & $\mathrm{x}$ & & & \\
\hline 8 & Soil Type & & X & & & \\
\hline 9 & Pipe Location & & & X & & \\
\hline
\end{tabular}

B. Blockage

issue

\begin{tabular}{|c|c|c|c|c|c|c|c|}
\hline \multirow[t]{2}{*}{ No. } & \multirow[t]{2}{*}{ Factor } & \multicolumn{5}{|c|}{ Significance } & \multirow[b]{5}{*}{$\begin{array}{l}\text { Not } \\
\text { permitred }\end{array}$} \\
\hline & & Very Low & Low & Medium & High & Very High & \\
\hline 1 & Debris Level & & & & $x$ & & \\
\hline 2 & Sedimentation Level & & & & $x$ & & \\
\hline 3 & $\begin{array}{l}\text { Number of Lateral } \\
\text { Connections }\end{array}$ & & & $x^{x+1}$ & & & \\
\hline 4 & $\begin{array}{l}\text { If Inlet is attached or if } \\
\text { Pipe changes Direction }\end{array}$ & & $x$ & & & 1 & $\begin{array}{l}\text { change in } \\
\text { divedim } \\
\text { affeds capacits }\end{array}$ \\
\hline 5 & Smell or Vermin Level & $x$ & & & & & hore thin \\
\hline 6 & Pipe Length max $460^{\prime}$ & & & & $x$ & & \\
\hline 7 & Pipe Diametermin $15^{11}$ & & & & $x$ & & \\
\hline 8 & Pipe Slope & & & & $x$ & & \\
\hline 9 & Minimum Flow Velocity & & & & $x$ & & \\
\hline
\end{tabular}

\begin{tabular}{|c|c|c|c|c|c|c|}
\hline \multirow{2}{*}{ No. } & Factor & \multicolumn{5}{|c|}{ Significance } \\
\cline { 3 - 7 } & & Very Low & Low & Medium & High & Very High \\
\hline 1 & $\begin{array}{c}\text { Surface Wear Condition } \\
\text { Rating as per Visual, } \\
\text { CCTV or other Inspections }\end{array}$ & & & $X$ & & \\
\hline
\end{tabular}




\begin{tabular}{|c|c|c|c|c|c|c|}
\hline 2 & Maintenance Method Type & \multicolumn{4}{|c|}{} & \multicolumn{3}{|c|}{ Significance } & \\
\hline \multirow{2}{*}{ No. } & Factor & \multicolumn{5}{|c|}{} \\
\cline { 3 - 7 } & & Very Low & Low & Medium & High & Very High \\
\hline 3 & Pipe Age & & $X$ & & & \\
\hline 4 & Pipe Material & & & & & $X$ \\
\hline 5 & Pipe Shape & & & $X$ & & \\
\hline 6 & Minimum Flow Velocity & & & & & $X$ \\
\hline
\end{tabular}

D. Load

\begin{tabular}{|c|c|c|c|c|c|c|}
\hline \multirow{2}{*}{ No. } & Factor & \multicolumn{5}{|c|}{ Significance } \\
\cline { 3 - 6 } & & Very Low & Low & Medium & High & Very High \\
\hline 1 & $\begin{array}{c}\text { Rating of Pipe Structure } \\
\text { per Visual, CCTV or other } \\
\text { Inspections }\end{array}$ & & & & \\
\hline 2 & $\begin{array}{c}\text { Loading Condition (Dead } \\
\text { Load) }\end{array}$ & & & $X$ & & \\
\hline 3 & $\begin{array}{c}\text { Loading Condition (Live } \\
\text { Load) }\end{array}$ & & $X$ & & \\
\hline 4 & Depth of Cover & & & & \\
\hline 5 & Pipe Bedding Type & & & & \\
\hline 6 & Trench Backfill Type & & & & \\
\hline 7 & Groundwater Table Level & & & $X$ & & $X$ \\
\hline 8 & Exfiltration Level & & $X$ & & & \\
\hline 9 & Pipe Shape & & $X$ & & & \\
\hline
\end{tabular}

E. Structural Defects (crack, fracture, broken, hole, leaking joint, lining failure etc.)

\begin{tabular}{|c|c|c|c|c|c|c|}
\hline \multirow{2}{*}{ No. } & Factor & \multicolumn{5}{|c|}{ Significance } \\
\cline { 3 - 7 } & & Very Low & Low & Medium & High & Very High \\
\hline 1 & $\begin{array}{c}\text { Condition Rating as per } \\
\text { Visual, CCTV or other } \\
\text { Inspections }\end{array}$ & & & & & \\
\hline 2 & Pipe Age & $X$ & & & & \\
\hline 3 & Pipe Material & & & & $X$ & \\
\hline 4 & Pipe Diameter & & $X$ & & & \\
\hline 5 & Pipe Joint Type & & & & & $X \times X$ \\
\hline
\end{tabular}

\section{F. Other factors:}

\begin{tabular}{|c|c|c|c|c|}
\hline No. & Factor & Failure Mode & Explanation & Significance \\
\hline & pintseparation & blockage. & dropped pipe sections & Care-ins dovebs \\
\hline & cross-bones & blockenfe & catch débris & bleckage \\
\hline & & stractires & holes, infitration & care-ins \\
\hline
\end{tabular}

Note that oursystem is required to be designed to convey the 10-yr storm event and a check must be made for overland relief to be provided (no stracture flooding) in the event Mat the pipe systen beaine blocked. 


\section{Response 2}

\section{STEP 1:}

Column

\begin{tabular}{|c|c|c|c|c|c|c|c|}
\hline \multicolumn{2}{|c|}{} & Capacity & Blockage & $\begin{array}{c}\text { Surface } \\
\text { Wear }\end{array}$ & \multicolumn{2}{c|}{ Load } & $\begin{array}{c}\text { Structural } \\
\text { Defects }\end{array}$ \\
\hline \multirow{4}{*}{ Capacity } & - & 5 & 3 & 3 & 3 \\
\hline Blockage & 0 & - & 3 & 1 & 0 \\
\hline $\begin{array}{c}\text { Surface } \\
\text { Wear }\end{array}$ & 0 & 5 & - & 1 & 1 \\
\hline Load & 0 & 5 & 3 & - & 1 \\
\hline $\begin{array}{c}\text { Structural } \\
\text { Defects }\end{array}$ & 0 & 5 & 3 & 3 & - \\
\hline
\end{tabular}




\section{STEP 2:}

\section{A. Capacity}

\begin{tabular}{|c|c|c|c|c|c|c|}
\hline \multirow{2}{*}{ No. } & Factor & \multicolumn{5}{|c|}{ Significance } \\
\cline { 3 - 7 } & & Very Low & Low & Medium & High & Very High \\
\hline 1 & Overflow Frequency & & $V$ & & & \\
\hline 2 & Pipe Surcharging & & $\checkmark$ & & & \\
\hline 3 & Inflow/Infiltration Level & & & $\sqrt{ }$ & & \\
\hline 4 & Exfiltration Level & & & $\checkmark$ & & \\
\hline 5 & Average Rainfall Intensity & & & & & \\
\hline 6 & Average Rainfall Duration & & & & & \\
\hline 7 & Average Flow Velocity & & & & & \\
\hline 8 & Soil Type & & & & & \\
\hline 9 & Pipe Location & & & & & \\
\hline
\end{tabular}

\section{B. Blockage}

\begin{tabular}{|c|c|c|c|c|c|c|}
\hline \multirow{2}{*}{ No. } & Factor & \multicolumn{5}{|c|}{ Significance } \\
\cline { 3 - 7 } & & Very Low & Low & Medium & High & Very High \\
\hline 1 & Debris Level & & & & & \\
\hline 2 & Sedimentation Level & & & & & \\
\hline 3 & $\begin{array}{c}\text { Number of Lateral } \\
\text { Connections }\end{array}$ & & & & & \\
\hline 4 & $\begin{array}{c}\text { If Inlet is attached or if } \\
\text { Pipe changes Direction }\end{array}$ & & & & & \\
\hline 5 & Smell or Vermin Level & & & & & \\
\hline 6 & Pipe Length & & & & & \\
\hline 7 & Pipe Diameter & & & & & \\
\hline 8 & Pipe Slope & & & & & \\
\hline 9 & Minimum Flow Velocity & & & & & \\
\hline
\end{tabular}

\section{Surface Wear}

\begin{tabular}{|c|c|c|c|c|c|c|}
\hline \multirow{2}{*}{ No. } & Factor & \multicolumn{5}{|c|}{ Significance } \\
\cline { 3 - 7 } & & Very Low & Low & Medium & High & Very High \\
\hline 1 & Surface Wear Condition & & & & & \\
\hline
\end{tabular}




\begin{tabular}{|c|c|c|c|c|c|c|}
\hline & $\begin{array}{c}\text { Rating as per Visual, } \\
\text { CCTV or other Inspections }\end{array}$ & & & & & \multirow{2}{*}{} \\
\hline 2 & Maintenance Method Type & & \multicolumn{2}{|l|}{} \\
\hline No. & Factor & \multicolumn{4}{|c|}{ Significance } \\
\hline & & Very Low & Low & Medium & High & Very High \\
\hline 3 & Pipe Age & & & & $\checkmark$ & \\
\hline 4 & Pipe Material & & & & & $\checkmark$ \\
\hline 5 & Pipe Shape & & $\checkmark$ & & & \\
\hline 6 & Minimum Flow Velocity & & & & & \\
\hline
\end{tabular}

D. Load

\begin{tabular}{|c|c|l|l|l|l|l|}
\hline \multirow{2}{*}{ No. } & Factor & \multicolumn{5}{|c|}{ Significance } \\
\cline { 3 - 6 } & & Very Low & Low & Medium & High & Very High \\
\hline 1 & $\begin{array}{c}\text { Rating of Pipe Structure } \\
\text { per Visual, CCTV or other } \\
\text { Inspections }\end{array}$ & & & & & \\
\hline 2 & $\begin{array}{c}\text { Loading Condition (Dead } \\
\text { Load) }\end{array}$ & & $\checkmark$ & & & \\
\hline 3 & $\begin{array}{c}\text { Loading Condition (Live } \\
\text { Load) }\end{array}$ & & $\checkmark$ & & & \\
\hline 4 & Depth of Cover & & & $\checkmark$ & & \\
\hline 5 & Pipe Bedding Type & & & $\checkmark$ & & \\
\hline 6 & Trench Backfill Type & & & $\checkmark$ & & \\
\hline 7 & Groundwater Table Level & & & & & \\
\hline 8 & Exfiltration Level & $\checkmark$ & & & & \\
\hline 9 & Pipe Shape & & & & & \\
\hline
\end{tabular}

E. Structural Defects (crack, fracture, broken, hole, leaking joint, lining failure etc.)

\begin{tabular}{|c|c|c|c|c|c|c|}
\hline \multirow{2}{*}{ No. } & Factor & \multicolumn{5}{|c|}{ Significance } \\
\cline { 3 - 7 } & Very Low & Low & Medium & High & Very High \\
\hline 1 & $\begin{array}{c}\text { Condition Rating as per } \\
\text { Visual, CCTV or other } \\
\text { Inspections }\end{array}$ & & & & & \\
\hline 2 & Pipe Age & & & & \\
\hline 3 & Pipe Material & & & & & \\
\hline 4 & Pipe Diameter & $\checkmark$ & & & & \\
\hline 5 & Pipe Joint Type & & & $\checkmark$ & & \\
\hline
\end{tabular}

\section{F. Other factors:}

\begin{tabular}{|l|l|l|l|l|}
\hline No. & Factor & Failure Mode & Explanation & Significance \\
\hline & & & & \\
\hline & & & & \\
\hline
\end{tabular}




\section{Response 3}

\section{STEP 1:}

Column

\begin{tabular}{|c|c|c|c|c|c|}
\hline- & Capacity & Blockage & $\begin{array}{c}\text { Surface } \\
\text { Wear }\end{array}$ & Load & $\begin{array}{c}\text { Structural } \\
\text { Defects }\end{array}$ \\
\hline Capacity & - & 3 & 3 & 0 & 3 \\
\hline \begin{tabular}{c|c|c|c|c|c|}
\hline Blockage \\
Surface \\
Wear
\end{tabular} & 0 & - & 0 & 0 & 1 \\
\hline $\begin{array}{c}\text { Load } \\
\text { Structural } \\
\text { Defects }\end{array}$ & 3 & 5 & 3 & - & 3 \\
\hline
\end{tabular}

\section{STEP 2:}

\section{A. Capacity}

\begin{tabular}{|c|c|c|c|c|c|c|}
\hline \multirow{2}{*}{ No. } & Factor & \multicolumn{5}{|c|}{ Significance } \\
\cline { 4 - 6 } & & Very Low & Low & Medium & High & Very High \\
\hline 1 & Overflow Frequency & & & & X & \\
\hline 2 & Pipe Surcharging & & $X$ & & & \\
\hline 3 & Inflow/Infiltration Level & & $X$ & & & \\
\hline 4 & Exfiltration Level & & & $X$ & & \\
\hline 5 & Average Rainfall Intensity & & & & & X \\
\hline 6 & Average Rainfall Duration & & $X$ & & & \\
\hline 7 & Average Flow Velocity & & & $X$ & & \\
\hline 8 & Soil Type & & $X$ & & & \\
\hline 9 & Pipe Location & & & & & X \\
\hline
\end{tabular}




\section{B. Blockage}

\begin{tabular}{|c|c|c|c|c|c|c|}
\hline \multirow{2}{*}{ No. } & Factor & \multicolumn{5}{|c|}{ Significance } \\
\cline { 4 - 6 } & Very Low & Low & Medium & High & Very High \\
\hline 1 & Debris Level & & & & $\mathrm{X}$ & \\
\hline 2 & Sedimentation Level & & & $\mathrm{X}$ & & \\
\hline 3 & $\begin{array}{c}\text { Number of Lateral } \\
\text { Connections }\end{array}$ & & & & $\mathrm{X}$ & \\
\hline 4 & $\begin{array}{c}\text { If Inlet is attached or if Pipe } \\
\text { changes Direction }\end{array}$ & & $\mathrm{X}$ & & & \\
\hline 5 & Smell or Vermin Level & & $\mathrm{X}$ & & & \\
\hline 6 & Pipe Length & & & $\mathrm{X}$ & & \\
\hline 7 & Pipe Diameter & & & $\mathrm{X}$ & & \\
\hline 8 & Pipe Slope & & & $\mathrm{X}$ & & \\
\hline 9 & Minimum Flow Velocity & & & & \\
\hline
\end{tabular}

\section{Surface Wear}

\begin{tabular}{|c|c|c|c|c|c|c|}
\hline No. & Factor & \multicolumn{5}{|c|}{ Significance } \\
\cline { 3 - 6 } & & Very Low & Low & Medium & High & Very High \\
\hline 1 & $\begin{array}{c}\text { Surface Wear Condition } \\
\text { Rating as per Visual, CCTV } \\
\text { or other Inspections }\end{array}$ & & & & & \\
\hline 2 & Maintenance Method Type & & & & & \\
\hline 3 & Pipe Age & & & & & $\mathrm{X}$ \\
\hline 4 & Pipe Material & & & & & $\mathrm{X}$ \\
\hline 5 & Pipe Shape & & $\mathrm{X}$ & & & \\
\hline 6 & Minimum Flow Velocity & & $\mathrm{X}$ & & & \\
\hline
\end{tabular}

\section{Load}

\begin{tabular}{|c|c|c|c|c|c|c|}
\hline \multirow[t]{2}{*}{ No. } & \multirow[t]{2}{*}{ Factor } & \multicolumn{5}{|c|}{ Significance } \\
\hline & & Very Low & Low & Medium & High & Very High \\
\hline 1 & $\begin{array}{l}\text { Rating of Pipe Structure per } \\
\text { Visual, CCTV or other } \\
\text { Inspections }\end{array}$ & & & & & \\
\hline 2 & $\begin{array}{l}\text { Loading Condition (Dead } \\
\text { Load) }\end{array}$ & & $\mathrm{X}$ & & & \\
\hline 3 & Loading Condition (Live Load) & & $\mathrm{X}$ & & & \\
\hline 4 & Depth of Cover & & & & $\mathrm{X}$ & \\
\hline 5 & Pipe Bedding Type & & & & $\mathrm{X}$ & \\
\hline 6 & Trench Backfill Type & & & $\mathrm{X}$ & & \\
\hline 7 & Groundwater Table Level & & & $\mathrm{X}$ & & \\
\hline 8 & Exfiltration Level & & & & & \\
\hline 9 & Pipe Shape & & $\mathrm{X}$ & & & \\
\hline
\end{tabular}


E. Structural Defects (crack, fracture, broken, leaking joint, lining failure etc.)

\begin{tabular}{|c|c|c|c|c|c|c|}
\hline No. & Factor & \multicolumn{4}{|c|}{ Significance } \\
\cline { 3 - 6 } & Very Low & Low & Medium & High & Very High \\
\hline 1 & $\begin{array}{c}\text { Condition Rating as per } \\
\text { Visual, CCTV or other } \\
\text { Inspections }\end{array}$ & & & & & \\
\hline 2 & Pipe Age & & & & & X \\
\hline 3 & Pipe Material & & & & & X \\
\hline 4 & Pipe Diameter & & X & & & \\
\hline 5 & Pipe Joint Type & & & X & & \\
\hline
\end{tabular}

\section{F. Other factors}

\begin{tabular}{|c|c|c|c|c|}
\hline No. & Factor & Failure Mode & Explanation & Significance \\
\hline & & & & \\
\hline & & & & \\
\hline & & & & \\
\hline
\end{tabular}




\section{Response 4}

\section{STEP 1:}

Column

\begin{tabular}{|c|c|c|c|c|c|}
\hline- & Capacity & Blockage & $\begin{array}{c}\text { Surface } \\
\text { Wear }\end{array}$ & Load & $\begin{array}{c}\text { Structural } \\
\text { Defects }\end{array}$ \\
\hline Capacity & - & 5 & 0 & 0 & 3 \\
\hline Blockage & 0 & - & 0 & 0 & 0 \\
\hline $\begin{array}{c}\text { Surface } \\
\text { Wear }\end{array}$ & 5 & 9 & - & 3 & 7 \\
\hline $\begin{array}{c}\text { Load } \\
\text { Structural } \\
\text { Defects }\end{array}$ & 0 & 3 & 0 & 0 & 5 \\
\hline
\end{tabular}

\section{STEP 2:}

\section{A. Capacity}

\begin{tabular}{|c|c|c|c|c|c|c|}
\hline \multirow{2}{*}{ No. } & Factor & \multicolumn{5}{|c|}{ Significance } \\
\cline { 3 - 6 } & & Very Low & Low & Medium & High & Very High \\
\hline 1 & Overflow Frequency & & & & X & \\
\hline 2 & Pipe Surcharging & & & & $\mathrm{X}$ & \\
\hline 3 & Inflow/Infiltration Level & & $\mathrm{X}$ & & & \\
\hline 4 & Exfiltration Level & $\mathrm{X}$ & & & & \\
\hline 5 & Average Rainfall Intensity & & & & & $\mathrm{X}$ \\
\hline 6 & Average Rainfall Duration & & & & $\mathrm{X}$ & \\
\hline 7 & Average Flow Velocity & & $\mathrm{X}$ & & & \\
\hline 8 & Soil Type & & & & & \\
\hline 9 & Pipe Location & & & $\mathrm{X}$ & & \\
\hline
\end{tabular}




\section{B. Blockage}

\begin{tabular}{|c|c|c|c|c|c|c|}
\hline No. & Factor & \multicolumn{5}{|c|}{ Significance } \\
\cline { 3 - 6 } & Very Low & Low & Medium & High & Very High \\
\hline 1 & Debris Level & & & & & X \\
\hline 2 & Sedimentation Level & & $\mathrm{X}$ & & & \\
\hline 3 & $\begin{array}{c}\text { Number of Lateral } \\
\text { Connections }\end{array}$ & & & & $\mathrm{X}$ & \\
\hline 4 & $\begin{array}{c}\text { If Inlet is attached or if Pipe } \\
\text { changes Direction }\end{array}$ & & & & & \\
\hline 5 & Smell or Vermin Level & & & & & \\
\hline 6 & Pipe Length & & & $\mathrm{X}$ & & \\
\hline 7 & Pipe Diameter & & $\mathrm{X}$ & & & \\
\hline 8 & Pipe Slope & & & $\mathrm{X}$ & & \\
\hline 9 & Minimum Flow Velocity & & & & \\
\hline
\end{tabular}

\section{Surface Wear}

\begin{tabular}{|c|c|l|c|c|c|c|}
\hline No. & Factor & \multicolumn{5}{|c|}{ Significance } \\
\cline { 3 - 6 } & & Very Low & Low & Medium & High & Very High \\
\hline 1 & $\begin{array}{c}\text { Surface Wear Condition } \\
\text { Rating as per Visual, CCTV } \\
\text { or other Inspections }\end{array}$ & & & $\mathrm{X}$ & & \\
\hline 2 & Maintenance Method Type & & & $\mathrm{X}$ & & \\
\hline 3 & Pipe Age & & $\mathrm{X}$ & & & \\
\hline 4 & Pipe Material & & & $\mathrm{X}$ & & \\
\hline 5 & Pipe Shape & & & & & \\
\hline 6 & Minimum Flow Velocity & & $\mathrm{X}$ & & & \\
\hline
\end{tabular}

\section{Load}

\begin{tabular}{|c|c|c|c|c|c|c|}
\hline \multirow{2}{*}{ No. } & Factor & \multicolumn{5}{|c|}{ Significance } \\
\cline { 3 - 6 } & & Very Low & Low & Medium & High & Very High \\
\hline 1 & $\begin{array}{c}\text { Rating of Pipe Structure per } \\
\text { Visual, CCTV or other } \\
\text { Inspections }\end{array}$ & & & & $\mathrm{X}$ & \\
\hline 2 & $\begin{array}{c}\text { Loading Condition (Dead } \\
\text { Load) }\end{array}$ & & $\mathrm{X}$ & & & \\
\hline 3 & Loading Condition (Live Load) & & & & $\mathrm{X}$ & \\
\hline 4 & Depth of Cover & & & & & $\mathrm{X}$ \\
\hline 5 & Pipe Bedding Type & & & $\mathrm{X}$ & & \\
\hline 6 & Trench Backfill Type & & & $\mathrm{X}$ & & \\
\hline 7 & Groundwater Table Level & & & & & \\
\hline 8 & Exfiltration Level & & & & & \\
\hline 9 & Pipe Shape & & & & & \\
\hline
\end{tabular}


E. Structural Defects (crack, fracture, broken, leaking joint, lining failure etc.)

\begin{tabular}{|c|c|c|c|c|c|c|}
\hline \multirow{2}{*}{ No. } & Factor & \multicolumn{4}{|c|}{ Significance } \\
\cline { 4 - 7 } & & Very Low & Low & Medium & High & Very High \\
\hline 1 & $\begin{array}{c}\text { Condition Rating as per } \\
\text { Visual, CCTV or other } \\
\text { Inspections }\end{array}$ & & & & & \\
\hline 2 & Pipe Age & & & & & X \\
\hline 3 & Pipe Material & & $\mathrm{X}$ & & & \\
\hline 4 & Pipe Diameter & & & $\mathrm{X}$ & & \\
\hline 5 & Pipe Joint Type & & & & & \\
\hline & & & & $\mathrm{X}$ & & \\
\hline
\end{tabular}

\section{F. Other factors}

\begin{tabular}{|c|c|c|c|c|}
\hline No. & Factor & Failure Mode & Explanation & Significance \\
\hline & & & & \\
\hline & & & & \\
\hline & & & & \\
\hline & & & & \\
\hline
\end{tabular}

\section{Email Correspondence}

\section{August 1, 2014}

While the parameters look reasonable, the data which xxx collects on its linear assets is not detailed enough to support the proposed environmental and operational/functional attributes. Of the data we do capture, the only parameter on which I will comment is depth of cover. Xxx normally parses out depths from $0-5$ '; 5-10'; 10-20'; and >20'. I don't know how applicable our depth parameters would be at other locations around the country but storm lines are generally shallower than sanitary lines. The 3 different pipe materials which Xxx permits are all defined within the first 5'.

\section{August 5, 2014}

xxx tracks problem codes on requests for service and failure codes on appurtenances. When it comes to pipe inspections, it sounds like you are already familiar with the PACP failure codes. Xxx utilizes PACP inspections for longer pipe segments and for segments known to have problems. For inlet connections which are short enough to be inspected using a digital stick camera, xxx utilizes a maintenance rating of 1-3 and a structural rating of 1-3 (1 needs work now; 3 is ok). The criteria for these ratings is not clearly defined so the numbers vary among inspectors. $x x x$ 's criteria will become more definitive when we switch our CMMS from Maximo to CityWorks later this year or next.To back up the numerical ratings, our inspectors take photos from inside the pipe. All " 1 's" and " 2 's" are reviewed by a supervisor. I have attached a spreadsheet of raw stick camera inspection data from 2013. The data is sorted by pipe segment ID and inspection date with the more important columns highlighted. 


\section{August 6, 2014}

Spalling, scaling and efflorescence have had a nominal impact on the pipes in xxx's system. The one rare but related exception has been the buildup of mineral deposits where pipes connect to certain MH's.

Flow blockage is the primary cause of maintenance failure. Blockages most commonly occur at the intake side of the pipe but they are also prone to occur where the pipe changes direction. For that reason, $\mathrm{xxx}$ does not permit bends in storm sewers.

Holes and broken pieces are primarily found in VCP and PVC, most commonly at or near joints. They are typically related to stress from settlement, or to inadequate cover for the loading (especially point loading). xxx does not permit the use of VCP in new installations but most of our system is > 50 yrs old, so we have a lot of it. Holes and breaks are also found in concrete pipe and even in iron pipe, but not often. Occasionally, xxx discovers that another utility has laid (or in the case of gas mains, drilled) a hole through one of our storm conduits. A drilled hole does not damage the structural integrity of a pipe as much as a break, but it still must be repaired.

Wide cracks are also related to stress but they may be exacerbated by material defects.

Open joints and misalignment are typically due to settlement, but they may be due to poor installation.

Settlement itself may be caused by improper installation but is usually due to movement of the adjacent earth. Our local GIS has an overlay for soil stability which helps with the design of new sewers and with the forensics of failure.

Whereas sanitary sewers and newer storm sewers have water tight joints, older storm sewers did not. Nevertheless, root intrusion has been an infrequent problem because water is only available for the roots to seek during rain events. xxx has only experienced root problems where the pipe was flat or had a belly within the drip line of a tree.

While the rate of corrosion in CMP depends on the $\mathrm{pH}$ of the water and chemicals (natural or other) in the surrounding soil, we in the stormwater industry generally accept the fact that CMP will eventually rot out from 5-7 o'clock. xxx does not permit the use of CMP in new installations but we have inherited many segments. It has not been xxx's experience to observe deflection in metal pipes. We have observed deflection in HDPE pipes when the installation was not carefully controlled. The less rigid the pipe, the more critical it is to control the bedding and backfill.

Erosion/scouring is most common around outfall sewers laid in a ravines which discharge to creeks. Excepting a structural failure, it typically starts at the end wall and follows the pipe U/S. Backflow from the stream and steep slopes on the ravine are contributing factors. 


\section{Response 5}

\section{STEP 1:}

\begin{tabular}{|c|c|c|c|c|c|c|c|}
\hline \multicolumn{2}{|c|}{} & Capacity & Blockage & $\begin{array}{c}\text { Surface } \\
\text { Wear }\end{array}$ & \multicolumn{2}{c|}{ Load } & $\begin{array}{c}\text { Structural } \\
\text { Defects }\end{array}$ \\
\hline \multirow{4}{*}{ Capacity } & - & 0 & 0 & 1 & 7 \\
\hline Blockage & 5 & - & 3 & 3 & 7 \\
\hline $\begin{array}{c}\text { Surface } \\
\text { Wear }\end{array}$ & 7 & 7 & - & 5 & 7 \\
\hline Load & 1 & 0 & 0 & - & 3 \\
\hline $\begin{array}{c}\text { Structural } \\
\text { Defects }\end{array}$ & 0 & 0 & 0 & 0 & - \\
\hline
\end{tabular}




\section{STEP 2:}

\section{A. Capacity}

\begin{tabular}{|c|c|c|c|c|c|c|}
\hline \multirow{2}{*}{ No. } & Factor & \multicolumn{5}{|c|}{ Significance } \\
\hline & & Very Low & Low & Medium & High & Very High \\
\hline 1 & Overflow Frequency & & & & & $\nearrow$ \\
\hline 2 & Pipe Surcharging & & & & & $\nearrow$ \\
\hline 3 & Inflow/Infiltration Level & $\nearrow$ & & & & \\
\hline 4 & Exfiltration Level & $\chi$ & & & & \\
\hline 5 & Average Rainfall Intensity & & & & & $\nearrow$ \\
\hline 6 & Average Rainfall Duration & & & & & $\nearrow$ \\
\hline 7 & Average Flow Velocity & & & $\nearrow$ & & \\
\hline 8 & Soil Type & & & & $\nearrow$ & \\
\hline 9 & Pipe Location & & & $X$ & & \\
\hline
\end{tabular}

\section{B. Blockage}

\begin{tabular}{|c|c|c|c|c|c|c|}
\hline \multirow[t]{2}{*}{ No. } & \multirow[t]{2}{*}{ Factor } & \multicolumn{5}{|c|}{ Significance } \\
\hline & & Very Low & Low & Medium & High & Very High \\
\hline 1 & Debris Level & & & & X & \\
\hline 2 & Sedimentation Level & & & $X$ & & \\
\hline 3 & $\begin{array}{l}\text { Number of Lateral } \\
\text { Connections }\end{array}$ & & & & & \\
\hline 4 & $\begin{array}{l}\text { If Inlet is attached or if } \\
\text { Pipe changes Direction }\end{array}$ & & & & $x$ & \\
\hline 5 & Smell or Vermin Level & & & & & \\
\hline 6 & Pipe Length & & & $x$ & & \\
\hline 7 & Pipe Diameter & & & & $x$ & \\
\hline 8 & Pipe Slope & & & $x$ & & \\
\hline 9 & Minimum Flow Velocity & & & $x$ & & \\
\hline
\end{tabular}

\section{Surface Wear}

\begin{tabular}{|c|c|c|c|c|c|c|}
\hline No. & Factor & \multicolumn{5}{|c|}{ Significance } \\
\cline { 3 - 7 } & & Very Low & Low & Medium & High & Very High \\
\hline 1 & Surface Wear Condition & & $\not$ & & $\Varangle$ & \\
\hline
\end{tabular}




\begin{tabular}{|c|c|l|l|l|l|l|}
\hline & $\begin{array}{c}\text { Rating as per Visual, } \\
\text { CCTV or other Inspections }\end{array}$ & & & & & \\
\hline 2 & Maintenance Method Type & & & & & \\
\hline \multirow{2}{*}{ No. } & Factor & & \multicolumn{3}{|c|}{ Significance } \\
\hline & & Very Low & Low & Medium & High & Very High \\
\hline 3 & Pipe Age & & & & $X$ & \\
\hline 4 & Pipe Material & & & & & $X$ \\
\hline 5 & Pipe Shape & & & & & \\
\hline 6 & Minimum Flow Velocity & & & & & \\
\hline
\end{tabular}

D. Load

\begin{tabular}{|c|c|l|l|l|l|l|}
\hline No. & Factor & \multicolumn{5}{|c|}{ Significance } \\
\cline { 3 - 7 } & Very Low & Low & Medium & High & Very High \\
\hline 1 & $\begin{array}{c}\text { Rating of Pipe Structure } \\
\text { per Visual, CCTV or other } \\
\text { Inspections }\end{array}$ & & & & K & X \\
\hline 2 & $\begin{array}{c}\text { Loading Condition (Dead } \\
\text { Load) }\end{array}$ & & & & & \\
\hline 3 & $\begin{array}{c}\text { Loading Condition (Live } \\
\text { Load) }\end{array}$ & & & & & \\
\hline 4 & Depth of Cover & & & $X$ & & \\
\hline 5 & Pipe Bedding Type & & & & & \\
\hline 6 & Trench Backfill Type & & & & & \\
\hline 7 & Groundwater Table Level & & & & & \\
\hline 8 & Exfiltration Level & & & & & \\
\hline 9 & Pipe Shape & & & & & \\
\hline
\end{tabular}

E. Structural Defects (crack, fracture, broken, hole, leaking joint, lining failure etc.)

\begin{tabular}{|c|c|c|c|c|c|c|}
\hline \multirow{2}{*}{ No. } & Factor & \multicolumn{5}{|c|}{ Significance } \\
\cline { 3 - 7 } & Very Low & Low & Medium & High & Very High \\
\hline 1 & $\begin{array}{c}\text { Condition Rating as per } \\
\text { Visual, CCTV or other } \\
\text { Inspections }\end{array}$ & & & & & \\
\hline 2 & Pipe Age & & & & & \\
\hline 3 & Pipe Material & & & & $\nearrow$ & \\
\hline 4 & Pipe Diameter & & & & & \\
\hline 5 & Pipe Joint Type & & & & & \\
\hline
\end{tabular}

\section{F. Other factors:}

\begin{tabular}{|l|l|l|l|l|}
\hline No. & Factor & Failure Mode & Explanation & Significance \\
\hline & & & & \\
\hline & & & & \\
\hline
\end{tabular}


Response 6

STEP 1:

\begin{tabular}{|c|c|c|c|c|c|}
\hline- & Capacity & Blockage & $\begin{array}{c}\text { Surface } \\
\text { Wear }\end{array}$ & Load & $\begin{array}{c}\text { Structural } \\
\text { Defects }\end{array}$ \\
\hline Capacity & - & 1, & 0 & 0 & 5 \\
\hline Blockage & 1 & - & & 0 & 7 \\
\hline $\begin{array}{c}\text { Surface } \\
\text { Wear }\end{array}$ & 7 & 7 & - & 1 & 7 \\
\hline Load & 7 & 5 & 1 & - & 7 \\
\hline $\begin{array}{c}\text { Structural } \\
\text { Defects }\end{array}$ & 0 & 0 & 0 & 0 & - \\
\hline
\end{tabular}




\section{STEP 2:}

A. Capacity

\begin{tabular}{|c|c|c|c|c|c|c|}
\hline \multirow{2}{*}{ No. } & Factor & \multicolumn{5}{|c|}{ Significance } \\
\cline { 3 - 7 } & & Very Low & Low & Medium & High & Very High \\
\hline 1 & Overflow Frequency & & $X$ & & & \\
\hline 2 & Pipe Surcharging & & & & $X$ & \\
\hline 3 & Inflow/Infiltration Level & $X$ & & & & \\
\hline 4 & Exfiltration Level & $X$ & & & & \\
\hline 5 & Average Rainfall Intensity & & & $X$ & & \\
\hline 6 & Average Rainfall Duration & & & $X$ & & \\
\hline 7 & Average Flow Velocity & & & $X$ & & \\
\hline 8 & Soil Type & & $X$ & & & \\
\hline 9 & Pipe Location & & & & $X$ & \\
\hline
\end{tabular}

\section{B. Blockage}

\begin{tabular}{|c|c|c|c|c|c|c|}
\hline \multirow{2}{*}{ No. } & Factor & \multicolumn{5}{|c|}{ Significance } \\
\hline & & Very Low & Low & Medium & High & Very High \\
\hline 1 & Debris Level & & & & $X$ & \\
\hline 2 & Sedimentation Level & & & & $X$ & \\
\hline 3 & $\begin{array}{c}\text { Number of Lateral } \\
\text { Connections }\end{array}$ & & & $X$ & & \\
\hline 4 & $\begin{array}{c}\text { If Inlet is attached or if } \\
\text { Pipe changes Direction }\end{array}$ & & & $X$ & & \\
\hline 5 & Smell or Vermin Level & $X$ & & & & \\
\hline 6 & Pipe Length & & & $X$ & & \\
\hline 7 & Pipe Diameter & & & & $X$ & \\
\hline 8 & Pipe Slope & & & $X$ & & \\
\hline 9 & Minimum Flow Velocity & & $X$ & & & \\
\hline
\end{tabular}

\section{Surface Wear}

\begin{tabular}{|c|c|c|c|c|c|c|}
\hline No. & Factor & \multicolumn{5}{|c|}{ Significance } \\
\cline { 3 - 7 } & Very Low & Low & Medium & High & Very High \\
\hline 1 & $\begin{array}{c}\text { Surface Wear Condition } \\
\text { Rating as per Visual, } \\
\text { CCTV or other Inspections }\end{array}$ & & & & $X$ & \\
\hline 2 & Maintenance Method Type & & & $X$ & & \\
\hline
\end{tabular}




\begin{tabular}{|c|c|c|c|c|c|c|}
\hline \multirow{2}{*}{ No. } & Factor & \multicolumn{5}{|c|}{ Significance } \\
\cline { 3 - 6 } & & Very Low & Low & Medium & High & Very High \\
\hline 3 & Pipe Age & & & & & X \\
\hline 4 & Pipe Material & & & & & Х \\
\hline 5 & Pipe Shape & & & $\nearrow$ & & \\
\hline 6 & Minimum Flow Velocity & & $X$ & & & \\
\hline
\end{tabular}

D. Load

\begin{tabular}{|c|c|c|c|c|c|c|}
\hline \multirow{2}{*}{ No. } & Factor & \multicolumn{5}{|c|}{ Significance } \\
\cline { 3 - 6 } & & Very Low & Low & Medium & High & Very High \\
\hline 1 & $\begin{array}{c}\text { Rating of Pipe Structure } \\
\text { per Visual, CCTV or other } \\
\text { Inspections }\end{array}$ & & & & & \\
\hline 2 & $\begin{array}{c}\text { Loading Condition (Dead } \\
\text { Load) }\end{array}$ & & & & & \\
\hline 3 & $\begin{array}{c}\text { Loading Condition (Live } \\
\text { Load) }\end{array}$ & & & $X$ & & \\
\hline 4 & Depth of Cover & & & & $X$ & \\
\hline 5 & Pipe Bedding Type & & & $X$ & & \\
\hline 6 & Trench Backfill Type & & & & $X$ & \\
\hline 7 & Groundwater Table Level & & & $X$ & & \\
\hline 8 & Exfiltration Level & & $X$ & & & \\
\hline 9 & Pipe Shape & & $X$ & & & \\
\hline
\end{tabular}

E. Structural Defects (crack, fracture, broken, hole, leaking joint, lining failure etc.)

\begin{tabular}{|c|c|c|c|c|c|c|}
\hline \multirow{2}{*}{ No. } & Factor & \multicolumn{5}{|c|}{ Significance } \\
\cline { 3 - 7 } & & Very Low & Low & Medium & High & Very High \\
\hline 1 & $\begin{array}{c}\text { Condition Rating as per } \\
\text { Visual, CCTV or other } \\
\text { Inspections }\end{array}$ & & & & $X$ & \\
\hline 2 & Pipe Age & & & & & $X$ \\
\hline 3 & Pipe Material & & & & & $X$ \\
\hline 4 & Pipe Diameter & & & $X$ & & \\
\hline 5 & Pipe Joint Type & & & $X$ & & \\
\hline
\end{tabular}

\section{F. Other factors:}

\begin{tabular}{|l|l|l|l|l|}
\hline No. & Factor & Failure Mode & Explanation & Significance \\
\hline & & & & \\
\hline & & & & \\
\hline & & & & \\
\hline & & & & \\
\hline
\end{tabular}




\section{Response 7}

\section{STEP 1:}

Column

\begin{tabular}{|c|c|c|c|c|c|}
\hline- & Capacity & Blockage & $\begin{array}{c}\text { Surface } \\
\text { Wear }\end{array}$ & Load & $\begin{array}{c}\text { Structural } \\
\text { Defects }\end{array}$ \\
\hline Capacity & - & 5 & 5 & 7 & 7 \\
\hline $\begin{array}{c}\text { Blockage } \\
\begin{array}{c}\text { Surface } \\
\text { Wear }\end{array}\end{array} \quad 3$ & - & 5 & 5 & 1 \\
\hline $\begin{array}{c}\text { Load } \\
\text { Structural } \\
\text { Defects }\end{array}$ & 1 & 5 & - & 3 & 7 \\
\hline
\end{tabular}

\section{STEP 2:}

\section{A. Capacity}

\begin{tabular}{|c|c|c|c|c|c|c|}
\hline \multirow{2}{*}{ No. } & Factor & \multicolumn{5}{|c|}{ Significance } \\
\cline { 4 - 7 } & & Very Low & Low & Medium & High & Very High \\
\hline 1 & Overflow Frequency & & & $\mathrm{X}$ & & \\
\hline 2 & Pipe Surcharging & & & $\mathrm{X}$ & & \\
\hline 3 & Inflow/Infiltration Level & & & $\mathrm{X}$ & & \\
\hline 4 & Exfiltration Level & & & $\mathrm{X}$ & & \\
\hline 5 & Average Rainfall Intensity & & & & $\mathrm{X}$ & \\
\hline 6 & Average Rainfall Duration & & & & $\mathrm{X}$ & \\
\hline 7 & Average Flow Velocity & & & & $\mathrm{X}$ & \\
\hline 8 & Soil Type & & & & & $\mathrm{X}$ \\
\hline 9 & Pipe Location & & & & & $\mathrm{X}$ \\
\hline
\end{tabular}




\section{B. Blockage}

\begin{tabular}{|c|c|c|c|c|c|c|}
\hline \multirow{2}{*}{ No. } & Factor & \multicolumn{5}{|c|}{ Significance } \\
\cline { 4 - 7 } & Very Low & Low & Medium & High & Very High \\
\hline 1 & Debris Level & & & & $\mathrm{X}$ & \\
\hline 2 & Sedimentation Level & & & $\mathrm{X}$ & & \\
\hline 3 & $\begin{array}{c}\text { Number of Lateral } \\
\text { Connections }\end{array}$ & & & $\mathrm{X}$ & & \\
\hline 4 & $\begin{array}{c}\text { If Inlet is attached or if Pipe } \\
\text { changes Direction }\end{array}$ & & $\mathrm{X}$ & & & \\
\hline 5 & Smell or Vermin Level & & & $\mathrm{X}$ & & \\
\hline 6 & Pipe Length & & & & $\mathrm{X}$ & \\
\hline 7 & Pipe Diameter & & & & $\mathrm{X}$ & \\
\hline 8 & Pipe Slope & & & $\mathrm{X}$ & & \\
\hline 9 & Minimum Flow Velocity & & & & \\
\hline
\end{tabular}

\section{Surface Wear}

\begin{tabular}{|c|c|l|l|l|c|c|}
\hline No. & Factor & \multicolumn{5}{|c|}{ Significance } \\
\cline { 3 - 6 } & & Very Low & Low & Medium & High & Very High \\
\hline 1 & $\begin{array}{c}\text { Surface Wear Condition } \\
\text { Rating as per Visual, CCTV } \\
\text { or other Inspections }\end{array}$ & & & & & $\mathrm{X}$ \\
\hline 2 & Maintenance Method Type & & & & & \\
\hline 3 & Pipe Age & & $\mathrm{X}$ & & & \\
\hline 4 & Pipe Material & & & & $\mathrm{x}$ & \\
\hline 5 & Pipe Shape & & & & $\mathrm{x}$ & \\
\hline 6 & Minimum Flow Velocity & & & & $\mathrm{X}$ & \\
\hline
\end{tabular}

\section{Load}

\begin{tabular}{|c|c|c|c|c|c|c|}
\hline No. & Factor & \multicolumn{5}{|c|}{ Significance } \\
\cline { 3 - 6 } & & Very Low & Low & Medium & High & Very High \\
\hline 1 & $\begin{array}{c}\text { Rating of Pipe Structure per } \\
\text { Visual, CCTV or other } \\
\text { Inspections }\end{array}$ & & & & $\mathrm{X}$ & \\
\hline 2 & $\begin{array}{c}\text { Loading Condition (Dead } \\
\text { Load) }\end{array}$ & & & $\mathrm{X}$ & & \\
\hline 3 & Loading Condition (Live Load) & & & $\mathrm{X}$ & & \\
\hline 4 & Depth of Cover & & & $\mathrm{x}$ & & \\
\hline 5 & Pipe Bedding Type & & & & $\mathrm{X}$ & \\
\hline 6 & Trench Backfill Type & & & & $\mathrm{X}$ & \\
\hline 7 & Groundwater Table Level & & & & $\mathrm{X}$ & \\
\hline 8 & Exfiltration Level & & & & $\mathrm{X}$ & \\
\hline 9 & Pipe Shape & & & & $\mathrm{X}$ & \\
\hline
\end{tabular}


E. Structural Defects (crack, fracture, broken, leaking joint, lining failure etc.)

\begin{tabular}{|c|c|c|c|c|c|c|}
\hline \multirow{2}{*}{ No. } & Factor & \multicolumn{5}{|c|}{ Significance } \\
\cline { 4 - 7 } & Very Low & Low & Medium & High & Very High \\
\hline 1 & $\begin{array}{c}\text { Condition Rating as per } \\
\text { Visual, CCTV or other } \\
\text { Inspections }\end{array}$ & & & & $\mathrm{X}$ & \\
\hline 2 & Pipe Age & & & & & \\
\hline 3 & Pipe Material & & & & $\mathrm{x}$ & \\
\hline 4 & Pipe Diameter & & & & $\mathrm{x}$ & \\
\hline 5 & Pipe Joint Type & & & & & $\mathrm{x}$ \\
\hline & & & & & & \\
\hline
\end{tabular}

\section{F. Other factors}

\begin{tabular}{|c|c|c|c|c|}
\hline No. & Factor & Failure Mode & Explanation & Significance \\
\hline & & & & \\
\hline & & & & \\
\hline & & & & \\
\hline & & & & \\
\hline
\end{tabular}




\section{Response 8}

\section{STEP 1:}

Column

\begin{tabular}{|c|c|c|c|c|c|}
\hline- & Capacity & Blockage & $\begin{array}{c}\text { Surface } \\
\text { Wear }\end{array}$ & Load & $\begin{array}{c}\text { Structural } \\
\text { Defects }\end{array}$ \\
\hline Capacity & - & 0 & 0 & 0 & 0 \\
\hline Blockage & 9 & - & 1 & 3 & 5 \\
\hline $\begin{array}{c}\text { Surface } \\
\text { Wear }\end{array}$ & 9 & 1 & - & 5 & 7 \\
\hline $\begin{array}{c}\text { Load } \\
\text { Structural } \\
\text { Defects }\end{array}$ & 5 & 0 & 0 & - & 5 \\
\hline
\end{tabular}

\section{STEP 2:}

\section{A. Capacity}

\begin{tabular}{|c|c|c|c|c|c|c|}
\hline \multirow{2}{*}{ No. } & Factor & \multicolumn{5}{|c|}{ Significance } \\
\cline { 4 - 6 } & & Very Low & Low & Medium & High & Very High \\
\hline 1 & Overflow Frequency & & & & $\mathrm{X}$ & \\
\hline 2 & Pipe Surcharging & & & & $\mathrm{X}$ & \\
\hline 3 & Inflow/Infiltration Level & & & & & \\
\hline 4 & Exfiltration Level & & & & & \\
\hline 5 & Average Rainfall Intensity & & & & & $\mathrm{X}$ \\
\hline 6 & Average Rainfall Duration & & & & & $\mathrm{X}$ \\
\hline 7 & Average Flow Velocity & & & $\mathrm{X}$ & & \\
\hline 8 & Soil Type & & & & & \\
\hline 9 & Pipe Location & & & & & \\
\hline
\end{tabular}




\section{B. Blockage}

\begin{tabular}{|c|c|c|c|c|c|c|}
\hline No. & Factor & \multicolumn{5}{|c|}{ Significance } \\
\cline { 3 - 6 } & Very Low & Low & Medium & High & Very High \\
\hline 1 & Debris Level & & & & $\mathrm{X}$ & \\
\hline 2 & Sedimentation Level & & & & $\mathrm{X}$ & \\
\hline 3 & $\begin{array}{c}\text { Number of Lateral } \\
\text { Connections }\end{array}$ & & & & & \\
\hline 4 & $\begin{array}{c}\text { If Inlet is attached or if Pipe } \\
\text { changes Direction }\end{array}$ & $\mathrm{X}$ & & & & \\
\hline 5 & Smell or Vermin Level & & & & & \\
\hline 6 & Pipe Length & & $\mathrm{X}$ & & & \\
\hline 7 & Pipe Diameter & & $\mathrm{X}$ & & & \\
\hline 8 & Pipe Slope & & & $\mathrm{X}$ & & \\
\hline 9 & Minimum Flow Velocity & $\mathrm{X}$ & & & & \\
\hline
\end{tabular}

\section{Surface Wear}

\begin{tabular}{|c|c|c|c|c|c|c|}
\hline \multirow{2}{*}{ No. } & Factor & \multicolumn{5}{|c|}{ Significance } \\
\cline { 3 - 6 } & & Very Low & Low & Medium & High & Very High \\
\hline 1 & $\begin{array}{c}\text { Surface Wear Condition } \\
\text { Rating as per Visual, CCTV } \\
\text { or other Inspections }\end{array}$ & & & & & $\mathrm{X}$ \\
\hline 2 & Maintenance Method Type & & & & \\
\hline 3 & Pipe Age & & $\mathrm{X}$ & & & \\
\hline 4 & Pipe Material & & $\mathrm{X}$ & & & \\
\hline 5 & Pipe Shape & & $\mathrm{X}$ & & & \\
\hline 6 & Minimum Flow Velocity & $\mathrm{X}$ & & & & \\
\hline
\end{tabular}

\section{Load}

\begin{tabular}{|c|c|c|c|c|c|c|}
\hline \multirow{2}{*}{ No. } & Factor & \multicolumn{5}{|c|}{ Significance } \\
\cline { 3 - 6 } & & Very Low & Low & Medium & High & Very High \\
\hline 1 & $\begin{array}{c}\text { Rating of Pipe Structure per } \\
\text { Visual, CCTV or other } \\
\text { Inspections }\end{array}$ & & & & $\mathrm{X}$ & \\
\hline 2 & $\begin{array}{c}\text { Loading Condition (Dead } \\
\text { Load) }\end{array}$ & & & & & \\
\hline 3 & Loading Condition (Live Load) & & & & & \\
\hline 4 & Depth of Cover & & $\mathrm{X}$ & & & \\
\hline 5 & Pipe Bedding Type & & & $\mathrm{X}$ & & \\
\hline 6 & Trench Backfill Type & & & $\mathrm{X}$ & & \\
\hline 7 & Groundwater Table Level & $\mathrm{X}$ & & & & \\
\hline 8 & Exfiltration Level & $\mathrm{X}$ & & & & \\
\hline 9 & Pipe Shape & $\mathrm{X}$ & & & & \\
\hline
\end{tabular}


E. Structural Defects (crack, fracture, broken, leaking joint, lining failure etc.)

\begin{tabular}{|c|c|c|c|c|c|c|}
\hline \multirow{2}{*}{ No. } & Factor & \multicolumn{5}{|c|}{ Significance } \\
\cline { 4 - 7 } & Very Low & Low & Medium & High & Very High \\
\hline 1 & $\begin{array}{c}\text { Condition Rating as per } \\
\text { Visual, CCTV or other } \\
\text { Inspections }\end{array}$ & & & & $\mathrm{X}$ & \\
\hline 2 & Pipe Age & & $\mathrm{X}$ & & & \\
\hline 3 & Pipe Material & & $\mathrm{x}$ & & & \\
\hline 4 & Pipe Diameter & & $\mathrm{x}$ & & & \\
\hline 5 & Pipe Joint Type & & $\mathrm{x}$ & & & \\
\hline & & & & & & \\
\hline
\end{tabular}

\section{F. Other factors}

\begin{tabular}{|c|c|c|c|c|}
\hline No. & Factor & Failure Mode & Explanation & Significance \\
\hline & & & & \\
\hline & & & & \\
\hline & & & & \\
\hline & & & & \\
\hline
\end{tabular}




\section{Response 9}

\section{August 4, 2014}

We do have some of the information you have requested in our GIS system. However, the information not in our GIS system is scattered in drawings and files. Being that we have over 600 miles of storm drain pipeline, it would be quite a task to gather all of this information. I can put you in touch with one of our GIS techs and could provide you some of your requested information that is stored in the GIS database. However, a lot of this requested information would take several weeks of research that we don't available.Here are some quick answers to your requests:

Physical/Structural Attributes:

- Pipe Material - we have this information in our GIS database

- Pipe Diameter - we have this information in our GIS database

- Depth of Cover - we do not keep record of this, can be determined from as-built drawings

- Pipe Age - we have this information in our GIS database

- Pipe Thickness - we do not keep record of this

- Pipe Shape - we do not keep record of this, but very few of our pipelines are not round (I know of one older square section)

- Slope - we have this information in our GIS database

- Pipe Joint - we do not keep record of this

- Pipe Coating - we do not keep record of this

- Pipe Lining - we do not keep record of this

- End Section - we have this information in our GIS database (we call them outfalls, most discharge to stormwater basins)

Environmental Attributes:

- Pipe Location - we have this information on a GIS map and the construction drawings, I'm not sure if it is stored in a database

- Loading Conditions - we do not have loading conditions recorded

- Root Intrusion - We have had root intrusion issues, but they are not recorded other than through work orders

- Groundwater Level - we do not monitor groundwater level. However, groundwater in the Fresno area is $120+$ below the ground surface, so this is not an issue here

- Rainfall - Fresno rainfall can be accessed from the National Weather Service's website (I can send you the link if you'd like)

- Frost Penetration - we don't keep records of this, I don't think this is an issue in Fresno.

- Soil pH - we don't keep records of this

- Pipe Bedding - only noted in construction drawings

- Backfill type - we don't keep records of this, possibly through inspector diaries or compaction tests

- Changes in Temperature - we don't keep records of this (you can get this information from the National Weather Service) 
- Extreme Events - we don't keep records of this

- Soil Disturbances - we don't keep records of this

Operational/Functional Attributes

- Runoff Rate - we keep records of this in our Hydrology and Hydraulics files, but it is not linked to any pipeline database

- Flow Velocity - same as above

- Overflow Frequency - we do not keep records of this

- Inflow/Infiltration - we do not keep records of this

- Presence of Stagnant Water within Structure - we do not keep records of this

- Debris Level - we do not keep records of this

- Sedimentation Level - we do not keep records of this

- Smell - we have some records from public concern calls, but nothing linked to specific pipelines

- Insects - we do not keep records of this

- Maintenance Methods - the only records would be through work orders

- Maintenance Frequency - the only records would be through work orders

- Inspection/CCTV Record - we do have pipes videoed, but we don't link this to any pipeline database

- Pipe Renewal Record - we do not keep records of this

- Pipe Failure Record - we haven't had any pipe failures to the best of my knowledge

- Frequent Complaints - we do log calls from the public but haven't linked them to our GIS database

Other Attributes

- Annual Capital Cost - this information is available through our budget and accounting records

- Annual Operation Cost - this information is available through our budget and accounting records

- Annual Maintenance Cost - this information is available through our budget and accounting records

I hope this information helps. Good luck with your project.

\section{August 5, 2014}

- Your list is very thorough and I can't think of anything related to pipeline information to add to it. I did notice that there isn't a mention of appurtenances such as manholes, inlets, and valves; but I guess those could be an entire separate thing. 


\section{Response 10}

\section{November 3, 2014}

Capacity is not viewed as a failure in our stormwater pipes, rather, pipes surcharged are viewed as the limit to the level of service provided by that part of the system. While the level of service might not reach the level desired by the citizens today, it is not a failure of the system in any way. We have some corrugated metal pipes that have corroded at the invert. In some cases that process has been hastened by the bed load of the stream. I am not aware of surface wear failure in other pipe materials.

I think it is very difficult to distinguish between Load and structural defects as a failure mode. We have some locations where pipes have failed, especially corrugated metal and lightweight plastics. Both seem to crush at the joints.

A failure mode you did not mention is earth movement. We have had several instances of slope failure or erosion near the point of discharge of a pipeline that resulted in a flared end section and the last few segments of pipe move leaving separated joints. We have had failure of gabion baskets that moved the end of a pipeline, and we have had failure of headwalls and channel lining that have resulted in pipe failure. 


\section{Appendix B. Calculation of the Parameter Weights}

This appendix contains the Microsoft Excel based calculations to determine the module weights form the received responses, followed by calculation of the parameter weights. Contact Sowmya Bhimanadhuni (sowmyareddy.b@gmail.com) or Dr. Sunil K. Sinha (ssinha@vt.edu) for the Excel file. 


\section{Appendix C. Performance Index}

This appendix contains the Microsoft Excel based prototype performance index prepared using the real time data form Utility A. Contact Sowmya Bhimanadhuni (sowmyareddy.b@gmail.com) or Dr. Sunil K. Sinha (ssinha@vt.edu) for the Excel file. 


\section{Appendix D. ArcMap representation of Performance Indices}

This appendix contains a pictorial representation of the results generated from applying the

performance index to stormwater pipeline data from Utility A. The results are showcased in ArcMap 


\section{Performance Index for Stormwater Pipelines}

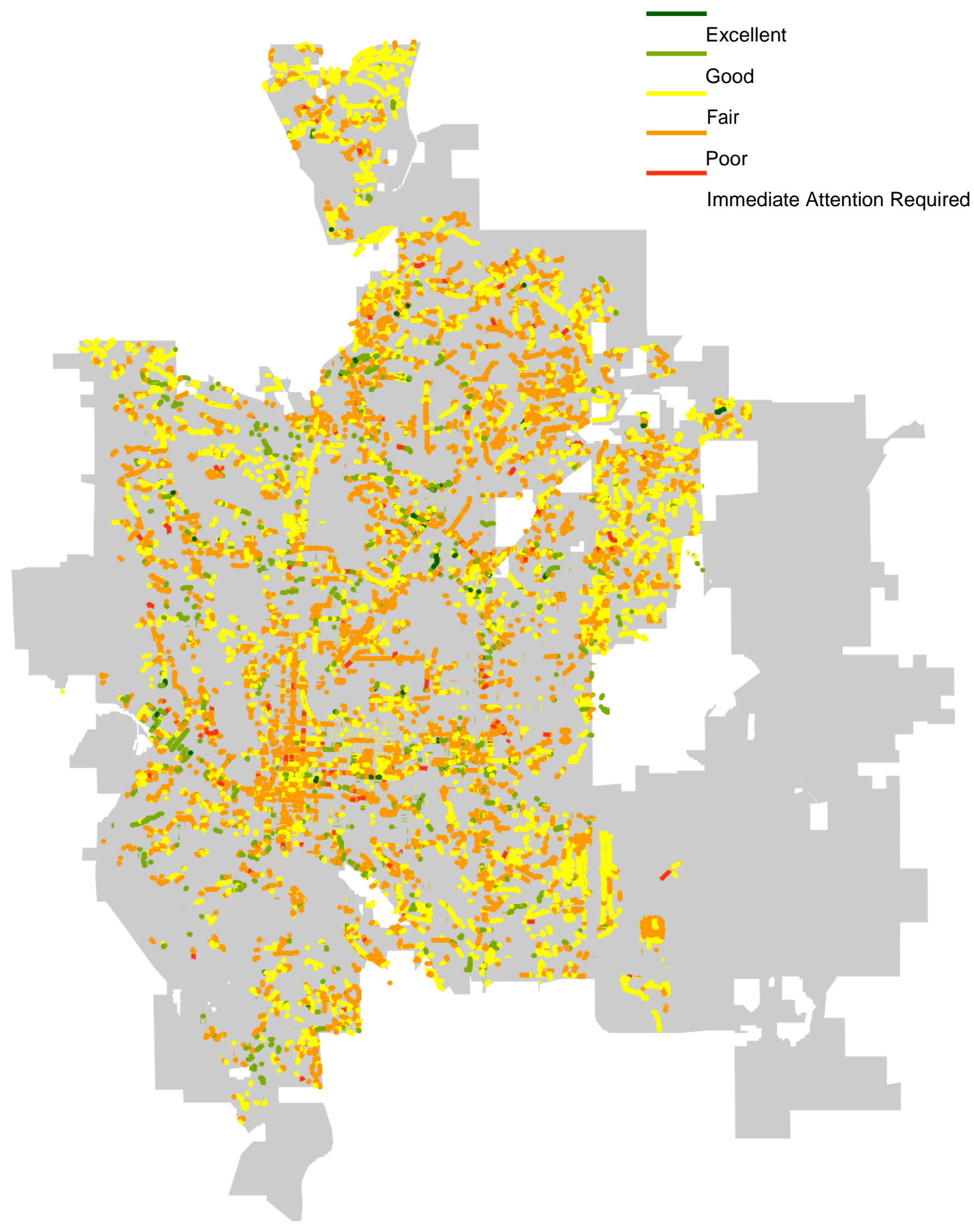




\section{Appendix E. Partial Validation of the Prototype Performance Index}

This appendix contains an email response from the Asset Management supervisor of Utility A expressing his opinion on the results generated. 


\section{May 12, 2015}

This is about what I would expect from the results. I think with the available data we have this excellent. We are continually adding information that will help with further refining the results. The Excel Model or GIS Model will help us in the future. We really need more inspections to really get a picture of condition and remaining life, but this is fantastic.

It is ok to include the results of your model without mentioning the name of our organization. 